\title{
Detecting personality disorders in older adults in general practice
}

Citation for published version (APA):

Penders, K. A. P. (2021). Detecting personality disorders in older adults in general practice: The evaluation and validation of the Gerontological Personality Disorders Scale. [Doctoral Thesis, Maastricht University]. Maastricht University. https://doi.org/10.26481/dis.20210121kp

Document status and date:

Published: 01/01/2021

DOI:

10.26481/dis.20210121kp

Document Version:

Publisher's PDF, also known as Version of record

\section{Please check the document version of this publication:}

- A submitted manuscript is the version of the article upon submission and before peer-review. There can be important differences between the submitted version and the official published version of record.

People interested in the research are advised to contact the author for the final version of the publication, or visit the DOI to the publisher's website.

- The final author version and the galley proof are versions of the publication after peer review.

- The final published version features the final layout of the paper including the volume, issue and page numbers.

Link to publication

\footnotetext{
General rights rights.

- You may freely distribute the URL identifying the publication in the public portal. please follow below link for the End User Agreement:

www.umlib.nl/taverne-license

Take down policy

If you believe that this document breaches copyright please contact us at:

repository@maastrichtuniversity.nl

providing details and we will investigate your claim.
}

Copyright and moral rights for the publications made accessible in the public portal are retained by the authors and/or other copyright owners and it is a condition of accessing publications that users recognise and abide by the legal requirements associated with these

- Users may download and print one copy of any publication from the public portal for the purpose of private study or research.

- You may not further distribute the material or use it for any profit-making activity or commercial gain

If the publication is distributed under the terms of Article $25 \mathrm{fa}$ of the Dutch Copyright Act, indicated by the "Taverne" license above, 


\section{DETECTING PERSONALITY DISORDERS}

IN OLDER ADULTS

IN GENERAL PRACTICE

The evaluation and validation of

the Gerontological Personality disorders Scale

Krystle Penders 
DETECTING PERSONALITY DISORDERS IN OLDER ADULTS

IN GENERAL PRACTICE

The evaluation and validation of the Gerontological Personality disorders Scale

PROEFSCHRIFT

ter verkrijging van de graad van doctor aan de Universiteit Maastricht, op gezag van de Rector Magnificus, Prof. dr. Rianne M. Letschert volgens het besluit van het College van Decanen

in het openbaar te verdedigen

op donderdag 21 januari 2021 om 12.00 uur

door

Krystle Alena Priscilla Penders

Copyright $\odot$ Krystle Penders, Maastricht, 2020

All rights reserved. No part of this dissertation may be reproduced or transmitted in any form or by any means without prior permission of the author.

Cover design: Krystle Penders

Lay-out and design by: Robin Weijland, persoonlijkproefschrift.nt

Printing: $\quad$ Ridderprint | www.ridderprint.nl

ISBN: $\quad 978-94-6416-277-6$ 
Prof. dr. J.F.M. Metsemakers

Prof. dr. S. P.J. van Alphen (Vrije Universiteit Brussel, Universiteit Tilburg)

Copromotor:

Dr. I.G.P. Peeters

Beoordelingscommissie:

Prof. dr. J. W. M. Muris (voorzitter)

Prof. dr. R.C. Oude Voshaar (Rijksuniversiteit Groningen)

Prof. dr. R.W.H.M. Ponds

Prof. dr. E. Rosowsky (Williams James College, Harvard Medical School, USA)

Prof. dr. J. M. G. A. Schols

The research presented in this dissertation was conducted at the Care and Public Health Research Institute (CAPHRI), Department of Family Medicine Maastricht University, the Nether participates in the Netherlands School of Public Health and Care Research (CaRe).

The studies presented in this dissertation were funded by Envida, Maastricht, the Netherlands, and the National Care for the Elderly Program from The Netherlands Organization for Health Research and Development (ZonMw) under Grant 311070201 as acquired by Mondriaan Ouderen, Heerlen, the Netherlands. 


\section{Table of contents}

Chapter 1 General introduction

Chapter 2 Personality disorders in older adults: A review of epidemiology, assessment and treatment

Published as: Penders, K.A.P., Peeters, I.G.P. Metsemakers, J. F. M., \& van Alphen, S.P.J. (2020). Current Psychiatry Reports, 22(3), 1-14

Chapter 3 Diagnostic accuracy of the Gerontological Personality disorders Scale (GPS) in Dutch general practice van Alphen, S.P.J. (2016). Aging and Mental Health, 20(3), 318-328

Chapter 4 Mapping the nomological network of the Gerontological Personality disorders Scale (GPS) by the HiTOP approach Submitted

Chapter 5 Personality disorders in older adults: Explanatory factors of selfinformant agreement Submitted

Chapter 6 Feasibility and acceptability of the Gerontological Personality disorders Scale (GPS) in general practice: A mixed methods study

Published as: Penders, K.A.P., van Zadel hoff, E., Rossi, G., Duimel-Peeters, I.G.P., van Alphe

Chapter 7 General discussion

Addenda Summary

Samenvatting

Valorisation

versie

Dankwoord

About the author

Publications and conference contributions 


\section{1}

General introduction

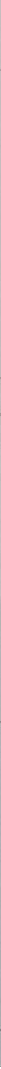




\section{Case description Mr. Johnson}

After one glance on his planned consultations for that day, doctor Petersen, a genera practitioner (GP), sinks into his chair feeling highly irritated. "Oh no, Mr. Johnson again, what a hell of a start", he moans. His relaxed post-holiday feeling instantly vanishes into thin air. His irritation only grows after reading up on Mr. Johnson's medical record which shows that he is now, against all agreements, using Serevent ${ }^{\circ}$, as prescribed by his substitute. "For once, why does he always have to be so stubborn, why can't he just do as we agreed upon? Why does it always have to be such a hassle?"

Mr. Johnson is a 70-year-old married man who lives his life according to the rules. If he, or others, don't follow the rules, he gets upset, feels uncomfortable and worried. He likes things just the way they were, to remain in order, and to be predictable. $\mathrm{He}$ detests change on every level, which is even evident when visiting his home.

The interior of the house is exactly the same as it was when Mr. and Mrs. Johnson moved in, over 50 years ago. The attic and basement are piled up with things that may never be used again, which is a major source of stress to his wife. Offering to clean up, results in quarrels after which Mr. Johnson stays angry and silent for quite a while. The pantry is also packed with canned food, all of a certain amount and having its own place. When one can is used, although enough in stock, a new can has to be bought.

Mr. Johnson worked as an accountant, a job he took very seriously. He was an excessively dutiful, reliable and dedicated employee which was at the expense of relaxation, friendships as well as his health. In the past, he suffered multiple times from burn-out (symptoms) for which he received psychological treatment. He wasn't able to enjoy his retirement as he believes he should be working and spending his time usefully. Ever since, he structures his day with checking his health, going to physical therapy, cycling his daily $5.3 \mathrm{~km}$, and doing groceries. Mr. and Mrs. Johnson have been married for 52 years and have a son together. Mrs. Johnson describes her husband as a loyal, serious, stubborn, distant, neurotic and inflexible man, although he means well.

Mr. Johnson has chronic obstructive pulmonary disease for which he uses a bronchodilator, which he takes faithfully at a set time. He plans his visit to doctor Petersen at the day his prescribed medication runs out. He shows doctor Petersen the table he made in which he monitored his saturation values twice a day as well as his activities of that day during the last six months. Despite the good results, he wants to change his medication as he experiences incontinence and mild abdominal stomach pains from time to time in the last two weeks. He has a rather peculiar explanation for this; he claims it is the result of missing his physical therapy appointment once, having to skip his daily bike ride twice, in combination with a change in his metabolism after he ate a different type of rye bread than he normally eats, two and half weeks ago. Prior to his consultation, he searched the internet and discussed it with his wife and son (who is a pharmacist) and he asks doctor Petersen to replace the bronchodilator he is currently using (Spiriva $\left.{ }^{\circledR}\right)$, for Serevent $₫$, another bronchodilator.

Doctor Petersen explains multiple times that Mr. Johnson wrongly assumes these coincidences are causally linked and therefore there is no need for medication change. Furthermore, he states that Mr. Johnson is quite preoccupied with his saturation and advices him to quit the home measurements. He continues to prescribe the Spiriva $\Re_{\text {. }}$

\section{Personality disorders}

A patient as Mr. Johnson, might have a personality disorder (PD). In the most wellknown and used diagnostic manual for mental disorders, the DSM-5 ${ }^{(1)}$, a PD is defined as "an enduring pattern of inner experience and behavior that deviates markedly from the expectations of the individual's culture" (p.646). These maladaptive and enduring patterns of perceiving, relating to, and thinking about others and oneself are inflexible and pervasive across a broad range of personal and social situations, resulting in distress or impairment in important areas of functioning. The definition dictates a stable and chronic course tracing back to at least early adulthood. Moreover, this pattern may not be attributed to an another psychiatric disorder, arise from a general medica condition, or be the direct physiological effect of a substance. In brief, a PD is "a way of thinking, feeling and behaving that deviates from the expectations of the culture causing distress or problems functioning, and lasts over time" (1).

The DSM- 5 differentiates 10 specific PDs grouped into three clusters (A, B, and C) based on descriptive commonalities (Table 1). Cluster A PDs, including paranoid schizoid, and schizotypal PDs, are characterized by eccentricity. Cluster B personalities, all sharing features of emotionality or unpredictability, include antisocial, borderline, narcissistic and histrionic PDs. Cluster C PDs are notable for their anxious features and include avoidant dependent, and obsessive-compulsive PDs. Furthermore, the DSM-5 also includes three diagnoses for maladaptive personality types not matching these ten specific disorders, but yet show features of a PD, such as 'personality change due to another medical condition', 'other specified personality disorder', and the 'unspecified personality disorder'. 


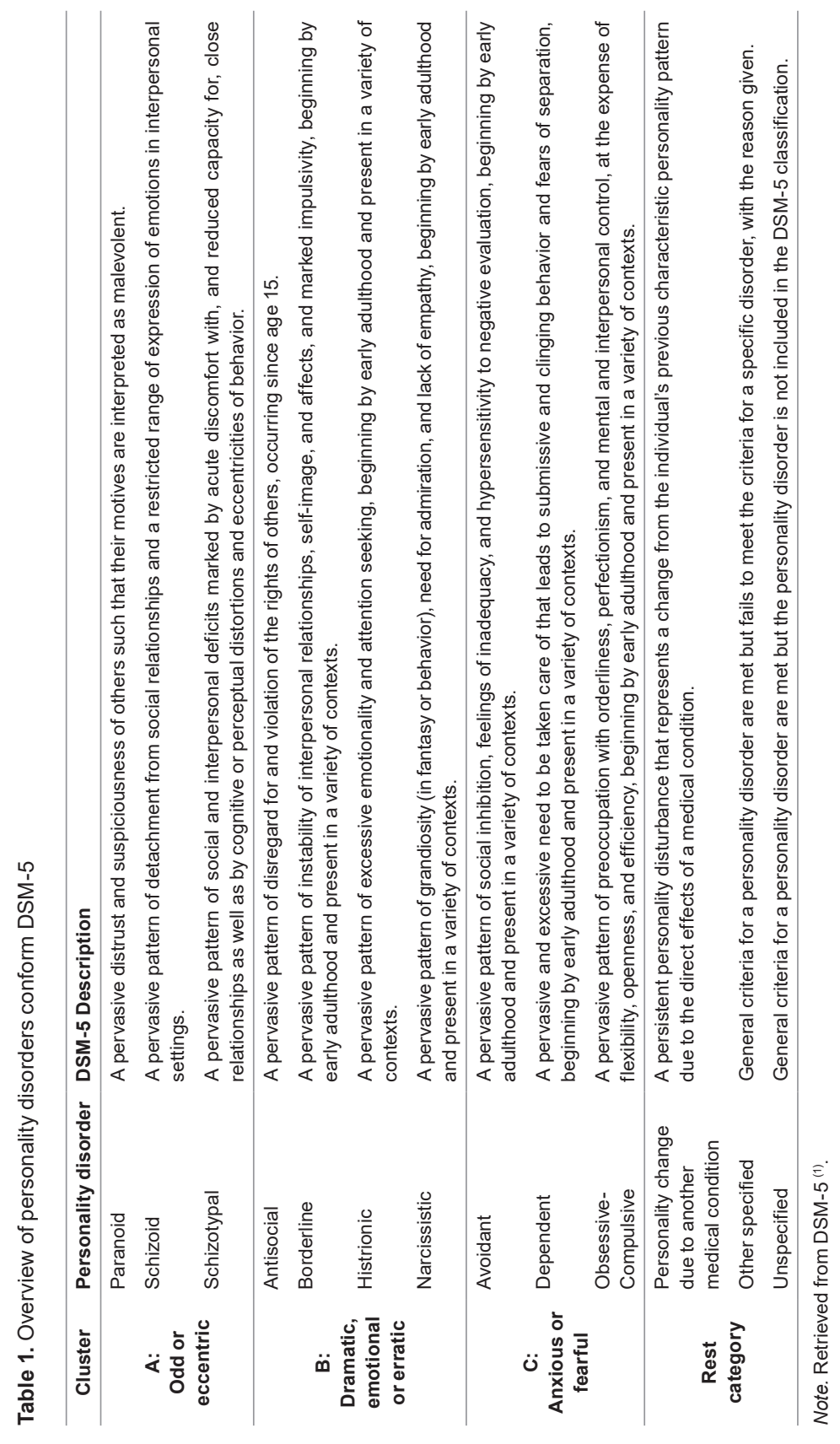

The prevalence of PDs in late life in general practice

Considering his central role in healthcare, the GP is often the first and probably the most frequently contacted healthcare provider who is consulted by older adults $(\geq$ 60 yrs.) with PDs. Especially since research points out that the presence of PDs is associated with increased healthcare consumption and use of medical resources ${ }^{(2-4)}$. This might even further increase because PDs in later life may not only be a current but also a growing problem given the aging population. According to the 'World Population Prospects 2019' from the United Nations ${ }^{(5)}$, by 2050 , one in four people living in Europe and Northern America is estimated to be aged 65 or over. The number of people aged $\geq 80$ years is even expected to increase substantially from 143 million in 2019 to 426 million in 2050. Given this growing double aging population, the number of older adults with PDs are likely to increase accordingly. For a long time the number of PDs was thought to decrease with age. In contrary to former beliefs, the prevalence of PDs in late life is fairly high, ranging from $10.6-14.5 \%^{(6-8)}$ in community-dwelling adults over 50 years, and is comparable to the rate in the general adult population $12.2 \%$, ${ }^{9}$.

An average general practice has 2,095 patients ${ }^{(10)}$ of which $19.1 \%$ (about 400 patients) are $\geq 65$ years ${ }^{(11)}$. Based on aforementioned prevalence rates of $10.6-14.5 \%$, this means that now, per general practice, 43 to 58 elderly patients have a PD. Based on the World Population Prospects, in 2050 the GP's caseload of aged patients is estimated at $25 \%$ (about 524 patients); meaning that 55 to 76 elderly patients are likely to have a PD. Hence, the GP is likely to see quite some older adults with PDs during his consultations, although the severity of these disorders may differ from patient to patient.

\section{The challenges for the GP in dealing with PDs in older adults}

Older adults with PDs, as Mr. Johnson might be, may pose quite a challenge for the GP as these disorders are notable to strain the doctor-patient relationship due to interpersonal difficulties. Direct or indirect treatment rejection, non-compliance to somatic and mental care, an excessively dependent attitude, and/or verbally aggressive outbursts when service is not exactly given as desired ${ }^{(2,12-13)}$ which are all associated with PDs, not rarely add stress and frustration on the GP's behalf. When confronted with these 'difficult' patients, GPs often become more directive and less collaborative ${ }^{(14)}$, which may often only aggravate the situation. Regular acts such as addressing the practice rules, explaining, or trying to reassure the patient, might be less effective. Moreover, the presence of a PD affects health negatively; it complicates the detection 
of, and adversely affects treatment of comorbid disorders and conditions ${ }^{(15)}$. Treatment outcomes are poor(er) ${ }^{(2)}$, and the number of relapse and readmission increases ${ }^{(16)}$ Furthermore, PDs are associated with a wide variety of negative effects such as decreased physical functioning (2), lower perceived quality of life ${ }^{(17)}$, and increased mortality rates as to suicide ${ }^{(18)}$. Thereby, PDs pose a high economic burden in health care ${ }^{(19-20)}$.

Fortunately, research gradually shows that therapeutic nihilism is rather obsolete with respect to PDs in late life. Treatment of PDs in older adults, ranging from supportive-structuring treatment approaches (e.g., psychoeducation, behaviora counseling) to adaptation focused (e.g., social skills training) to personality-changing interventions (e.g., schema therapy, dialectical behavior therapy) ${ }^{(21-22)}$, appears both feasible and effective ${ }^{(23-24)}$, especially when tailored to patients ${ }^{(25-26)}$. Moreover, initia results demonstrate that adopting clinical staging of PDs in treatment indication may improve its outcomes and may facilitate early detection as well ${ }^{(27-28)}$

\section{Detection in general practice}

However, PDs in older adults often remain unrecognized, as the detection is hampered. These disabling disorders, due to their ego-syntonic nature, are usually not the main reason for consultation ${ }^{(29)}$. As PDs are highly comorbid with both medical and mental disorders ${ }^{(30)}$ and are believed to have a more atypical presentation in later life (31-32), the already complex clinical picture gets even more cumbersome in older adults. This is due to multiple medical conditions whether or not accompanied by psychiatric comorbidity and polypharmacy ${ }^{(33)}$ frequently related to aging. To top it off, the GP's task of detection is further impeded as resources for identifying PDs in older adults are scarce ${ }^{(34-36)}$ and are even absent in general practice, as is the amount of research A literature search in Medline/Pubmed and PsycINFO reviewing papers of primary empirical research addressing PDs in older adults in general practice using the keywords "personality disorder(s)" or "personality pathology" and "older adults" or "elderly" or "late life", and "general practice" or "primary care" or "family medicine" resulted in only 23 hits. Twenty of which were excluded for reasons of wrong population $(n=2)$, wrong setting $(n=4)$, PDs were accessory $(n=6)$, and secondary research $(n=8)$. Of the remaining three relevant papers, two originated from this dissertation. Hence, despite GPs are frequently confronted with and challenged by older adults with $\mathrm{PDs}$, these disorders in general practice are an un(der)explored field.

Improving the detection of PDs in general practice is urgently needed, as it could alert the GP that personality pathology might be present thereby preparing him for potential challenges during the consultations ${ }^{(13)}$. It would also allow the GP to take personality functioning into account by adjusting his own behavior when interacting with the older adult as well as by tailoring his interventions which may optimize treatment compliance thereby minimizing noncompliance. Having more insight in the 'difficult patient' by an improved understanding of the older adult's behavior may also decrease stress and frustration which may increase work satisfaction ( ${ }^{37}$ ). Furthermore, it would enable the GP to make a timely and more specified referral to mental health settings where diagnostic assessment and treatment options are available. Hence, detection of PDs in late life in general practice may contribute to decreasing adverse consequences from patients' perspective, by improving the quality of healthcare ${ }^{(13)}$, and reducing economic costs.

Regarding the above described case, although this does not nearly have enough information about Mr. Johnson, let's assume that he has a PD. By recognizing that his behavior is maladaptive, and depending on the severity of the patient's disability and whether or not he or his environment has a request for care, doctor Petersen would be able to refer Mr. Johnson to (specialized) mental healthcare for formal diagnosis and treatment. Knowing the type of maladaptive traits or PD, in this case probably obsessive-compulsive PD traits, is beneficial for doctor Petersen as it would explain Mr. Johnson's preoccupation with details and routine, his rigidness, and his need to control. It would also explain why Mr. Johnson politely said he will give it another try but does not, as well as why doctor Petersen's attempts to convince him of his wrong fail. Furthermore, it could help doctor Petersen in attuning his approach to Mr. Johnson. Perhaps following Mr. Johnson in his request would be a more sensible approach improving the doctor-patient relationship, as the requested medication was medically a proper alternative. Also, doctor Petersen could have complimented Mr. Johnson for his detailed overview and asked for a copy of his saturation table, knowing that this would be a sign of trust and a token of taking Mr. Johnson seriously. This trust may increase treatment compliance in the future.

As previously noted, an important barrier in the detection of PDs in later life in general practice is the lack of both age-specific and validated instruments. Most instruments are based on the DSM-IV (38) and have been merely developed for young(er) adults (39). As these instruments do no take the specific aging context into account, they are not necessarily fully applicable to older adults ${ }^{\left({ }^{36}\right)}$. Moreover, PD instruments often consist of many items, which make them impractical and unfeasible in genera practice where the GP has limited time. Another weakness is that many instruments predominantly rely on self-report, which may not fully capture one's (maladaptive) personality as individuals displaying high rates of PD features may be unaware of how their behavior affects others ${ }^{(40)}$. Also, as aging is associated with cognitive decline, older adults with severe cognitive impairments may not be capable to reliably report on their personality. 
As the absence of suitable instruments is not unique to general practice, van Alphen and colleagues developed the Gerontological Personality disorders Scale (GPS), an age-specific 16-item instrument for the initial evaluation of the presence or absence of PDs in older adult psychiatric outpatients which consists of both a patient (i.e. self-report version, GPS-pv) and an informant version (GPS-iv). The GPS proved to be a reliable and valid tool to screen for PDs in elderly psychiatric outpatients ${ }^{(41)}$ and has been recently validated in geriatric medicine outpatients ${ }^{(42)}$. Given these promising results, as well as being a brief instrument, this could potentially be a suitable instrument for general practice. In order to provide the GP a tool for the recognition of PDs in older adults, we examined the GPS in general practice.

\section{Research questions}

The main objective of underlying research was to examine various aspects of the Gerontological Personality disorders Scale (GPS) in general practice. The following research questions are addressed in this dissertation:

1. What is the current status of PDs in older adults with respect to epidemiology, assessment and treatment?

2. What is the reliability and diagnostic accuracy of the GPS in general practice?

3. What is the convergent and divergent validity of GPS in general practice?

4. What is the concordance between the self- and informant-report version of the GPS in general practice, and what factors may contribute to this?

5. What is the feasibility and acceptability of the GPS according to professionals as well as older adults and their informants?

\section{Outline of the dissertation}

To keep track of recent developments and research initiatives which may provide considerations for clinical practice, chapter 2 presents the results of a literature review focusing on epidemiological aspects, assessment and treatment of PDs in older adults. The results of this study are relevant for clinicians and researchers as it not only gives an overview, but also states clinical implications and suggests new areas of interest.

Next, the reliability and diagnostic accuracy of both the self-report and informantreport version of the Gerontological Personality disorders Scale (GPS) in general practice are examined and presented in chapter 3 . As part of evaluating the reliability of the GPS, internal consistency, test-retest reliability and inter-rater reliability were examined. The validity was assessed by calculating classical diagnostic validity statistics such as sensitivity, specificity, positive predictive power, negative predictive power, and the overall correct classification. Additionally, the incremental validity of positive and negative test scores was also calculated as well as which items were the most predictive for the presence of a PD. Results will provide insight in the diagnostic accuracy of the GPS and are relevant for GPs who intend to screen for PDs in their elderly patients but who lack the resources and time to systematically conduct extended diagnostic procedures.

Then, in chapter 4 the convergent and divergent validity of the GPS was explored by correlating both versions of the GPS with measures of personality and psychopathology. Furthermore, its nomological network is examined in light of the Hierarchical Taxonomy of Psychopathology (HiTOP), a new proposed classification system aiming at improving research and clinical practice by overcoming the shortcomings of the current traditiona nosology ${ }^{\left({ }^{43}\right)}$.The findings of this study are relevant as they elaborate construct validity, which is a crucial step in the evaluation and validation of an instrument ${ }^{(44)}$.

In chapter 5 the concordance between the self-report and informant-report version of the GPS was examined, as well as potentially explanatory factors such as which perspective reports more pathology, item accessibility and relational aspects. The findings underscore the importance of including both self- and informant-report in the assessment of PDs in older adults.

Chapter $\mathbf{6}$ focusses on the feasibility and the acceptability of the GPS in general practice from an older adult, informant and professional perspective. These were assessed using a convergent parallel mixed methods design, in which the professionals (general practitioners and nurse practitioners) provided qualitative data and the older adults and informants quantitative data. The findings of this study facilitate development of effective strategies to implement the GPS in general practice.

Finally, in chapter 7 the major findings of the studies are summarized, and discussed in the context of 1 ) what is an acceptable reference standard, 2) what is acceptable diagnostic accuracy for assessing PDs in late life in general practice, 3) how can the GPS be improved, and 4) implemented in general practice? Furthermore, methodological considerations will be addressed as well as implications for genera practice and suggestions for further research. 


\section{References}

1. American Psychiatric Association. Diagnostic and statistical manual of mental disorders. $5^{\text {th }}$ ed. Arlington, VA: American Psychiatric Publishing; 2013.

2. Powers AD, Oltmanns TF. Personality disorders and physical health: A longitudina examination of physical functioning, healthcare utilization, and health-related behaviors in middle-aged adults. Journal of Personality Disorders. 2012;26(4):524-38.

3. Lawton EM, Oltmanns TF. Personality pathology and mental health treatment seeking in a community sample of older adults. Personality and Mental Health. 2013;7:203-12.

4. Twomey CD, Baldwin DS, Hopfe M, Cieza A. A systematic review of the predictor of health service utilisation by adults with mental disorders in the UK. BMJ Open. 2015;5:e007575.

5. United Nations. World population prospects 2019 [Available from: https://population un.org/wpp/Download/Standard/Population/

6. Holzer KJ, Huang J. Physical health-related quality of life among older adults with personality disorders. Aging and Mental Health. 2019;23(8):1031-40.

7. Oltmanns TF, Rodrigues MM, Weinstein $Y$, Gleason MEJ. Prevalence of personality disorders at midlife in a community sample: Disorders and symptoms reflected in interview, self, and informant reports. Journal of Psychopathology and Behavioral Assessment. 2014;36:177-88

8. Reynolds K, Pietrzak RH, El-Gabalawy R, Mackenzie CS, Sareen J. Prevalence of psychiatric disorders in US. Older adults; findings from a nationally representative survey. World Psychiatry. 2015;14(1):74-81

9. Volkert J, Gablonski T-C, Rabung S. Prevalence of personality disorders in the general adult population in western countries: Systematic review and meta-analysis. The British Journal of Psychiatry. 2018;213(6):709-15

10. Landelijke Huisartsen Vereniging. Feiten en cijfers huisartsenzorg: Kerncijfers 2020 [Available from: https://www.lhv.nl/uw-beroep/over-de-huisarts/kerncijfers-huisartsenzorg.

11. Meijer W, Verberne L, Weesie Y, Davids R, Winckers M, Korteweg L, et al. Zorg door de huisarts. Nivel zorgregistraties eerste lijn: Jaarciifers 2018 en trendcijfers 2014-2018 2019 [Available from: https://www.nivel.nl/sites/default/files/Jaarrapport\%20Huisarts 2018.pdf.

12. van Alphen SPJ, Derksen JLL, Sadavoy J, Rosowsky E. Features and challenges of personality disorders in late life. Aging and Mental Health. 2012;16(7):805-10.

13. Huprich SK. Personality pathology in primary care: Ongoing needs for detection and intervention. Journal of Clinical Psychology in Medical Settings. 2018;25(1):43-54.

14. Porcerelli JH, Jones JR. Uses of psychological assessment in primary care settings. In Maruish ME, editor. Handbook of psychological assessment in primary care settings. Second edition. New York: Routledge; 2017.

15. van Alphen SPJ, Videler AC, Bouckaert F, Oude Voshaar R. In vogelvlucht. In van Alphen SPJ, Oude Voshaar R, Bouckaert F, Videler AC, editors. Handboek persoonlijkheidsstoornissen bij ouderen. Utrecht, NL: De Tijdstroom uitgeverii; 2018.
16. Stevenson J, Brodaty H, Boyce P, Byth K. Personality disorder comorbidity and outcome: Comparison of three age groups. Australian and New Zealand Journal of Psychiatry. 2011;45(9):771-9.

17. Condello $\mathrm{C}$, Padoani W, Uguzzoni U, Caon F, De Leo D. Personality disorders and selfperceived quality of life in an elderly psychiatric outpatient population. Psychopathology. 2003;36:78-83.

18. Björkenstam E, Björkenstam C, Holm H, Gerdin B, Ekselius L. Excess cause-specific mortality in in-patient-treated individuals with personality disorder: 25 -year nationwide population-based study. The British Journal of Psychiatry. 2015;207(4):339-45.

19. Soeteman D, Hakkaart-van Roijen L, Verheul R, Busschbach JJ. The economic burden of of personality disorders in mental health care. Journal of Clinical Psychiatry. 2008:69(2):259-65.

20. Rendu A, Moran P, Patel A, Knapp M, Mann A. The economic impact of personality disorders in UK primary care attenders. British Journal of Psychiatry. 2002;181:62-6.

21. van Alphen SPJ, Bolwerk N, Videler AC, Tummers JHA, van Royen RJJ, Barendse H, et al. Age-related aspects and clinical implications of diagnosis and treatment of personality disorders in older adults. Clinical Gerontologist. 2012;35(1):27-41.

22. Rosowsky E, Young AS, Malloy MC, van Alphen SPJ, Ellison JM. A cross-validation delph method approach to the diagnosis and treatment of personality disorders in older adults. Aging and Mental Health. 2018;22(3):371-8 .

23. Videler AC, Rossi G, Schoevaars M, van der Feltz-Cornelis CM, van Alphen SPJ. Effects of schema group therapy in older outpatients: A proof of concept study. Internationa Psychogeriatrics. 2014;26(10):1709-17.

24. Videler AC, van Alphen SPJ, van Royen RJJ, van der Feltz-Cornelis CM, Rossi G, Arntz A. Schema therapy for personality disorders in older adults: A multiple-baseline study Aging and Mental Health. 2018;22(738-747):1-10.

25. Videler AC, van Royen R, Heijnen-Kohl SMJ, Rossi GMP, van Alphen SPJ, Van de Feltz-Cornelis CM. Adapting schema therapy for personality disorders in older adults. International Journal of Cognitive Therapy. 2017;10(1):62-78

26. Videler AC, Van der Feltz-Cornelis CM, Rossi G, van Royen RJJ, Rosowsky E, van Alphen SPJ. Psychotherapeutic treatment levels for personality disorders in older adults. Clinical Gerontologist. 2015;38(4):325-41.

27. Hutsebaut $\mathrm{J}$, Hessels $\mathrm{CJ}$. Clinical staging and early intervention for borderline personality disorder. Tijdschrift voor Psychiatrie. 2017;59(3):166-74

28. Hutsebaut $J$ Verheul $R$, Videler AC, van Alphen SPJ. Managing borderline personality disorder from a life course perspective: Clinical staging and health management. Personality Disorders: Theory, Research, and Treatment. 2019.

29. Devens M. Personality disorders. Primary Care. 2007;34:623-40.

30. Schuster JP, Hoertel N, Le Strat Y, Manetti A, Limosin F. Personality disorders in older adults: Findings from the national epidemiologic survey on alcohol and related conditions. American Journal of Geriatric Psychiatry. 2013;21(8):757-68. 
31. Mroczek DK, Hurt SW, Berman WH. Conceptual and methodological issues in the assessment of personality disorders in older adults. In: Rosowsky E, Abrams RC, Zweig RA, editors. Personality disorders in older adults: Emerging issues in diagnosis and treatment. Mahwah, NJ: Erlbaum; 1999. p. 135-52.

32. Debast I, van Alphen SPJ, Rossi G, Tummers JHA, Bolwerk N, Derksen JJL, et al. Personality traits and personality disorders in late middle and old age: Do they remain stable? A literature review. Clinical Gerontologist. 2014;37(3):253-71.

33. Junius-Walker $U$, Theile G, Hummers-Pradier E. Prevalence and predictors of polypharmacy among older primary care patients in Germany. Family Practice. 2007;24:14-9.

34. Penders KAP, Peeters IGP, Metsemakers JFM, van Alphen SPJ. Personality disorders in older adults: A review of epidemiology, assessment, and treatment. Current Psychiatry Reports. 2020;22:1-14.

35. van Alphen SPJ, Dijk v, S, Videler AC, Rossi G, Dierckx E, Bouckaert F, et al. Personality disorders in older adults: Emerging research issues. Current Psychiatric Reports. 2015; 17:538-45.

36. Rossi G, van den Broeck J, Dierckx E, Segal D, van Alphen SPJ. Personality assessmen among van den Brock J, Dierkx EE, Segal D, van Alphen SPJ. Pers Alying and Mental Health. 2014:18(8):936-40.

37. Schafer S, Nowlis D. Personality disorders among difficult patients. Archives of Family Medicine. 1998:7:126-9

38. American Psychiatric Association. Diagnostic and statistical manual of mental disorders. $4^{\text {th }}$; text revison ed. Washington DC: Author; 2000.

39. Agronin ME, Maletta G. Personality disorders in late life: Understanding and overcoming the gap in research. American Journal of Geriatric Psychiatry. 2000;8(1):4-18.

40. Klonsky ED, Oltmanns TF, Turkheimer E. Informant-reports of personality disorder: Relation to self-reports and future research directions. Clinical Psychology Science and Practice. 2002;9:300-11.

41. van Alphen SPJ, Engelen GJJA, Kuin Y, Hoijtink HJA, Derksen JLL. A preliminary study of the diagnostic accuracy of the Gerontological Personality disorders Scale (GPS) International Journal of Geriatric Psychiatry. 2006;21(9):862-8.

42. Meeuwissen-van Pol E, Rossi G, De Weerd-Spaetgens C, van Alphen SPJ. Screening of personality disorders in a geriatric medicine population. European Geriatric Medicine 2020;11:289-95

43. Kotov R, Krueger RF, Watson D, Achenbach TM, Althoff RR, Bagby RM, et al. The Hierarchical Taxonomy of Psychopathology (HiTOP): A dimensional alternative to traditional nosologies. Journal of Abnormal Psychology. 2017;126(4):454-77.

44. American Psychiatric Association. Standards for educational and psychological testing. Washington, DC: Author: 2014 


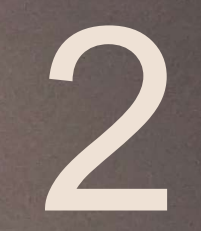

Personality disorders in older adults: A review of epidemiology, assessment and treatment

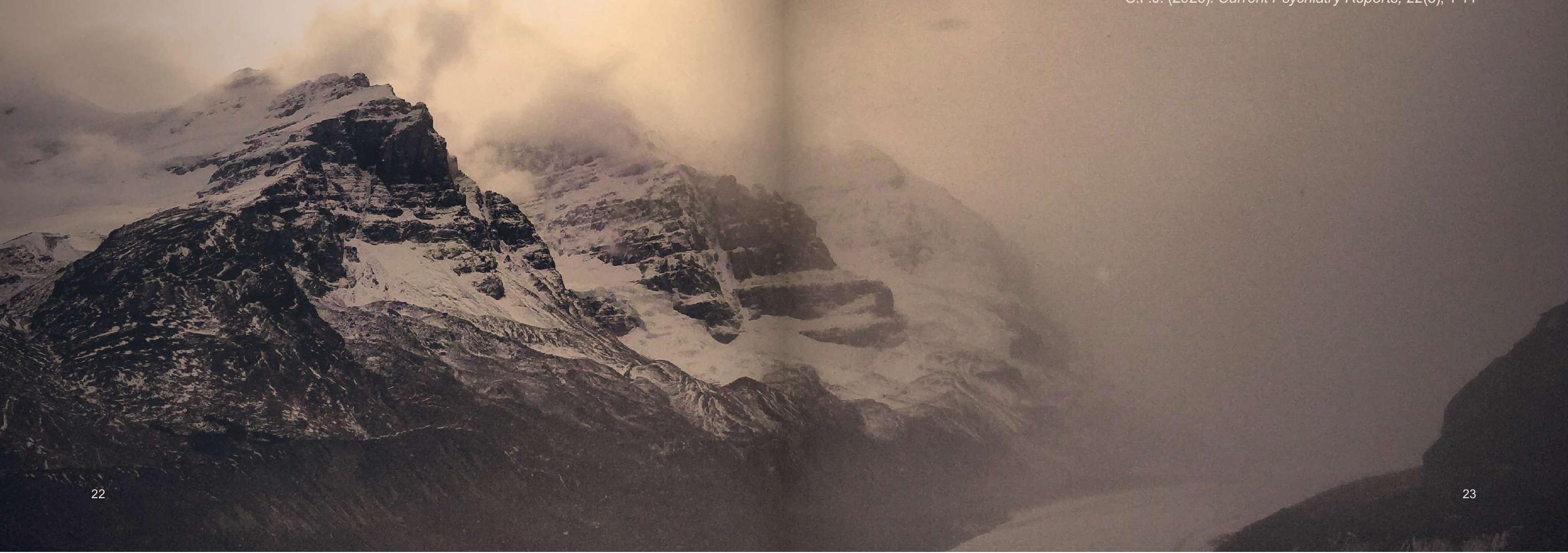




\section{Abstract}

\section{Purpose of the review}

The aim of the paper is reviewing recent literature on the epidemiology, assessment and treatment of personality disorders (PDs) among older adults ( $\geq 60 \mathrm{yrs}$.).

\section{Recent findings}

Since 2015, 12 primary empirical studies have been published addressing PDs in older adults; three addressing epidemiological aspects, six on assessment, two exploring both epidemiology and assessment and one examining treatment. PD research in older adults is steadily growing and is predominantly focused on assessment. The studies showed that PDs were rather prevalent ranging from 10.6-14.5\% in communitydwelling older adults, to $57.8 \%$ in nursing home-residing older adults. The SIPP-SF, GPS and ADP-IV turned out to be promising instruments for assessing PDs in later life. Furthermore, schema therapy seems to be a feasible and effective intervention.

\section{Summary}

Despite promising findings, there is an urgent need for studies addressing PDs in older adults, especially studies investigating epidemiological aspects and treatment options. Furthermore, new areas of interest arise such as PDs in other settings, and behavioral c

ounseling.

\section{Keywords}

personality disorder(s), older adults, elderly, epidemiology, assessment, treatment

\section{Introduction}

In 2000, Agronin and Maletta highlighted the research gap on personality disorders (PDs) in older adults, suggesting that the lack of longitudinal data, the absence of age-appropriate diagnostic instruments as well as an elderly-adjusted nosology contributed to this dearth of research (1). Fifteen years later, van Alphen and colleagues reviewed the scientific data and concluded that still only a modest number of studies have focused on PDs in later life. However, empirical research within this field did increasingly address the absence of appropriate assessment options by focusing on psychometric properties of age-specific personality tests, the age-neutrality of instruments, and validation of personality inventories in older adults. Treatment studies were nevertheless scarce ${ }^{(2)}$.

Meanwhile, the nosological difficulties remained. Although the age-appropriateness of the PD criteria was increasingly debated ${ }^{(3)}$, the upcoming editions of the DSM ${ }^{(4-5)}$ are inattentive to PDs in later life nor age-related aspects. As van Alphen and colleagues (2) discussed the role of the current classification system of PDs in later life, they also saw opportunities which the recent included alternative dimensional model might have in stimulating PD research in older adults.

PDs in older adults are quite prevalent and given the aging population, clinicians are often confronted with these older adults. Considering the serious consequences, there is a clinical need for adequate assessment and treatment options for PDs in older adults. To keep track of recent developments and research initiatives which may provide considerations for clinical practice, this article evaluates primary studies on the epidemiological, diagnostic, and treatment aspects of PDs in older adults of the last six years.

\section{Methods}

A literature search was performed between November 2018 and April 2019, using the databases of Medline/Pubmed and PsycINFO, to review papers published between July, 2014 and April, 2019, describing the epidemiology, assessment and treatment of personality disorders (PDs) in older adults ( $\geq 60 \mathrm{yrs}$.). This interval was chosen in order to include studies published after the most recent literature review on a similar subject matter ${ }^{(2)}$.

The search consisted of the keywords "personality disorder(s)" or "personality pathology" and "older adults" or "elderly" or "late life", which were required to appear 
in the article title or abstract. English and Dutch articles of primary empirical studies were included when PDs (conform DSM) in adults aged 60 years and older were the primary focus and, the studies addressed PDs in relation to epidemiology, assessment or treatment. Articles were excluded if 1) PDs were accessory (e.g. covariate or comorbid condition) or when 2) they addressed personality or (adaptive) personality traits, 3) other than DSM typologies (e.g. "type A") were used, 4) the main focus was on adults $<60$ yrs., 5) they addressed themes beyond the scope of this review, 6 ) it contains primary non-empirical or secondary research (e.g. case-studies, Delphistudies, reviews). The abstracts and articles were reviewed by the first author. In case of doubt, the other authors reviewed the concerning abstracts and/or articles as well. Then, in- or exclusion followed when consensus (agreement between at least three authors) was reached. Figure 1 describes the selection process in detail.
Figure 1. Flowchart review process

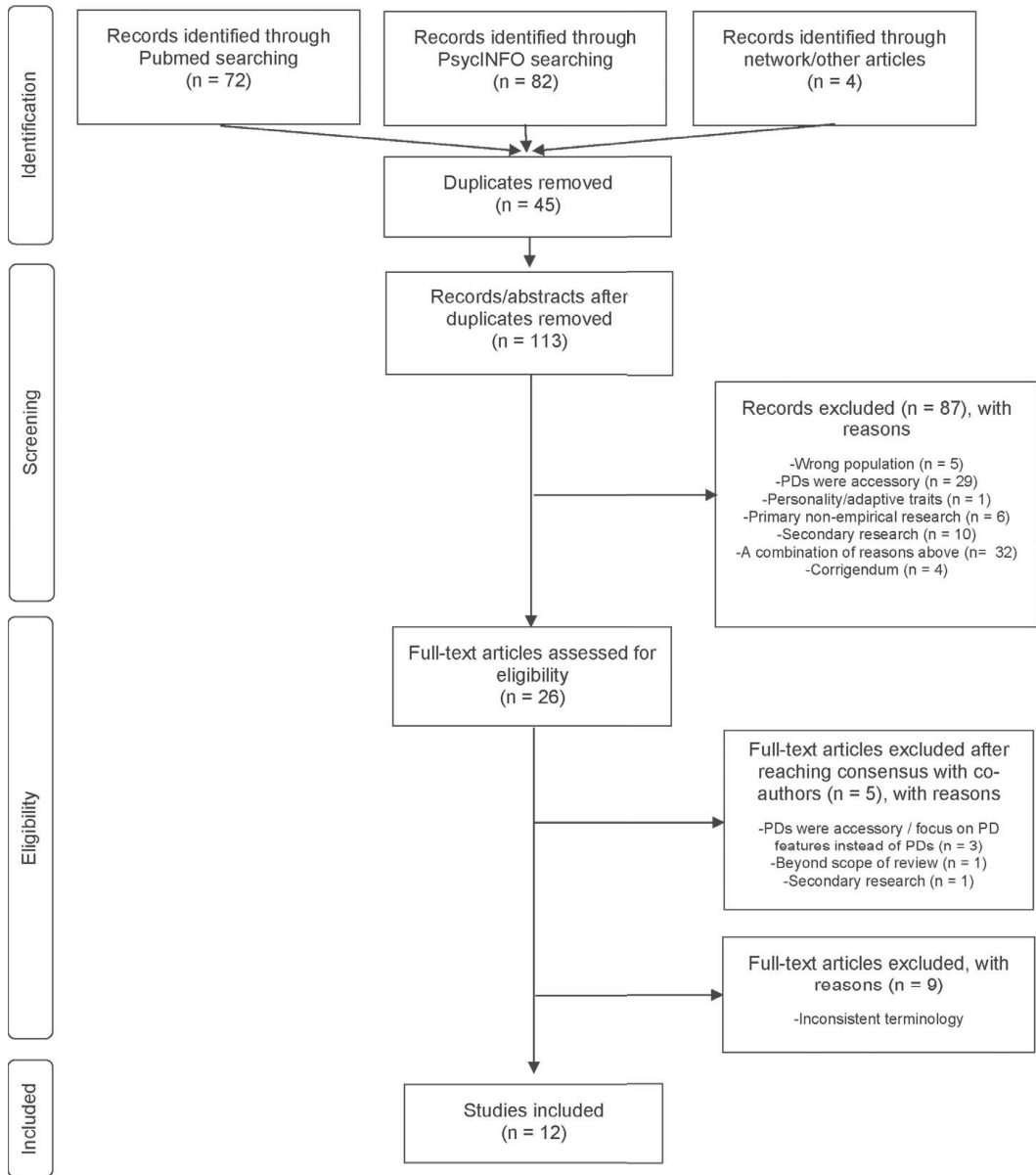




\section{Results}

Epidemiology: Prevalence, and associations with cognitive disorders and quality of life

In total, five studies reported prevalence rates of PDs in older adults. One of these studies also addressed the association with cognitive disorders and another one examined health-related quality of life in the presence of PDs as well. Table summarizes the reported prevalence rates across studies.

The largest study ${ }^{(6)}$, based on the National Epidemiologic Survey on Alcohol and Related Conditions (NESARC) using Wave 1 data of 16,884 community-dwelling adults aged 50 and older, revealed a prevalence rate of roughly $10.7 \%$ for having at leas one PD. The highest rates were found for obsessive-compulsive PD $(6.5 \%)$ followed by paranoid PD $(2.5 \%)$, while dependent PD $(0.4 \%)$ and histrionic PD $(0.8 \%)$ were the least prevalent. Furthermore, the individuals with PDs were more likely to be male younger, and higher educated than the individuals without PDs. However, this study did not address the whole PD range; borderline, schizotypal and narcissistic PDs were not assessed.

Using Wave 2 data of NESARC, which covered all ten PDs, Reynolds and colleagues ${ }^{(7)}$ found that the prevalence of PDs among older adults is approximately $14.5 \%$. Again, obsessive-compulsive PD was the most prevalent (7.6\%), now followed by narcissistic PD (3.9\%). Once more, dependent PD $(0.3 \%)$ as well as histrionic PD $(0.7 \%)$ were the least common PDs. The higher prevalence rate might be explained by the inclusion of all ten PD, as borderline (3.2\%) narcissistic, and schizotypal $(2.4 \%)$ PDs which were absent in Wave 1 data, appeared to be quite prevalent in this study. Furthermore, PDs were significantly more common in older men (16.8\%) than in elderly women $(12.7 \%)$, with the exception of paranoid, avoidant and dependent PD which were more prevalent in females. They also differentiated the prevalence rate within four age groups; young-old, middle-old, old-old, and oldest-old. Aside from dependent PD, all PDs differed significantly across age-groups. Overall, with increasing age prevalence rates decreased. However, for avoidant obsessive-compulsive, paranoid, and histrionic $\mathrm{PD}$, a slight but non-significant upturn in occurrence was noted from the old-old to the oldest-old. This was mainly due to increasing prevalence rates for these PDs among men, except for obsessive-compulsive PD which rose with almost $35 \%$ in the most aged women.

The study of Oltmanns and colleagues (8) using data of 1,630 middle-aged community-dwelling adults (55-65 yrs.) of the St. Louis Personality and Aging Network (SPAN), revealed a prevalence rate of about $11 \% ; 8.2 \%$ had at least $1 \mathrm{PD}, 1.8 \% \mathrm{met}$ de criteria of PDNOS (i.e. personality disorder not otherwise specified), and roughly
$1 \%$ qualified for having two or three PDs. In line with the other studies obsessivecompulsive PD was most frequently observed $(2.9 \%)$ now followed by avoidant PS (2.5\%). Schizotypal $(0.1 \%)$, dependent $(0.1 \%)$, and histrionic PD $(0.2 \%)$ were the least common. Additionally, they found that $9.3 \%$ of the participants fell one criteria short of a diagnosis, and could therefore be classified as having a 'subthreshold' PD. When comparing these findings to those of Reynolds and colleagues ${ }^{(7)}$ subsample of youngold adults, the prevalence rates in the latter study are substantially higher with the exception of avoidant PD and even remain higher when the PD rates in Oltmanns' study are combined with the subthreshold rates. As both research groups used seemingly comparable samples, namely community-dwelling adults aged 55-64 years living in the United States, and the assessment of PDs differed, this might explain these deviating PD rates.

Although the findings from NESARC and SPAN studies showed that dependent PD is quite infrequently observed $(0.1 \%-0.3 \%$,$) this \mathrm{PD}$ appeared to be substantially more prevalent in Central Africa. In a cross-sectional multicenter community-dwelling population in Central Africa $(n=1,772)$, the prevalence of dependent PD was $14.4 \%$ (9). Moreover, the prevalence rates differed depending on cognitive status. The highes rates were found among the elderly with Mild Cognitive Impairment ( $\mathrm{MCl} ; 26.5 \%$ ) followed by the elderly with dementia (25.8\%). In older adults without cognitive disorders, the prevalence rate was $12.7 \%$. Pilleron and colleagues attributed their surprisingly high prevalence rate to the use of DSM-IV criteria ${ }^{(4)}$ which are insufficiently adapted to older adults, as well as to the older adults' proneness to respond confirmatory on PD items due to physical illnesses rather than psychological disturbances. Although these factors are known to complicate the assessment of PDs within the aged, they seem unlikely to explain the discrepancy in prevalence as the NESARC and SPAN studies (and nearly all studies for that matter) rely on instruments based on DSM PD criteria as well. Furthermore, these studies should encompass this 'proneness' at least to a certain extent as well, as they all sampled older adults. It seems more likely that the use of the PDQ-4, which has a high false positive rate ${ }^{(10)}$ and cultural aspects migh account for this difference, as studies show that individuals living in more traditional societies, as is Central Africa, score higher om dependent traits than those in more westernized cultures ${ }^{(11)}$. Moreover, the cognitive status might bias the judgements about PDs; interviewees might have attributed some items (incorrectly) to enduring personality patterns instead of to the person's current (cognitive) state. In some cases, informants even responded to the PD questionnaire on behalf of the older adult, which might introduce bias too.

One study examined PD prevalence in a non-community-dwelling elderly population. In a sample of 83 older adults living in nursing centers or joining senior citizen clubs, about $58 \%$ were diagnosed with a PD when using the French version of the Questionnaire on Personality Traits ${ }^{(12)}$. Avoidant (20.5\%), obsessive-compulsive 
(12.0\%) and paranoid PD (12.0\%) appeared to be the most prevalent while both histrionic and antisocial PD were absent in this sample. All PDs were more prevalent in men, except schizotypal PD which was more often seen in women than men $(1.7 \%$ versus $0.0 \%$ ). However, some caution is warranted when interpreting the numbers, as the sample size is rather small, it relied on self-report which might be biased due to interference of age-related cognitive decline, and the QPT tends to overestimate the prevalence of PDs ${ }^{(13)}$.

Aside from the prevalence rates, Pilleron and colleagues ${ }^{(9)}$ examined the relationship between dependent PD and cognitive disorders. They found that after controlling for sociodemographic, vascular and psychological covariates, the elderly with dependent $\mathrm{PD}$ were 2.18 times more likely to have $\mathrm{MCl}$, than the older adults without this $\mathrm{PD}$. Although dependent $\mathrm{PD}$ was also associated with dementia after adjusting for sociodemographic factors $(\mathrm{OR}=1.98, \mathrm{Cl}=1.25-3.14, \rho=.004)$, this association faded when vascular and psychological factors were taken into account.

Holzer and Huang ${ }^{(6)}$ investigated the association between PDs and physical healthrelated quality of life (PHRQoL). They found that the presence of a PD was related to clinically significant worse PHRQoL compared to older adults without these disorders. However, after taken sociodemographic and psychosocial covariates into account, only dependent, paranoid and obsessive-compulsive PD remained associated with decreased PHRQoL. These findings suggest that specific symptoms of these PDs may be related to PHRQoL. Still, it's also possible that an unmeasured covariate may be present given that PD diagnoses combined with sociodemographic factors only explain $15 \%$ of the variance of PHRQoL score.

As these five studies used a variety of research methods and PD measures, direct comparison between prevalence rates is complex. Most of these instruments, although validated in various settings, haven't yet been corroborated in older adults Furthermore, these are based on the DSM criteria which contain measurement bias in older adults ${ }^{(3,14)}$. Different sample types (community-dwelling, non-communitydwelling) with varying comorbidity, differences in age distribution across samples as well as diverse cultures (United States of America, Europe, Africa) may affect prevalence rates as well.

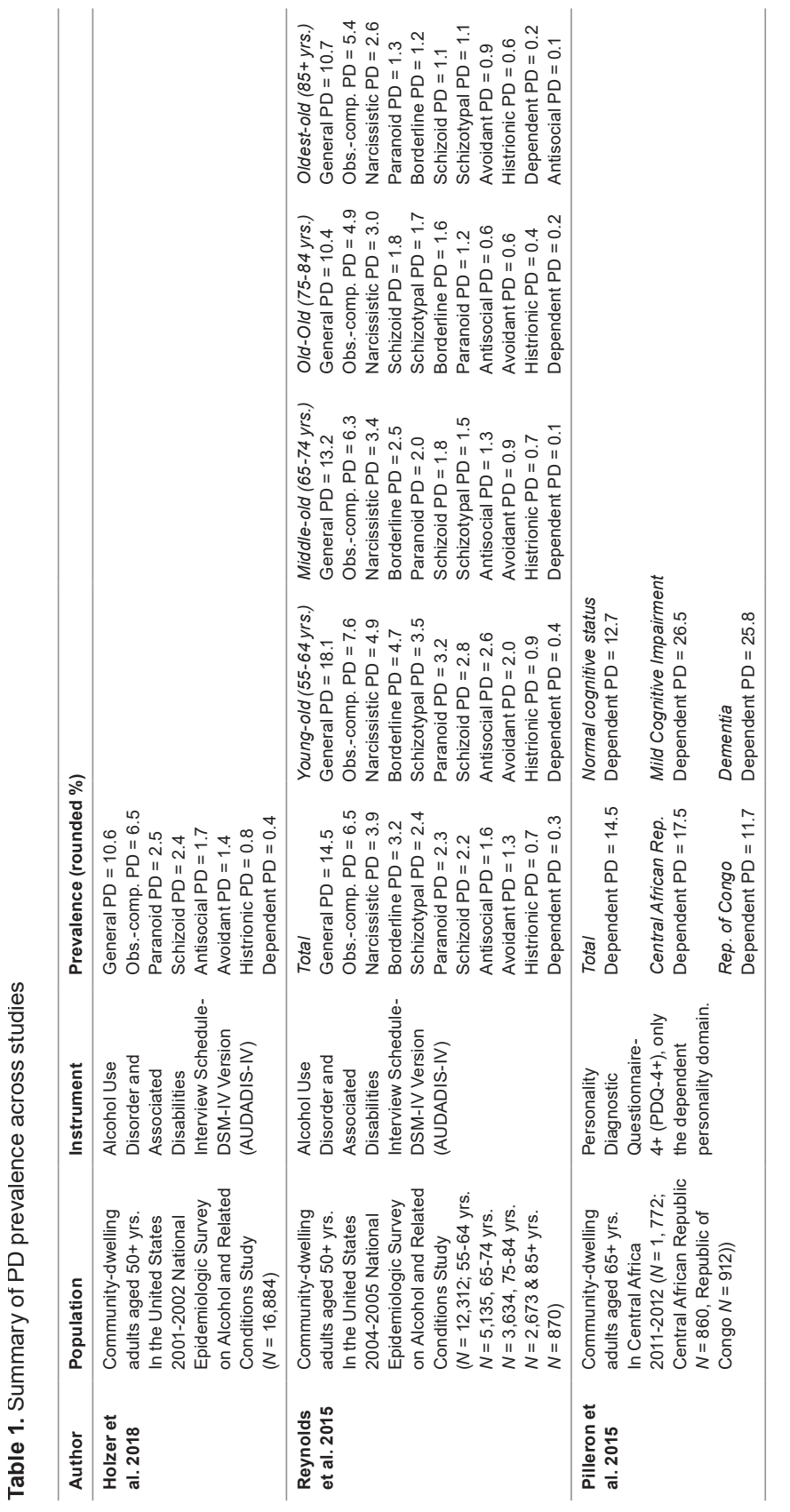




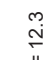

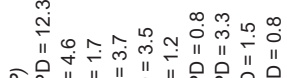

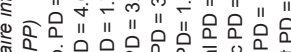

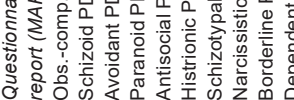

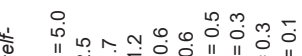

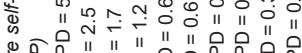

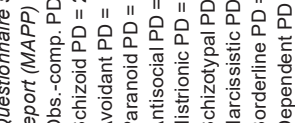

Clinical implications

These studies prove that PDs are quite prevalent in later life ${ }^{(6-9,12)}$ and as they are known to have a serious impact on one's life, such as high levels of suffering and decreased functioning ${ }^{(15)}$, straining the clinician-patient relationship by (interpersonal) difficulties, treatment rejection and noncompliance ${ }^{(15)}$, it is important for clinicians to be alert to PDs in older adults.

Moreover, the presences of a PD may complicate the recognition of/and adversely affect treatment of comorbid disorders ${ }^{(16)}$. In the case of PDs, treatment outcomes are poor(er), whereas the rates of relapse and readmission increases ${ }^{177)}$. This, in addition to the already complex clinical picture of older adults who often have multiple medical conditions, whether or not combined with psychiatric comorbidity and polypharmacy (18), seems to make it all the more important to have valid and reliable instruments to facilitate 'early' detection of PDs in older adults ${ }^{(19)}$. Being more attentive to PDs in late life may enable the clinician to take personality functioning into account when considering his approach and communication to optimize older adults' treatment compliance and to tailor interventions to accommodate the specific needs of individual patients ${ }^{(20)}$ which may enhance the odds of a positive response to treatment and circumvent treatment dropout. Furthermore, it may allow the clinician (such as general practitioners, geriatricians) to screen for PDs and to make faster and more specific referrals to mental health settings where further diagnostic assessments and treatment options are available ${ }^{(20)}$

\section{Assessment}

Diagnosing PDs, which ideally requires the use of multiple sources of information, is a challenging endeavor due to the complex and multifaceted nature of these disorders. This is even more true when assessing PDs in older adults where multimorbidity obscuring the clinical picture is the rule rather than the exception, and available instruments, mostly designed for (young) adults, are not automatically applicable to the elderly ${ }^{(19)}$. This severely complicates the already complex diagnostic process. Hence, there is a need for age-appropriate instruments.

Since 2015, eight studies addressed the assessment of PDs in older adults, mostly by validating existing instruments within older adults or by examining their ageneutrality. The investigated instruments parallel the full PD spectrum of DSM-5; the studies used the Gerontological Personality disorders Scale (GPS; ${ }^{21)}$ which is based on section II general PD criteria, the Structured Interview for DSM-IV Personality (SIDP-IV

22), the Questionnaire in Personality traits (QTP/VKP-4; ${ }^{23)}$, the Multisource Assessment of Personality Pathology (MAPP; ${ }^{24)}$, and the Assessment of DSM-IV Personality Disorders (ADP-IV; ${ }^{25}$ ) all addressing section II specific PD criteria. To overcome the 
issues linked to categorical classification, such as diagnostic heterogeneity within categories and extensive co-occurrence of PDs, a dimensional counterpart, the alternative model for personality, was included in the DSM- 5 section III "emerging measures and models" which stimulated research in the elderly as well. The Severity Indices of Personality Problems Short Form (SIPP-SF, derived from the SIPP-118; ${ }^{26}$ ) which covers criterion $A$ level of personality functioning, and the Personality Inventory for DSM-5 Brief Form (27) tapping onto the trait dimensions of criterion B were both validated as well as investigated with regard to their age-neutrality. Table 2 summarizes the main findings per study.

In the past years, three personality measures have been examined regarding their construct validity in older adults. These were all relatively short instruments, mainly relying on self-report; the SIPP-SF ${ }^{28-29)}$, the PID-5-BF ${ }^{(28,30)}$ and the GPS ${ }^{(20,31)}$. The 60 -item version of the SIPP was significantly correlated to other PD instruments (i.e. the GPS, the PID-5-BF, and the DAPP-BQ.(28-29) and was able to differentiate between older adults with normal personality functioning and those with personality dysfunctioning ${ }^{(28)}$. Beside construct validity, the concurrent validity of the PID-5-BF in older adults was established as well. This brief version, consisting of 25 items, was significantly positively correlated to the 220 items of the original PID-5, and the same higher-order domains were corroborated ${ }^{\left({ }^{30}\right)}$. Furthermore, the PID-5-BF proved to be able to discriminate older adults with maladaptive personality traits from the elderly with adaptive personality traits ${ }^{(28)}$. These short tests appeared to be useful for assessing personality functioning and maladaptive personality traits, which taken together form the basis of the DSM-5's alternative model of personality disorders (5). Lastly, both self and informant-report versions of the Gerontological Personality disorders Scale GPS; ${ }^{21)}$ which is a 16-item age-specific screener for PDs among older outpatients in mental healthcare have been validated in community-dwelling older adults sampled from five general practices. The sensitivity $(78 \%)$ and specificity $(65 \%)$ of the informant version have been found to be adequate. However, the diagnostic accuracy of the selfreport version was limited ${ }^{(20)}$. Aside from its validity, the feasibility and acceptability of the GPS was examined as well ${ }^{(31)}$. The GPS appeared to be a useful tool in general practice as it was judged to be feasible and acceptable by professionals as well as by older adults and informants.

In addition, since 2015 a number of studies have examined the cross-age validity of personality measures. Aside from construct validity, the SIPP-SF and the PID-5$\mathrm{BF}$ have been examined for age-neutrality ${ }^{(28-29)}$ as has the ADP-IV (32), by comparing mean scores across age groups, differential items functioning (DIF) and differential test functioning (DTF). When an item has DIF, this implies that the probability of endorsing an item response is not the same across two groups (e.g. old and young), even when they display the same level on a common latent personality dimension. The aggregated impact of DIF may jeopardizing the comparability of the scale scores across the perspectives, which is assessed with DTF. In the ADP-IV when used categorically, only two out of $79(2.5 \%)$ items assessing personality disorder symptoms had DIF in favor of older adults. When used dimensionally, four items were not age-neutral. The amount of DIF, however, did not result in the whole PD scale scores being biased. The mean scores of eight out of ten PDs displayed significant age differences; overall older adults scored lower than young adults. However, there were no age differences between older adults and middle-aged adults ${ }^{(32)}$. Personality functioning as measured with the SIPP-IV displayed somewhat more DIF; three out of 60 items were biased favoring one age-group over the other. On a scale level, relational capacities showed DTF ${ }^{28}$. Furthermore, there were limited to no age differences in mean scores ${ }^{(28}$ 29). A more cautious approach is needed when assessing maladaptive traits in older adults with the PID-5-BF, as $25 \%$ of the items and all domains appeared to function differently across age ${ }^{(28)}$

Courtois and colleagues did an exploratory study toward development of the French version of the QPT by assessing its association with the Big Five Inventory. They found that PDs in older adults as assessed with the QPT were significantly correlated with Openness, Conscientiousness, Extraversion, Agreeableness, and Neuroticism (12).

As assessment of PDs should ideally involve multiple sources, questions emerge regarding agreement and which source indicates more pathology. Oltmanns and colleagues ${ }^{(8)}$ compared three sources of information in a sample of older adults; a clinical interview (SIDP-IV), a self-report questionnaire and an informant-report questionnaire (both MAPP). They found that the concordance between the measures was low to moderate, indicating that they identify some of the same symptoms but mainly provide unique information. Unsurprisingly, the agreement between the SIDP-IV and the self-report MAPP was the highest, which is probably due to shared variance as they both tap into the self-report perspective. Further, the clinical interview appears to be the most conservative in assessing PDs in older adults, followed by self-report Informants, then again, reported the most pathology.

Current research revealed that the SIPP-SF, the PID-5-BF, the ADP-IV, and the GPS are adequate instruments for assessing PDs in older adults. However, as the studies were conducted in either general population or highly specific and relatively small clinical populations, the generalizability of these results may be limited. Overall, these studies pointed out that the expressions of personality functioning (criterion A) can be more reliably compared and assessed over age-groups than maladaptive personality traits (criterion B) can. Furthermore, it appeared that personality functioning and pathological traits were more and stronger correlated in older adults than in young adults, suggesting that in older adults certain domains of personality functioning can be more indicative for the presence of maladaptive traits. Including other sources of information, such as informant-report, can aid in the assessment of 
PDs. However, the choice of source can impact the findings as they may vary in leve of conservativeness.

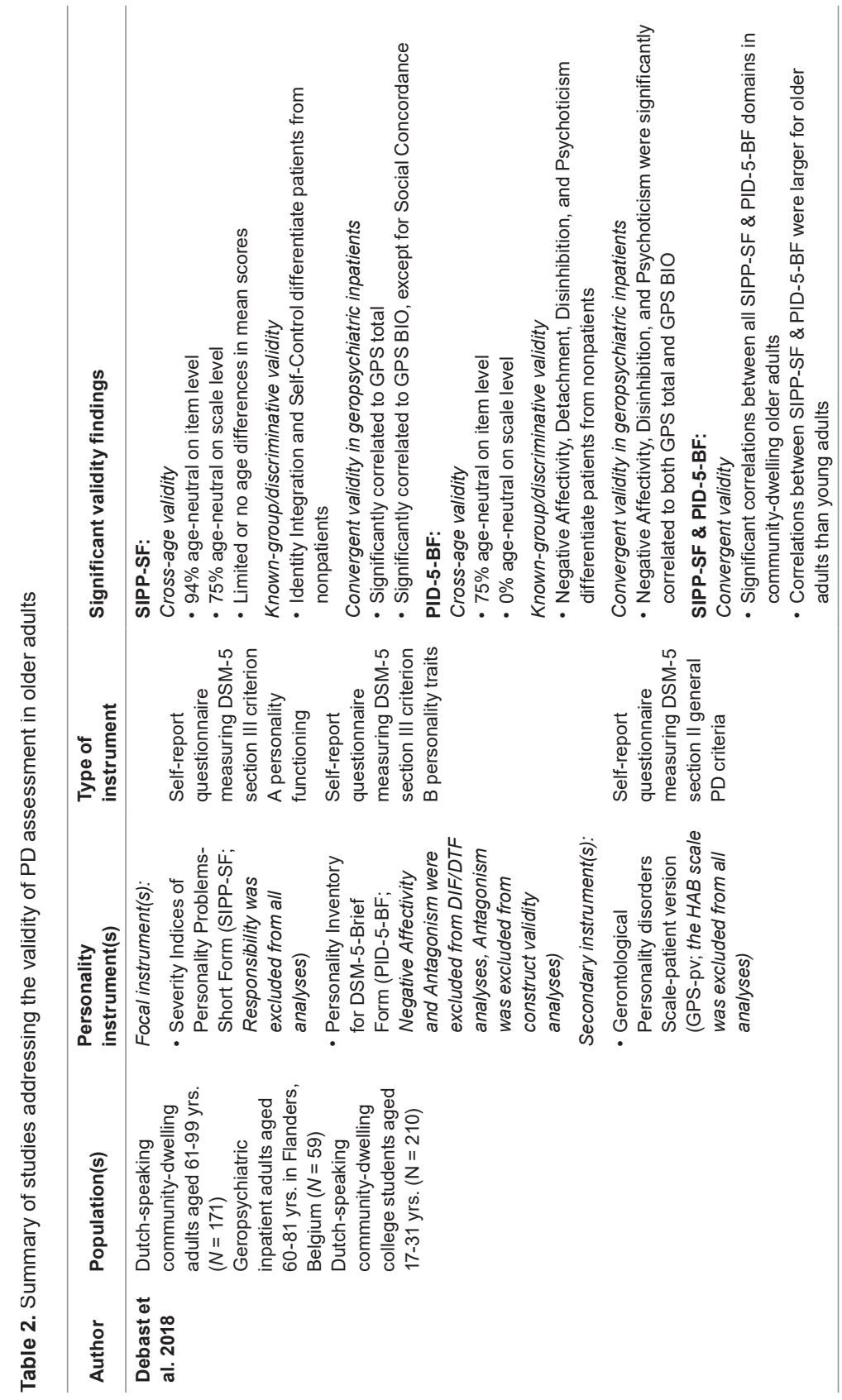




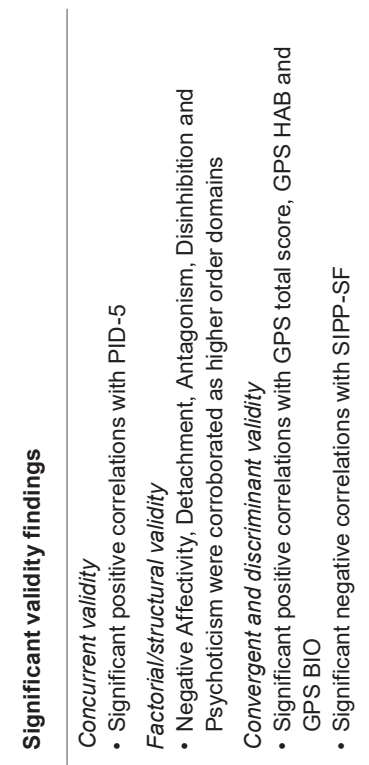

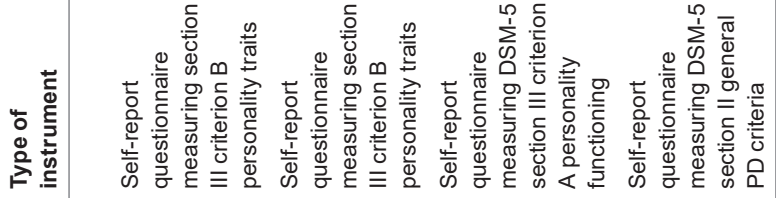

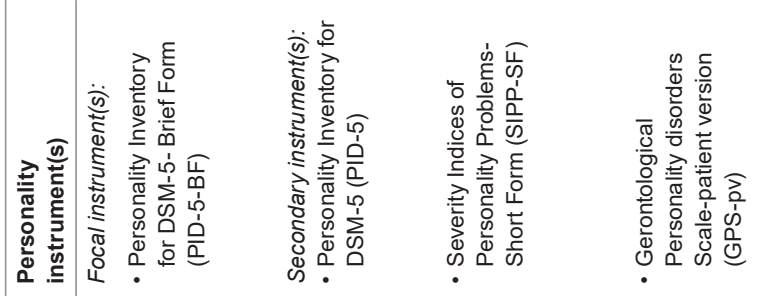

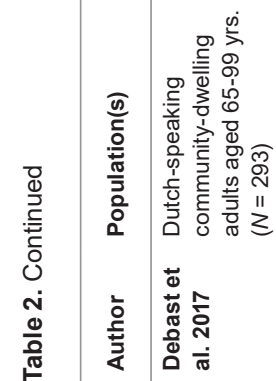

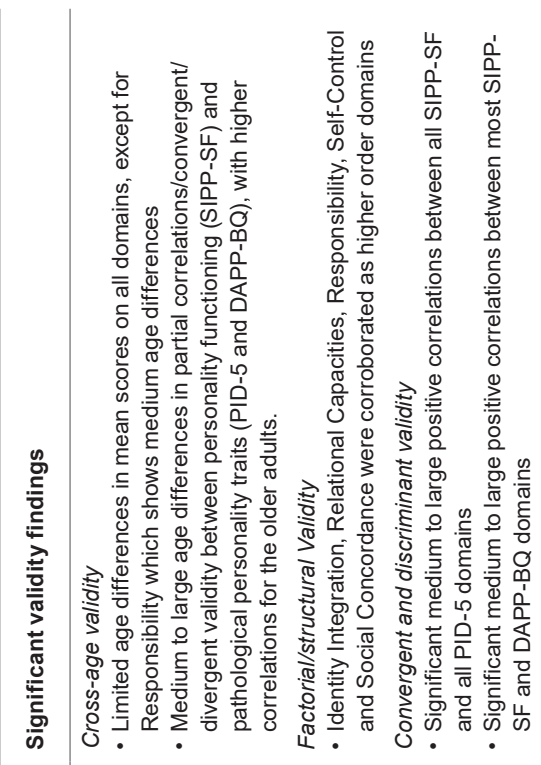

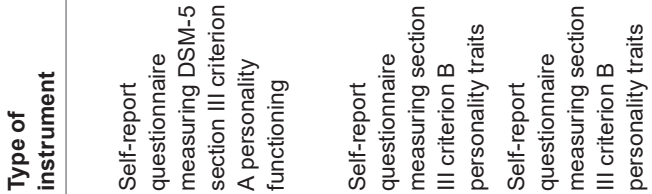

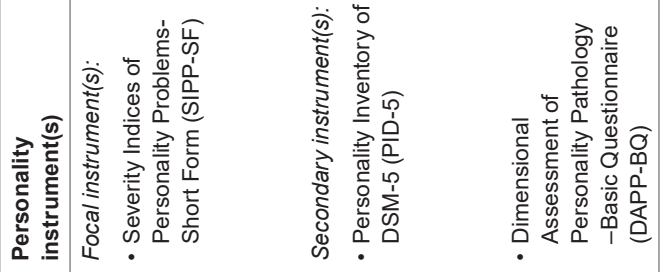

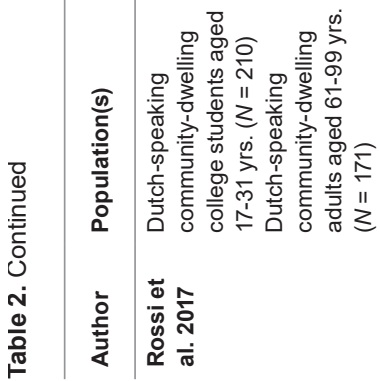




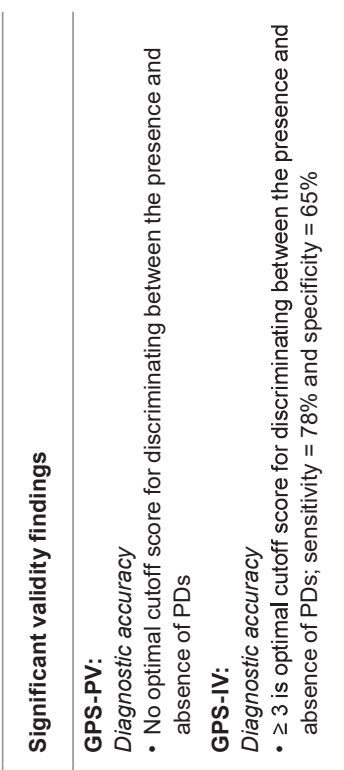

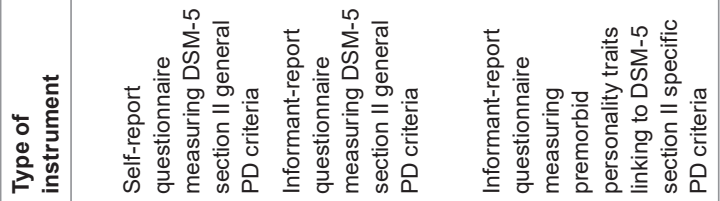

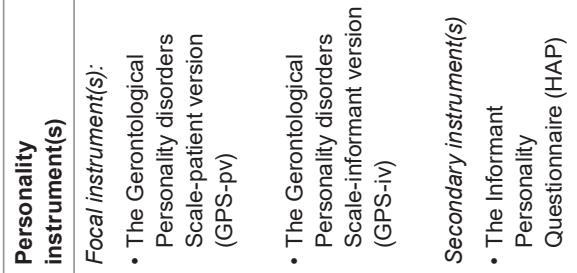

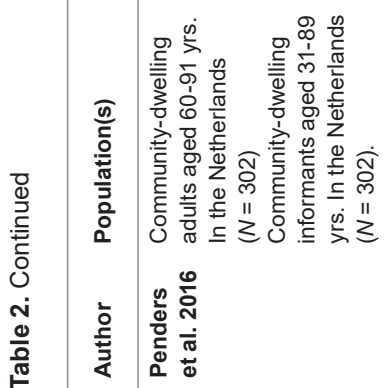

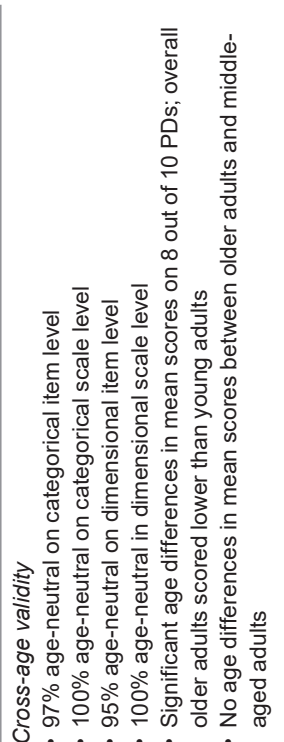
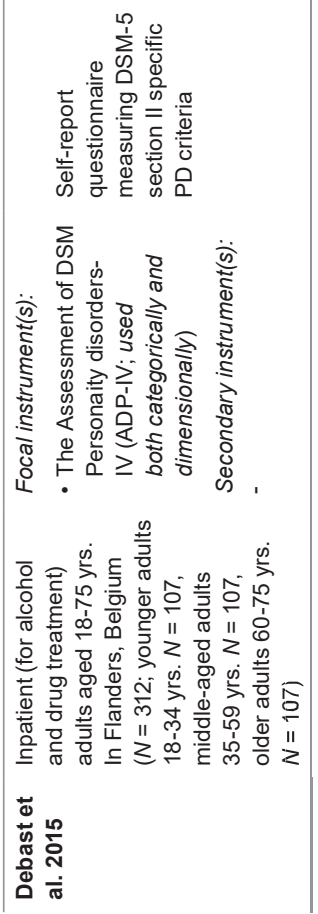

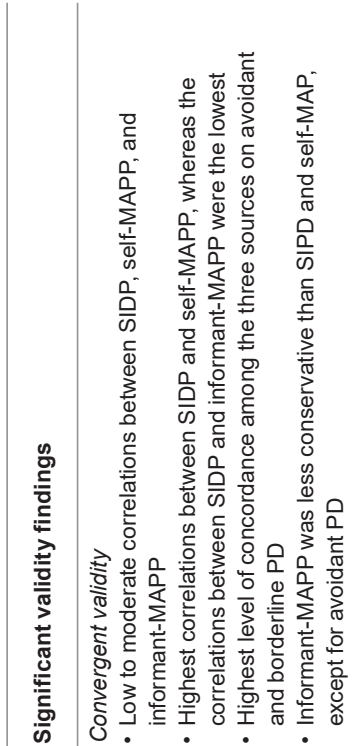

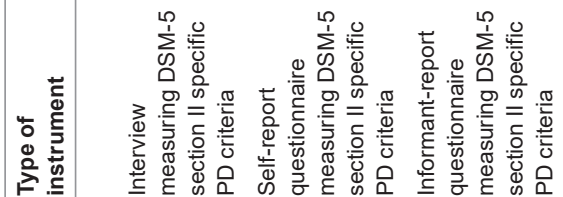

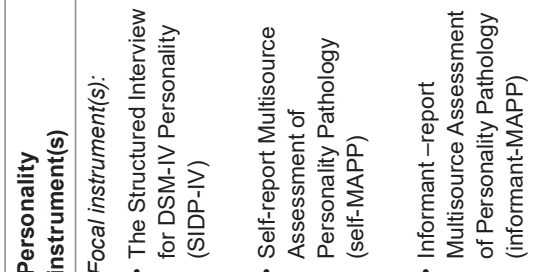

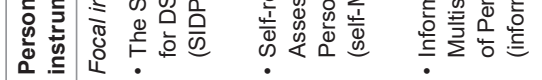

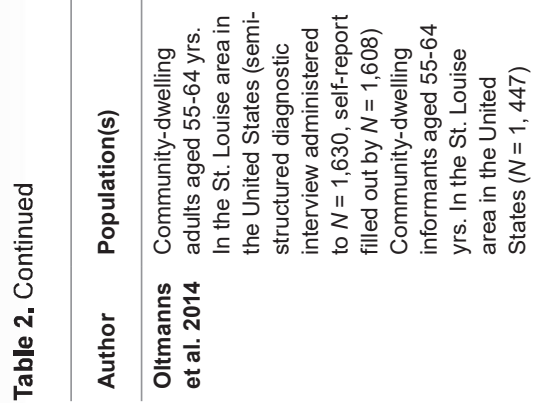

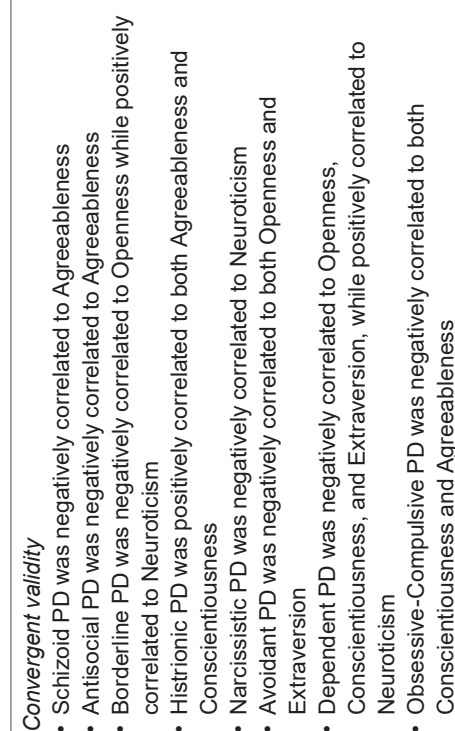

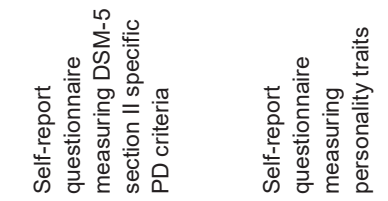
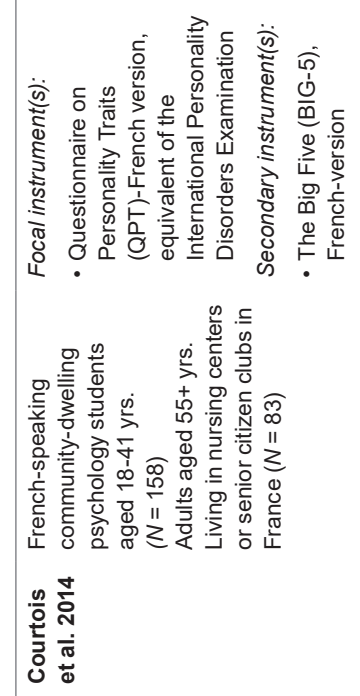
Clinical implications

In comparison to adults (<60 yrs.), there are only few reliable and valid instruments for diagnosing PDs in older adults. Aside from the lack of age-adjustments, many PD selfreport questionnaires and semi-structured interviews rely a large number of complex items (e.g. abstract language use, use of double negatives), which may often be quite burdensome for older adults. Fortunately, research on assessing PD in older adults is growing and recent efforts show that there are now a number of brief, age-neutral and valid (although mostly self-report) instruments available, albeit for general or highly specific populations ${ }^{(8,20,28-32)}$.

However, it is important to also use other sources of information in complementing PD assessment as well as guiding its interpretation ${ }^{\left({ }^{33}\right)}$. Older adults might have had several (psychological) treatments during their life, wherewithal medical and/or psychiatric records ${ }^{(34)}$. Biographical information and informant information might be available as well which could provide insight regarding personality traits and psychosocia (dys)functioning. This information can shed some light on the enduringness of personality pathology. Informant-report may prove useful when verifying life-events, overcoming the possible effects of sensory and cognitive impairment troubling selfreport. Additionally, it may also have incremental value by adding crucial information in PD assessment, as self-report might be biased due to the presence of severe psychopathology, limited self-awareness, distorted self-perceptions or as a result of reluctance to disclose problems ${ }^{(35-37)}$. Furthermore, as the clinical presentation of PDs in late life might be more complex due to cognitive aging, psychopathology, medical conditions, and polypharmacy ${ }^{(18)}$, including various sources of information to the assessment of PD, if needed complemented by medical examination (e.g. excluding medical conditions such as head trauma), is therefore recommendable.

\section{Treatment}

Since 2015, only one study has been published examining PD treatment effectiveness in later life. This study used a non-concurrent multiple-baseline design to investigate the value of schema therapy in eight elderly mental health outpatients (62-76 yrs.) with a primary diagnosis of a cluster C PD or PD Not Otherwise Specified with cluster C traits as assessed by the Dutch version of the Structured Clinical Interview for DSM-IV PDs (SCID-II; ${ }^{38}$ ). Videler and colleagues ${ }^{\left({ }^{39}\right)}$ found that schema therapy decreased the credibility of dysfunctional core beliefs, led to symptom and complaint reduction and improved the quality of life. At follow-up, the participants did no longer meet the genera or cluster-specific criteria of a PD; they were remitted from PD diagnosis. Moreover, most of the effect sizes of these findings were high, which is in line treatment effects in (young) adults ${ }^{(40)}$
Although this showed that schema therapy is feasible and effective in later life PDs, results can't be merely generalized to other populations or other PDs, given the smal sample size and its focus on cluster C PDs only.

Clinical implications

The current search pointed out that treatment of PDs in older adults is still a highly underexplored topic, probably stemming from a therapeutic nihilism. However, the study of Videler and colleagues ${ }^{(39)}$ showed that treating PD in older adults can be effective and feasible, as do the findings of a small number of (case) studies ${ }^{\left({ }^{(4-43)} \text {, }\right.}$ thereby pointing out that this skepticism is unwarranted.

When deciding on the most appropriate intervention for an older adult with personality pathology, it is important to not only evaluate his/her needs, level of motivation and cooperation, type and severity of the PD, but to also take the degree of functional limitations reflecting somatic and cognitive comorbidity into account ${ }^{(44}$ 45). Besides, specific gerontological treatment concerns should be essential topics in treatment, such as beliefs about and the consequences of somatic ailments, changing life perspective, cohort and sociocultural context-bound beliefs, intergenerational linkages and the loss of social roles ${ }^{(42)}$. Treating PDs in older adults therefore seems to require a more tailored and personalized approach.

Furthermore, experts believe that interventions for PDs in older adults can be considered allocated on a continuum, ranging from supportive-structuring treatment approaches (e.g. psychoeducation, behavioral counseling), to adaptation-focused (e.g. social skills training) to personality-changing interventions (e.g. schema therapy, dialectical behavior therapy) for each of which in and exclusion criteria were formulated ${ }^{(44-45)}$. Moreover, initial results show that applying clinical staging of PDs in treatment indication might improve its outcomes and may facilitate early detection ${ }^{(46-47)}$. While empirical research addressing interventions for older adults with PDs are needed, the above described recommendations can aid in defining achievable treatment goals and choosing the most appropriate treatment level.

\section{Discussion}

While reviewing the eligibility of the articles addressing epidemiological, assessmen and treatment aspects of PD in older adults (Figure 1), there appeared to be an inconsistency of terminology. Although in the first instance all the articles seemed to be focused on PDs, a considerable number of articles (i.e. $n=9$ ) turned out to be less clear about their central theme, and were thereby excluded from the current review. 
The terms PDs, PD features, PD symptomatology, (high levels of) PD symptoms were used interchangeably. Furthermore, whereas a number of studies gave the impression to concentrate on PDs, after carefully reading only a minority of the participants met the full criteria of PDs. In other studies, the prevalence of PDs was absent or the information published did not permit the identification of participants with PDs.

With about $35 \%$ of the potentially eligible articles using inconsistent terminology, it seems that the construct and/or definition of PDs in older adults might be not that clear or straightforward. Factors like different and more atypical clinical presentations in later life, a more temporal instable course and late onset ${ }^{(48-49)}$ may have contributed to this. This has multiple implications. On a more practical level, it complicates comparability between studies, impeding generalizability of the findings which are already scarce in this age group. On a fundamental level it interferes the diagnostic process which especially in older adults, is already no sinecure. Consequently, as diagnosis precedes and guides interventions, it hampers treatment as well.

The inconsistency in terminology might also signal the importance of examining the full spectrum of personality functioning and traits. Indeed, the distinction between the presence and absence of a PD is somewhat arbitrary. With lowering by one criterion, the prevalence of PDs in older adults would almost double ${ }^{(8)}$. Furthermore, a substantial number of people exhibit at least some symptoms of personality pathology. Aside from investigating full-blown PDs, further research on PD symptoms in older adults is relevant as studies show that these symptoms may be vital in predicting physical health problems and other mental disorders ${ }^{(15,50-51)}$

Reviewing recent studies reveal that promising steps are taken in the field of late life PD. However, further PD research, irrespective of its theme, should be carried out among the full range of older adults, such as investigating the previous examined instruments across various settings and cultures of older adults. Furthermore, studies developing age-specific cutoff scores for domains displaying DIF (and not DTF which implies that it does not represent the same measurement across groups), establishing age-related norms and developing informant-report instruments are needed. Moreover it would be valuable to examine which content is best assessed by older adult selfreport and what kind of information should be captured from an informant perspective. Also replications of Videler's treatment study ${ }^{(39)}$, preferably RCTs, with larger sample sizes and addressing the whole PD spectrum are needed. Exploring the effectivity of other treatment modalities for PDs in older adults, albeit personality changing, adaptation enhancing or contextually focused, is of importance as well, including empirical studies addressing the usefulness of in and exclusion criteria per treatment level and clinical staging and health management of PDs.
New areas of interest

Because of the global aging population, increasing clinical and scientific attention for PDs in older adults is of importance, but also new areas of interest such as other settings, and behavioral counseling may arise.

Recent PD research has been mainly focused on older adults from either general or highly specific inpatient populations. Although research within these populations is should be stimulated, other settings, such as assisted living facilities, geriatric medicine and general practice should be considered as well.

Considering the prevalence of PDs in older adults, the aging population and their central role in healthcare, general practitioners (GPs), are often the first and perhaps the most frequently contacted healthcare provider, who is consulted by older adults with PDs, although these disorders are, given their ego-syntonic nature, usually not the main reason for consultation. Therefore, GPs can play a key role in the detection of PDs in older adults. Early detection is important as it may circumvent certain negative consequences of PDs and contribute in reducing economic costs, by making referrals to specialized mental health care for further assessment and treatment, preventing hospital admissions, taking personality into account and tailoring treatments whereby minimizing non-compliance and negative treatment outcomes. Given their often longtime involvement, GPs may also provide crucial additional information about the older adult's lifespan.

However, resources for recognizing and managing PDs in older adults are scarce within this setting (as is research), complicating the GP's work. Further research within this setting is, given the GP's central role, urgently needed.

Another new area of interest might be behavioral counseling. This review points out that research on the effectivity of treatment of PD in older adults is still limited. Research that has been conducted, was focused on interventions on (a more direct) patient-level. However, factors like severe cognitive deficits or treatment rejection can severely hamper intervention options in older adults with PD, sometimes making (direct) psychological treatments impossible. In these cases, a more contextual and indirect approach such as behavioral counselling might be an acceptable and appropriate alternative. In behavioral counseling the intervention is of an indirect nature, as the patient's behavior is treated by influencing his significant others, caretakers, or nursing staff.

A promising form of behavioral counselling, based on the cognitive therapy, is the Cognitive Model for Behavioral Interventions (CoMBI; ${ }^{52)}$, which is specifically developed for nursing staff-members dealing with older adults with PDs. In this protocol the ten 
PDs are described by means of self-image, perception of others, eliciting event and the patients' challenging behavior. The patient's core needs play a central role in this intervention. This model assumes that when the patient's core needs are insufficiently met, due to a triggering event, both his self-image and perceptions of others will be confirmed thereby provoking the challenging behavior. However, if the triggering event can be substituted by staff-members addressing the patient's core needs, the challenging behavior will decrease. The feasibility of this 4-step protocol is currently investigated in several facilities.

\section{Conclusions}

Since the review of van Alphen and colleagues (2), only a limited number of studies addressed epidemiological, assessment and treatment aspects of PDs in older adults. Nonetheless, these studies hold a promising view. Aside from the attempts to map the prevalence of PDs in later life, studies show continuing efforts examining the ageneutrality of existing items and instruments, developing age-specific measures and validating PD questionnaires in older adults, herewith mainly using instruments tapping into the DSM-5's alternative model of PDs. Moreover, there is initial proof of treatment effectiveness. These studies show that (research on) PD in older adults should not be dismissed, but that they hold the future.

\section{References}

1. Agronin ME, Maletta G. Personality disorders in late life: Understanding and overcoming the gap in research. American Journal of Geriatric Psychiatry. 2000;8(1):4-18.

2. van Alphen SPJ, Dijk v, S, Videler AC, Rossi G, Dierckx E, Bouckaert F, et al. Personality disorders in older adults: Emerging research issues. Current Psychiatric Reports. 2015;17:538-45.

3. Balsis SMA, Woods CM, Gleason MEJ, Oltmanns TF. Overdiagnosis and underdiagnosis of personality disorders in older adults. American Journal of Geriatric Psychiatry. 2007:15:742-53.

4. American Psychiatric Association. Diagnostic and statistical manual of mental disorders. $4^{\text {th }}$ t text revision ed. Washington DC: Author: 2000.

5. American Psychiatric Association. Diagnostic and statistical manual of mental disorders $5^{\text {th }}$ ed. Arlington, VA: American Psychiatric Publishing; 2013.

6. Holzer KJ, Huang J. Physical health-related quality of life among older adults with personality disorders. Aging and Mental Health. 2018.

7. Reynolds K, Pietrzak RH, El-Gabalawy R, Mackenzie CS, Sareen J. Prevalence of psychiatric disorders in US. Older adults; findings from a nationally representative survey. World Psychiatry. 2015;14(1):74-81.

8. Oltmanns TF, Rodrigues MM, Weinstein Y, Gleason MEJ. Prevalence of personality disorders at midlife in a community sample: Disorders and symptoms reflected in interview, self, and informant reports. Journal of Psychopathology and Behavioral Assessment 2014;36:177-88.

9. Pilleron S, Clement J-P, Ndamba-Bandzouzi B, Mbelesso P, Dartigues J-F, Preux $\mathrm{P}-\mathrm{M}$, et al. Is dependent personality disorder associated with mild cognitive impairmen and dementia in central Africa? A result from the epidemca programme. Internationa Psychogeriatrics. 2015;27(2):279-88.

10. De Reus RJ, van den Berg JF, Emmelkamp PM. Personality Diagnostic Questionnaire $4+$ is not useful as a screener in clinical practice. Clinical Psychology and Psychotherapy. 2013;20:49-54.

11. Rossier J, Ouedraogo A, Dahourou D, Verardi S, Meyer de Stadelhofen F. Personality and personality disorders in urban and rural Africa: Results froma field trial in Burkina Faso. Frontiers in Psychology. 2013;4(article 79):1-11.

12. Courtois R, Enfoux A, Plaisant O, Coutard N, Duijsens IJ, Reveillere C. Exploratory study toward development of the french version of the Questionnaire on Personality Traits (QPT/ VKP-4) in an elderly population in comparison to young adults. Psychological Reports: Measures \& Statistics. 2014;115(1):115-32.

13. Duijsens IJ, Bruinsma M, Jansen SJT, Eurlings-Bontekoe EHM, Diekstra RFW. Agreement between self-report and semi-structured interviewing in the assessment of personality disorders. Personality and Individual Differences. 1996;21(2):261-70. 
14. Balsis S, Gleason MEJ, Woods CM, Oltmanns TF. An item response theory analysis of DSM-IV personality disorder criteria across younger and older age groups. Psychology and Aging. 2007;22(1):171-85.

15. Powers AD, Oltmanns TF. Personality disorders and physical health: A longitudin examination of physical functioning, healthcare utilization, and health-related behaviors in middle-aged adults. Journal of Personality Disorders. 2012;26(4):524-38.

16. van Alphen SPJ, Videler AC, Bouckaert F, Oude Voshaar R. In vogelvlucht. In van Alphen SPJ, Oude Voshaar R, Bouckaert F, Videler AC, editors. Handboek persoonlijkheidsstoornissen bij ouderen. Utrecht, NL: De Tijdstroom uitgeverij; 2018.

17. Stevenson J, Brodaty H, Boyce P, Byth K. Personality disorder comorbidity and outcome: Comparison of three age groups. Australian and New Zealand Journal of Psychiatry. 2011:45(9):771-9.

18. van Alphen S, Barendse H, Tummers JHA, Rossi G. Diagnostiek [diagnostics]. In: van Alphen S, editor. Persoonlijkheidsstoornissen bij ouderen: Diagnostiek, behandeling en gedragsadvisering [personality disorders in older adults: Diagnostics, treatment and behavioral counseling]. Amsterdam, NL: Hogrefe; 2010.

19. Rossi G, Van den Broeck J, Dierckx E, Segal D, Van Alphen SJP. Personality assessmen among older adults: The value of personality questionnaires unraveled. Aging and Mental Health. 2014;18(8):936-40.

20. Penders KAP, Rossi G, Metsemakers JFM, Duimel-Peeters IGP, van Alphen SPJ Diagnostic accuracy of the Gerontological Personality disorder Scale (GPS) in Dutch general practice. Aging and Mental Health. 2016;20(3):318-28.

21. A preliminary study of the diagnostic accuracy of the Gerontological Personality disorders Scale (GPS). International Journal of Geriatric Psychiatry. 2006;21(9):862-8.

22. Pfohl BM, Blum N, Zimmerman M. Structured Interview for DSM-IV Personality (SIDP-iv). Washington: American Psychiatric Association; 1997.

23. Duijsens IJ, Eurlings-Bontekoe EHM, Diekstra RFW. The VKP, a selfreport instrument for DSM-iii-R and ICD-10 personality disorders: Construction and psychometric properties. Personality and Individual Differences. 1996;20(2):171-82

24. Oltmanns TF, Turkheimer E. Perceptions of self and others regarding pathological personality traits. In: Krueger RF, Tackett JL, editors. Personality and pathology. New York: Guilford; 2006. p. 71-111.

25. Schotte CKW, de Doncker D. ADP-IV vragenlijst [ADP-IV questionnaire]. Antwerp, Belgium: Universitair Ziekenhuis Antwerpen; 1994.

26. Verheul R, Andrea H, Berghout CC, Dolan C, Busschbach JJ, van der Kroft PJ, et al. Severity Indices of Personality Problems (SIPP-118): Development, factor structure, reliability, and validity. Psychological Assessment. 2008;20:23-34.

27. American Psychiatric Association. The personality inventory for DSM-5-brief form (PID-5-BF)-adult. Retrieved from http://www.Psychiatry.Org/practice/dsm/dsm5/onlineassessment-measures\#personality 2013

28. Debast I, Rossi G, van Alphen SPJ. Age-neutrality of a brief assessment of the section III alternative model for personality disorders in older adults. Assessment. 2018:1-14.
29. Rossi G, Debast I, van Alphen SPJ. Measuring personality functioning in older adults: construct validity of the Severity Indices of Personality Problems-short form (SIPP-SF) Aging and Mental Health. 2017;21(7):703-7-11.

30. Debast I, Rossi G, van Alphen SPJ. Construct validity of the DSM-5 section III maladaptive trait domains in older adults. Journal of Personality Disorders. 2017;31(5):671-88.

31. Penders KAP, van Zadelhoff E, Rossi G, Duimel-Peeters IGP, van Alphen SPJ, Metsemakers JFM. Feasbility and acceptability of the Gerontological Personality disorders Scale (GPS) in general practice: A mixed methods study. Journal of Personality Assessment. 2018:1-10.

32. Debast I, Rossi G, van Alphen SPJ, Pauwels E, Claes L, Dierckx E, et al. Age neutrality of categorically and dimensionally measured DSM- 5 section II personality disorder symptoms. Journal of Personality Assessment. 2015;97(4):321-9.

33. Klonsky ED, Oltmanns TF, Turkheimer E. Informant-reports of personality disorder: Relation to self-reports and future research directions. Clinical Psychology: Science and Practice. 2002;9:300-11

34. van Alphen SPJ, Engelen GJJA, Kuin Y, Derksen JJL. Persoonlijkheidsstoornissen bij ouderen. Een overzicht. [personality disorders in older adults. An overview.]. Tijdschrift voor Psychiatrie. 2004:46:145-56.

35. Cape J, McCulloch Y. Patients' reasons for not presenting emotional problems in general practice consultations. British Journal of General Practice. 1999;49(448):875-9.

36. Balsis S, Loehle-Conger E, Busch AJ, Ungredda T, Oltmanns TF. Self and informant report across the borderline personality disorders spectrum. Personality Disorders: Theory, Research, and Treatment. 2018;9(5):429-36.

37. Ganellen RJ. Assessing normal and abnormal personality functioning: Strenghts and weaknesses of self-report, observer, and performance-based methods. Journal of Personality Assessment. 2007;89(1):30-40.

38. Weertman A, Arntz A, Kerkhofs MLM. Gestructureerd diagnostisch interview door DSM-IV persoonlijkheidsstoornissen (SCID-II) [structured interview for DSM-IV personality disorders]. Lisse: Swets Test Publishers; 2000.

39. Videler AC, van Alphen SPJ, van Royen RJJ, van der Feltz-Cornelis CM, Rossi G, Arntz A. Schema therapy for personality disorders in older adults: A multiple-baseline study. Aging and Mental Health. 2017:1-10.

40. Bamelis LLM, Evers SMMA, Spinhoven P, Arntz A. Results of a multicenter randomized controlled trial of the clinical effectiveness of schema therapy for personality disorders. American Journal of Psychiatry. 2014;171(3):305-22.

41. Lynch TR, Cheavens JS, Cukrowicz KC, Thorp SR, Bronner L, Beyer J. Treatment of older adults with co-morbid personality disorder and depression: A dialectical behavior therapy approach. International Journal of Geriatric Psychiatry. 2007;22:131-43.

42. Videler AC, Rossi G, Schoevaars M, van der Feltz-Cornelis CM, van Alphen SPJ. Effects of schema group therapy in older outpatients: A proof of concept study. Internationa Psychogeriatrics. 2014;26(10):1709-17.

43. van Alphen SPJ. Psychotherapy of an older adult with an avoidant personality disorder International Psychogeriatrics. 2011;23(4):662-5 
44. van Alphen SPJ, Bolwerk N, Videler AC, Tummers JHA, van Royen RJJ, Barendse H, et al. Age-related aspects and clinical implications of diagnosis and treatment of personality disorders in older adults. Clinical Gerontologist. 2012;35(1):27-41.

45. Rosowsky E, Young AS, Malloy MC, van Alphen SPJ, Ellison JM. A cross-validation delph method approach to the diagnosis and treatment of personality disorders in older adults. Aging and Mental Health. 2018;22(3):371-8.

46. Hutsebaut $\mathrm{J}$, Hessels $\mathrm{CJ}$. Clinical staging and early intervention for borderline personality disorder. Tijdschrift voor Psychiatrie. 2017;59(3):166-74.

47. Hutsebaut J, Verheul R, Videler AC, van Alphen SPJ. Managing borderline personality disorder from a life course perspective: Clinical staging and health management. Personality Disorders: Theory, Research, and Treatment. 2019.

48. Debast I, van Alphen SPJ, Rossi G, Tummers JHA, Bolwerk N, Derksen JJL, et al. Personality traits and personality disorders in late middle and old age: Do they remain stable? A literature review. Clinical Gerontologist. 2014;37(3):253-71.

49. van Alphen SPJ, Derksen JLL, Sadavoy J, Rosowsky E. Features and challenges of personality disorders in late life. Aging and Mental Health. 2012;16(7):805-10.

50. Agrawal A, Narayanan G, Oltmanns TF. Personality pathology and alcohol dependence at midlife in a community sample. Personality Disorders: Theory, Research, and Treatment. 2013;4(1):55-61.

51. Galione JN, Oltmanns TF. The relationship between borderline personality disorder and major depression in later life: Acute versus temperamental symptoms. The American Journal of Geriatric Psychiatry. 2013;21(8):747-56.

52. Osterloh JWSA, Videler AC, Rossi GPM, van Alphen SPJ. Cognitive model for behavioura interventions for personality disorders in older adults: A nursing approach. Tijdschrift voo Gerontologie en Geriatrie. 2018; 49:210-212 


\section{3}

Diagnostic accuracy of the Gerontological Personality disorders Scale (GPS) in Dutch general practice

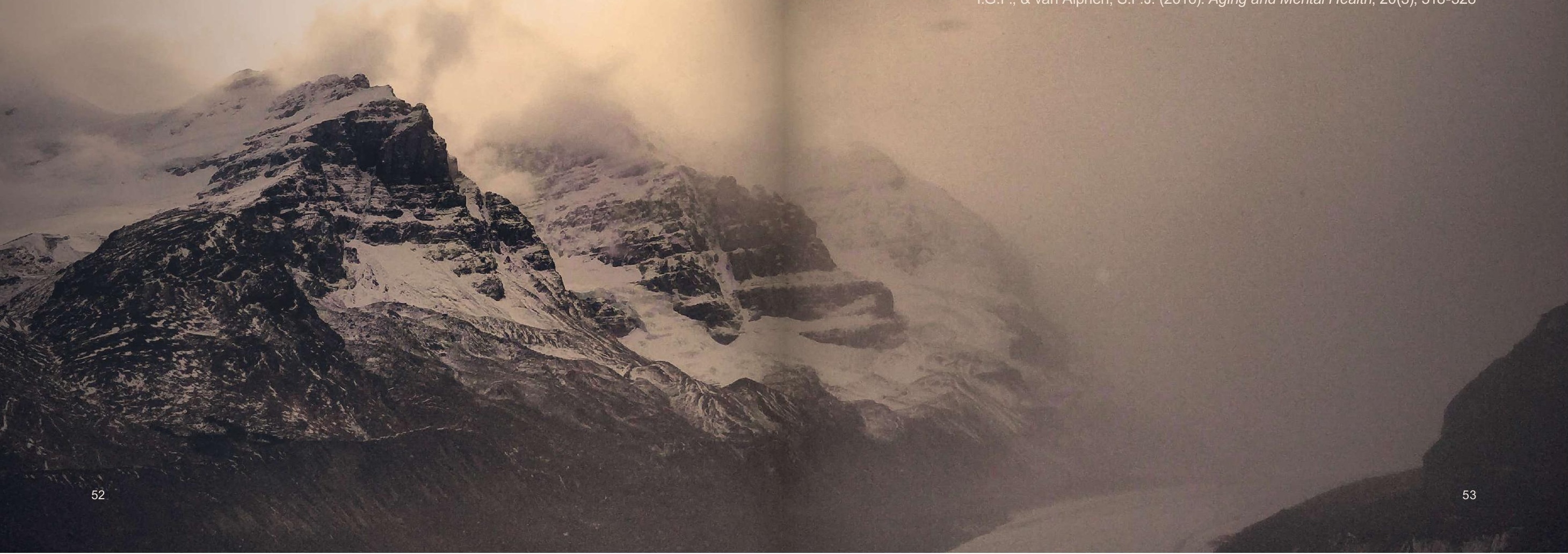




\section{Abstract}

\section{Objective}

Personality disorders (PDs) often remain unrecognized in older adults by doctors in general practice. Therefore, this study evaluated the diagnostic accuracy of a screening instrument, the Gerontological Personality disorder Scale (GPS), in a Dutch general practice population of older adults.

\section{Method}

The psychometric properties of the GPS patient (GPS-pv) and informant (GPS-iv) version were assessed in a sample of 302 (144 male) patients (mean $69.9 \mathrm{yrs}$.) and 302 (124 male) informants (mean 64.7 yrs.), respectively, using an informant-based personality questionnaire (the Hetero-Anamnestische Persoonlijkheidsvragenlijst $[\mathrm{HAP}])$ as a reference criterion.

\section{Results}

The internal consistency (average item correlation) of the subscale and total scores of the GPS-pv and GPS-iv were $.12(\mathrm{HAB}), 16(\mathrm{BIO})$, and .10 (total), and .16 (HAB) 15 (BIO), and .12 (total), respectively. The test-retest reliability was strong for both the GPS-pv $\left(r=.56\right.$ [HAB], $r_{s} .67$ [BIO], $r_{s} .66$ [total] $)$ and the GPS-iv $\left(r_{s} .52\right.$ [HAB], $r_{s} .65$ [BIO], $r_{s=} .68$ [total]) versions. The sensitivity and specificity of the GPS-pv were .83 and .27 , respectively, with a cutoff score of $\geq 1$. Raising the cutoff score to $\geq 2$, the sensitivity dropped to .59 , whereas the specificity rose to .57 . For the GPS-iv, a cutoff score of $\geq 3$ maximized the sensitivity (.78) and specificity (.65).

\section{Conclusion}

The diagnostic accuracy of the GPS-iv was preferable to that of the GPS-pv. This is the first psychometric study to use the GPS as an age-specific screening instrument for PDs.

\section{Keywords}

personality disorders, elderly, diagnostic accuracy, reliability, general practice

\section{Introduction}

The publication of the fifth edition of the Diagnostic and Statistical Manual of Mental Disorders (DSM-5; ${ }^{1)}$ has changed little with regard to the classification of personality disorders (PDs). In contrast to many researchers' opinions (e.g., ${ }^{2)}$, a clear revision of the section on PDs in the DSM-5 (1) did not occur; instead, Section II completely retained the DSM-IV ${ }^{(3)}$ categories and criteria. A growing number of researchers have been strongly stating the importance of investigating PDs in older adults ${ }^{(4-5)}$. They have argued that a deeper understanding and recognition of PDs in older adults is urgently needed because PDs are a widespread problem in this population. Although both scientific and clinical attention to PDs is slowly shifting towards older adults (i.e. individuals $>60 \mathrm{yrs}$.), the DSM- $5^{(1)}$ continues to focus solely on younger adults. Despite the ongoing discussion concerning the feasibility of including criteria assessing PD in older adults in the DSM ${ }^{(6-7)}$, the DSM is frequently used in older adults worldwide because there is no better alternative ${ }^{(8)}$.

The recognition of PDs, which is a multi-faceted construct, is of great clinical relevance because the presence of a PD may interfere with the diagnosis of other clinical disorders. From a treatment perspective, PDs are a complicating factor in two ways. First, patients with PDs are more complex because they are more resistant to the effects of treatment (cluster A), less compliant (cluster B), and tend to make extreme demands related to their care (cluster $C)^{(9)}$, which leads to an increase in healthcare consultations ${ }^{(10)}$. Second, PDs adversely affect treatment outcomes, resulting in less improvement and an increased risk for relapse and readmission ${ }^{(11)}$. One explanation might be when a PD is present, the symptoms of comorbid mental disorders are more severe and chronic ${ }^{(11)}$. Moreover, individuals with PDs tend to have 1) lower self-perceived quality of life and general health; 2) decreased physical, social, and cognitive functioning; 3) lower self-esteem; 4) less life satisfaction; 5) decreased wellbeing; 6) a lower number of, and satisfaction with, social support; and 7) an increased predisposition to other mental disorders compared to individuals without PDs (e.g. $10-11,12,13$. Moreover, PDs are highly prevalent, with rates between $3 \%$ and $13 \%$ in a population of community-dwelling older adults ${ }^{(14-16)}$

While there is a growing interest in PDs in older adults, there are several barriers to accurate screening and assessment. One significant barrier is the paucity of agespecific and well-validated instruments ${ }^{(5,17)}$. This may lead to reliance on instruments that are not suited for older adults, resulting in denial of the aging process and environmental-related changes known to occur in older adults (18). This may result in over- or under-diagnosis of PDs ${ }^{(7)}$. Another more general obstacle is the predominant reliance on self-report data, which is known to have limitations 'e.g., ${ }^{19}$. A more accurate view on PDs might be acquired by also obtaining informant information. 
In response to the lack of instruments assessing PD in older adults, van Alphen and colleagues ${ }^{(20)}$ developed the Gerontological Personality disorder Scale (GPS), an age-specific screening instrument for PDs in older adults consisting of both a patient (GPS-pv) and an informant version (GPS-iv). Psychometric properties of the GPS-pv in elderly psychiatric outpatients yielded fair to good internal consistency, test-retest reliability, and criterion validity when using clinical diagnoses of experienced medical doctors and psychologists as a reference criterion ${ }^{20}$. In a multi-center study by Tummers and colleagues ${ }^{(21)}$, the GPS items were added to an experimental poo of items formulated by a Dutch expert panel on PDs in older adults by identifying the items that were the most predictive of PDs (based on multidisciplinary diagnosis) in an elderly psychiatric outpatient population. Of this item pool, the GPS item, 'I have sometimes said to my family or friends that I don't want to live any longer,' combined with the experimental item, 'I like to be in control,' was the most accurate $(65 \%)$ in predicting the presence or absence of PDs.

The aim of this study was to evaluate the internal consistency, test-retest reliability, inter-rater reliability, and diagnostic accuracy of both GPS versions in older adults in Dutch general practice. Given the disability caused by PDs, the high prevalence of PDs, and PDs' complicating effect on treatment, it is of great clinical value for the general practitioner (GP) to have a reliable and validated brief instrument based on the DSM-5 definition of PD to use with older adults. Such an instrument will enable GPs to objectify the presence of PDs and to tailor treatment to accommodate the specific needs of individual patients. This may enhance the odds of a positive response to treatment and circumvent treatment drop-out.

\section{Methods}

Participants

From 2009-2012, 302 older adults receiving care from one of the five participating general practices (Heerlen $n=47$, Schinveld $n=48$, Hoensbroek $n=84$, Landgraa $n=39$, and Ubachsberg $n=84$ ) in the south of the Netherlands were included. These general practices (i.e. first line primary care) were representative of practices throughout the Netherlands.

To be eligible to participate, individuals had to be 60 years or older and have an informant who was also willing to participate. In addition, to guarantee adequate and reliable responding, older adults with severe psychiatric disorders, cognitive dysfunctions, and major attentional problems as a result of sedation and/or alcohol use intellectual disabilities, or a life expectancy of less than three months were excluded.
The presence of the exclusion criteria was determined by a two-part process. The GPs made an initial evaluation of eligible older adults; then, the following assessments were conducted during a home visit: the national list of illnesses from the Centraal Bureau voor de Statistiek (Central Office of Statistics in the Netherlands, CBS), the Mini-Mental State Examination (MMSE; 22), the Geriatric Depression Scale (GDS; ${ }^{23)}$, the Alcoho Use Disorder Identification Test (AUDIT; ${ }^{24)}$, and the Brief Symptom Inventory (BSI; ${ }^{25}$. Older adults with a GDS-score of $\geq 20$, BSI subscale scores for anxiety, phobia, and psychoticism categorized as 'very high' or MMSE score of $\leq 24$ were excluded. After exclusion (for an overview see Figure 1), the data from 302 patient-informant pairs were retained for analysis. Additionally, 104 patient-informant pairs were willing to complete a follow-up assessment.

Approximately half of the 302 older adults were male $(n=144)$. The average age was 69.9 years (range $=60-91$ ). Of the 302 informants, 124 were male. Their average age was 64.7 years (range $=32-89$ ). Table 1 shows demographic information for both the older adults and informants. 
Figure 1. Flow chart response and exclusion of older adults and informants

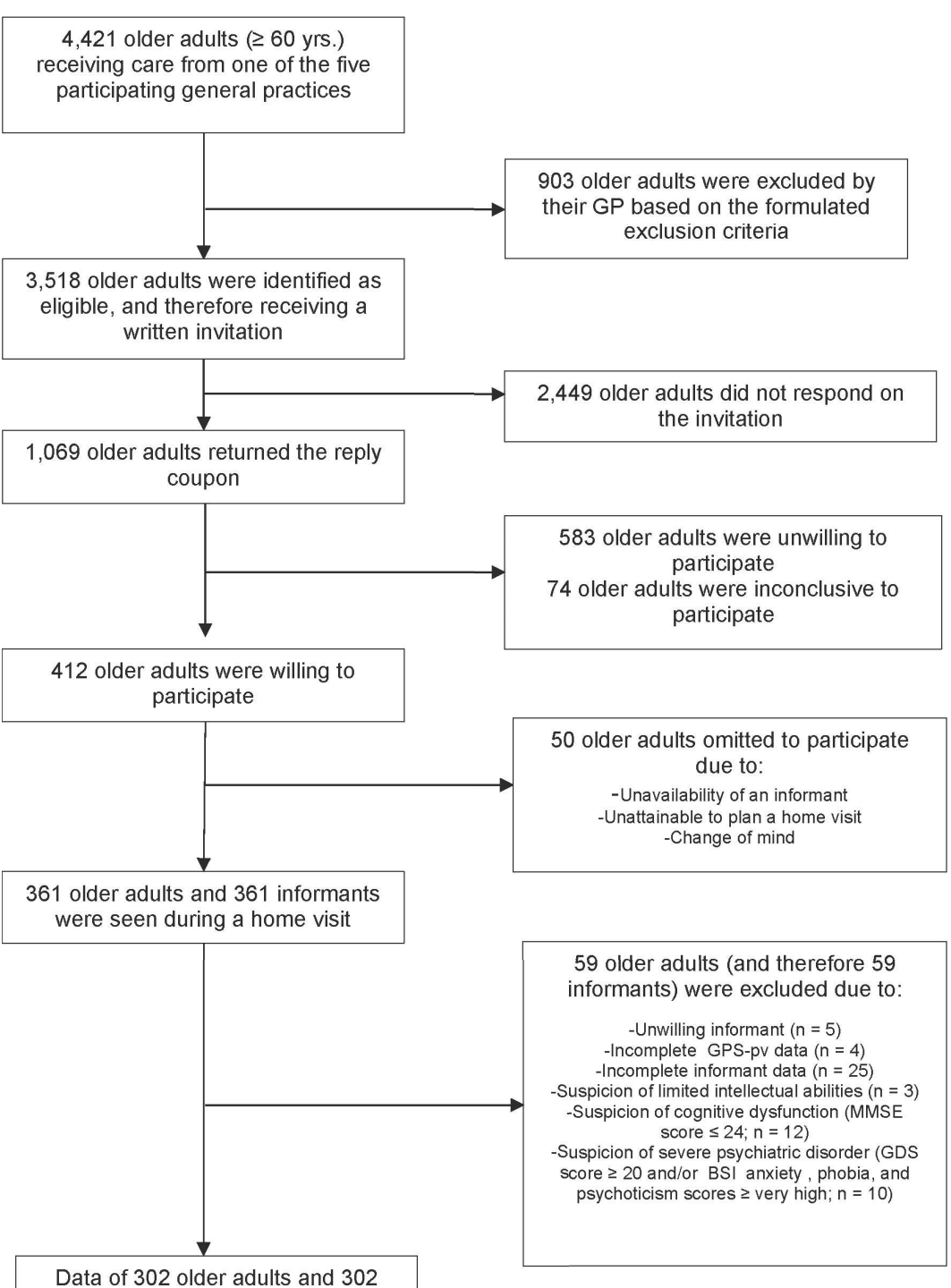

Data of 302 older adults and 302 informants were fit for data analyses
Table 1. Demographic features of older adults and informants

\begin{tabular}{|c|c|c|c|}
\hline & \multicolumn{2}{|c|}{ Older adults } & \multirow[t]{2}{*}{ Informants } \\
\hline & No $\mathrm{PD}^{*}$ & $\mathrm{PD}^{*}$ & \\
\hline \multicolumn{4}{|l|}{ Age } \\
\hline Years $(s d)$ & $69.6(7.4)$ & $71.5(7.3)$ & $64.7(11.3)$ \\
\hline Range & $60.0-91.0$ & $60.0-88.0$ & $32.0-89.0$ \\
\hline \multicolumn{4}{|l|}{ Gender (\%) } \\
\hline Men & $116(45.3)$ & $28(60.9)$ & $124(41.1)$ \\
\hline Women & $140(54.7)$ & $18(39.1)$ & $178(58.9)$ \\
\hline \multicolumn{4}{|l|}{ Marital status (\%) } \\
\hline Single & $9(3.5)$ & $4(8.7)$ & - \\
\hline Married / Civil partnership & $200(78.1)$ & $32(69.6)$ & - \\
\hline Cohabit & $7(2.7)$ & $1(2.2)$ & - \\
\hline Two household family (LAT) & $5(2.0)$ & $2(4.3)$ & - \\
\hline Divorced & $3(1.2)$ & $2(4.3)$ & - \\
\hline Widowed & $30(11.7)$ & $5(10.9)$ & - \\
\hline Missing data & $2(0.8)$ & $0(0.0)$ & \\
\hline \multicolumn{4}{|l|}{ Housing $(\%)$} \\
\hline Dwelling-house & $252(98.4)$ & $46(100.0)$ & - \\
\hline Sheltered accommodation & $1(0.4)$ & $0(0.0)$ & - \\
\hline Elderly home & $1(0.4)$ & $0(0.0)$ & - \\
\hline Other & $2(0.8)$ & $0(0.0)$ & - \\
\hline \multicolumn{4}{|l|}{ Educational level (\%) } \\
\hline Elementary school & $26(10.1)$ & $5(10.9)$ & $20(6.6)$ \\
\hline School of domestic science/trade school & $110(43.0)$ & $20(43.5)$ & $102(33.8)$ \\
\hline Sr secondary vocational ED & $50(19.5)$ & $9(19.6)$ & $83(27.5)$ \\
\hline Sr general secondary ED/pre- university ED & $10(3.9)$ & $2(4.3)$ & $8(2.6)$ \\
\hline Higher professional ED & $47(18.4)$ & $6(13.0)$ & $63(20.9)$ \\
\hline University & $13(5.1)$ & $4(8.7)$ & $26(8.6)$ \\
\hline \multicolumn{4}{|l|}{ Nature of relationship (\%) } \\
\hline Partner & \multicolumn{3}{|c|}{$238(78.8)$} \\
\hline Sibling & \multicolumn{3}{|c|}{$8(2.7)$} \\
\hline Child & \multicolumn{3}{|c|}{$38(12.6)$} \\
\hline Grandchild & \multicolumn{3}{|c|}{$1(0.3)$} \\
\hline Brother/sister-in-law & \multicolumn{3}{|c|}{$1(0.3)$} \\
\hline Friend & \multicolumn{3}{|c|}{$5(1.7)$} \\
\hline Son/daughter-in-law & \multicolumn{3}{|c|}{$2(0.6)$} \\
\hline Other & \multicolumn{3}{|c|}{$9(3.0)$} \\
\hline
\end{tabular}


Table 1. Continued

\begin{tabular}{|c|c|c|}
\hline & \multicolumn{2}{|c|}{ Older adults } \\
\hline & No $\mathrm{PD}^{*}$ & $P D^{*}$ \\
\hline \multicolumn{3}{|c|}{ Duration of relationship in years (\%) } \\
\hline $1-5$ & & $8(2.6)$ \\
\hline $6-10$ & & $9(3.0)$ \\
\hline $11-15$ & & $6(2.0)$ \\
\hline $16-20$ & & $7(2.3)$ \\
\hline $21-25$ & & $10(3.3)$ \\
\hline $26-30$ & & $7(2.3)$ \\
\hline $31-35$ & & $11(3.6)$ \\
\hline $36-40$ & & $35(11.6)$ \\
\hline $41-45$ & & $43(14.2)$ \\
\hline $46-50$ & & $58(19.2)$ \\
\hline $51-55$ & & $42(13.9)$ \\
\hline $56-60$ & & $34(11.3)$ \\
\hline $61-65$ & & $15(5.0)$ \\
\hline $66-70$ & & $4(1.3)$ \\
\hline $71-75$ & & $2(0.7)$ \\
\hline Missing data & & $11(3.6)$ \\
\hline
\end{tabular}

Note. - = data were not obtained. ${ }^{*}$ Classification based on score on HAP score (4 high/very high subscale scores or 2 high/very high subscale scores and 6 above average subscale scores).

Recruitment

Ethics approval was granted from the Medical Ethical Review Commission of the Maastricht University Medical Center+ (MUMC+), the Netherlands (approval no. MEC 09-4-060).

Prior to recruitment, the GPs and practice support staff (PSS) from the participating general practices were given in-depth information about the content and procedure of the study. Subsequently, the GPs and PSS were asked to check their electronic patient databases and, using the formulated inclusion and exclusion criteria, list the eligible older adults.

These older adults received a written invitation from their GP with a reply coupon, stamped envelope, and information regarding the study. Older adults willing to participate received a phone call from the researcher, who provided additiona information and inquired about the availability of an informant. After receiving informed consent orally from both the older adult and informant, a home visit was scheduled.
Measures

The following instruments were used. Instruments 1-6 were administrated to the older adults and instruments 6 and 7 were completed by the informants.

CBS list.

The CBS list is a Dutch questionnaire addressing the 24 most prevalent somatic conditions/complaints in the Netherlands according to the Dutch Central Office of Statistics ${ }^{(26)}$. The 25 items are scored with either a 'yes' or 'no' response.

Mini-Mental State Examination (MMSE).

The MMSE is a brief questionnaire addressing cognitive impairment ${ }^{(22)}$. Scores range from 0 to 30 , and a score $\geq 25$ indicates normal cognitive functioning.

Geriatric Depression Scale (GDS).

The GDS is an age-specific self-report measure concerning depressive symptomatology ${ }^{(23)}$ consisting of 30 yes/no questions. Scores range from 0 to 30 and higher scores indicate the presence of more depressive symptoms. The GDS has adequate psychometric properties ${ }^{(23)}$. In the current sample, the internal consistency reliability was $\alpha=.80$

Alcohol Use Disorders Identification Test (AUDIT).

The AUDIT is a self-report measure concerning hazardous alcohol use, harmful alcohol use, and dependence symptoms (24) and consists of 10 items. Scores range from 0 to 40 and higher scores indicate a higher risk of alcohol-related problems. The AUDIT is a widely recommended, reliable, and valid instrument ${ }^{24,27)}$. In the curren sample the internal consistency reliability, as measured with average item correlation (AIC), was .18 with $\alpha=.56$

The Brief Symptom Inventory (BSI).

The BSI ${ }^{25)}$ is a brief version of the Symptom Checklist-90, a multidimensional selfreport measure concerning psychopathology. It consists of 53 items that assess somatic complaints, cognitive problems, interpersonal sensitivity, depressed mood, anxiety, hostility, phobia, paranoid thoughts, and psychoticism. Each item is scored on a 5-point Likert scale ranging from 'entirely not' to 'very much.' The BSI is a reliable and valid instrument ${ }^{(25)}$. In the current sample, the internal consistency reliabilities (AIC) ranged from .06 with $\alpha=.28$ (psychoticism) to .22 with $\alpha=.54$ (hostility), and with $\alpha=.86$ for the total scale.

Gerontological Personality disorders Scale (GPS)

The GPS is a brief and age-specific screening instrument designed to measure PDs in older adults in mental healthcare ${ }^{(20)}$. The GPS measures the presence or absence 
of a PD based on general definitions in the DSM-IV and DSM-5, respectively ${ }^{(1,3)}$ Its construction was based on literature review and case studies, including a Delphi study of 53 Dutch experts in PDs in older adults ${ }^{(28)}$. The only difference between the GPS-pv and GPS-iv is the perspective from which the questions are asked (first versus third person, respectively). There are 16 yes/no statements addressing both habitual behaviors (HAB) and biographical information (BIO; i.e., life characteristics). Table 2 shows the GPS content.

Hetero-Anamnestische Persoonlijkheidsvragenlijst (HAP).

The HAP ${ }^{(29)}$ is a Dutch informant-based personality questionnaire that measures the premorbid personality of the older adult from the informant's perspective. The 62 ageneutral items address 10 content scales: socially avoidant behavior, uncertain behavior, vulnerability in interpersonal relationships, somatizing behavior, disorderly behavior rigid behavior, perfectionistic behavior, antagonistic behavior, self-satisfied behavior, and unpredictable and impulsive behavior. The HAP subscales and items are based on the biosocial-learning model ${ }^{(30-31)}$. Each statement is written in past tense, third person singular and is scored on a 3-point Likert scale with responses of 'no,' 'more or less,' and 'yes.' To control for possible confounding as a result of the informants' feelings of sympathy or antipathy towards the patient, items are formulated to assess and correct for positive and negative response tendencies. The HAP has good interna consistency, good to excellent inter-rater reliability, good test-retest reliability, and good construct and concurrent validity ${ }^{(32)}$. In the current sample, the internal consistency reliabilities (as measured with $\mathrm{AIC}$ ) ranged from .19 with $\alpha=.47$ (rigid behavior) to .38 with $\alpha=.69$ (disorderly behavior), and with Cronbach's $\alpha=.84$ for the total scale.

In this study, the HAP, which relies solely on informant information, served as the eference criterion. According to the HAP manual, four high/very high subscale scores or the combination of two high/very high subscale scores and six above average subscale scores indicate the presence of a PD ${ }^{(29)}$
Table 2. Items of the Gerontological Personality disorders Scale-patient version (GPS-pv)

\begin{tabular}{lllc}
\hline & The Gerontological Personality disorders Scale-patient version (GPS-pv) & Yes & No \\
\hline & Habitual behavior & & \\
\hline $\mathbf{1}$ & I don't like growing older because I become less attractive & 1 & 0 \\
$\mathbf{2}$ & I often worry about my health & 1 & 0 \\
$\mathbf{3}$ & I'm often concerned about my memory & 1 & 0 \\
$\mathbf{4}$ & I hope that others solve my problems & 1 & 0 \\
$\mathbf{5}$ & I'm often afraid of losing those who care for me, such as members of the family or my & 1 & 0 \\
& partner & 1 & 0 \\
$\mathbf{6}$ & I'm often taken advantage of by others & 1 & 0 \\
$\mathbf{7}$ & I find it difficult to fend for myself & & \\
\hline & Biographical information & 1 & 0 \\
\hline $\mathbf{1}$ & In my life l've been to see the doctor for many vague physical complaints & 1 & 0 \\
$\mathbf{2}$ & I have sometimes said to my family or friends that I don't want to live any longer & 1 & 0 \\
$\mathbf{3}$ & In the past I've been admitted to a psychiatric institution because of nerves & 1 & 0 \\
$\mathbf{4}$ & At important times in my life, lexperienced high levels of nervousness, stress or sadness & 1 & 0 \\
$\mathbf{5}$ & In the past I've already had treatment from a psychiatrist or psychologist & 1 & 0 \\
$\mathbf{6}$ & I have sometimes tried to end my life & 1 & 0 \\
$\mathbf{7}$ & At the most I've only had 1 acquaintance or friend in my life & 1 & 0 \\
$\mathbf{8}$ & In my life l've not been very interested in sexual contact & 1 & 0 \\
\hline $\mathbf{9}$ & In the past l've often taken tranquilizers and/or sleeping pills & \\
\hline
\end{tabular}

\section{Procedure}

Prior to data collection, the older adult, informant, and researcher signed the consent form. The informant then received a set of questionnaires and was asked to complete them in a separate room to prevent response bias. In an interview with the olde adults, demographic information was collected. Next, several questionnaires were administrated to ensure that the exclusion criteria were not met. Finally, the GPS-pv was completed by the older adult.

In order to determine the test-retest reliability, a follow-up assessment consisting of the GPS-pv or the GPS-iv and the Hetero-Anamnestische Persoonlijkheidsvragenlijst HAP (for the informants) was planned four weeks later.

Statistical analyses

All statistics were performed using the SPSS 19.0 package. 
Reliability

Internal consistency was examined using both Cronbach's a and AIC. The AIC is considered to be superior to Cronbach's a because it measures internal consistency independently of the number of scale items. We considered an AIC above .15 as acceptable ${ }^{(33)}$. Spearman's correlations $\left(r_{s}\right)$ were calculated to determine the testretest and inter-rater reliability of the GPS-pv and GPS-iv. The following rule was used to interpret the strength of the relationships: $r=.10-.29$ indicate a small effect, $r_{s}=.30-.49$ indicate a medium effect, and $r_{s}=.50-1.0$ indicate a large effect ${ }^{(34)}$

Diagnostic accuracy

The diagnostic accuracy of the GPS-pv and GPS-iv was assessed by calculating classical diagnostic validity statistics ${ }^{(35)}$, such as sensitivity (sens; the proportion of people with the disorder who are detected by the test), specificity (spec; the proportion of people without the disorder who are correctly identified by the test) positive predictive power (PPP; the probability that the disorder is present given the test is positive), negative predictive power (NPP; the probability that the disorder is absent given the test is negative), and the overall correct classification (OCC; the proportion correctly classified) for each possible cutoff score. As PPP and NPP are influenced by the prevalence of the disorder ${ }^{(36)}$, the prevalence rate was also reported. Additionally, the incremental validity of positive (IPPP) and negative (INPP) test scores was calculated; values greater than zero indicate that positive or negative test-based findings are more informative for diagnostic decisions than the disorder's prevalence rate (e.g. ${ }^{37,38)}$. For an example calculation, see Rossi and Sloore ${ }^{(37)}$

The area under the curve (AUC) was retrieved by performing receiver-operatingcharacteristic-curve $(\mathrm{ROC})$ analyses. The associated curve represents the ratio of sensitivity and specificity, according to the cutoff score used to differentiate individuals with and without disorders. The AUC can be interpreted as the probability that the test will yield a higher value for a randomly chosen individual with the disorder than for a randomly chosen individual without the disorder ${ }^{(39)}$. An AUC value greater than .70 is considered to be fair to excellent ${ }^{(40)}$.

\section{Predictive validity}

To examine the value of the GPS items in predicting the presence or absence of PDs, binary logistic regression analyses using Garson's method for testing the difference between any two nested models ${ }^{(41)}$ were conducted. The items' predictive power was evaluated by calculating endorsement rates and Cohen's effect sizes $(d)$ for the difference in response proportion ${ }^{(34)}$. Subsequently, validity statistics were calculated for the most predictive items of the GPS-pv and GPS-iv.

\section{Results}

Internal scale reliabilities

In the general practice setting, internal consistency as estimated by Cronbach's a was . 48 (HAB), .61 (BIO), and .63 (total) for the GPS-pv, and .57 (HAB), .58 (BIO), and .68 (total) for the GPS-iv, which are all below the minimum required level of .70 ${ }^{(42)}$. However, the internal consistency based on AIC values was .12 (HAB), .16 (BIO) and .10 (total) for the GPS-pv, and .16 (HAB), .15 (BIO), and .12 (total) for the GPS-iv. The correlation between the GPS-pv BIO subscale and both GPS-iv subscales was above the minimum level of $.15^{(33)}$

Test-retest reliability

The GPS-pv test-retest reliability, as assessed with Spearman's correlations $(n=104)$ was $r=.56(\mathrm{HAB}), r=.67(\mathrm{BIO})$, and $r=.66$ (total), and all were significant $(p=.00)$ indicating a large effect size (43). The GPS-iv test-retest reliability was $r_{s}=.52(\mathrm{HAB})$ $r_{s}=.65(\mathrm{BIO})$, and $r_{s}=.68$ (total). All the correlations were significant $(p=.00)$ and showed a large effect ${ }^{(43)}$

Inter-rater reliability

The agreement between the GPS-pv and GPS-iv, as measured with Spearman's correlations, was $r_{s}=.32(\mathrm{HAB}), r_{s}=.54(\mathrm{BIO})$, and $r_{s}=.46$ (total), and all were significant $(p=.00)$; effect size ranged from medium to large ${ }^{(34)}$.

\section{Diagnostic accuracy}

Table 3 shows the classical diagnostic validity statistics, chance-adjusted statistics, and odds measures for both GPS versions for the different cutoff scores. These statistics show that for the GPS-pv, there was no optimal cutoff score to discriminate between the presence and absence of PDs. The choice of cutoff score is at the expense of either sensitivity or specificity. The results indicate that the GPS-pv is better at excluding than identifying PDs. For detecting the presence versus absence of a PD, a ROC curve was calculated using sensitivity and one-specificity values. The AUC for the GPS-pv was only .58 $(95 \% \mathrm{Cl}[.48, .66])$ and not significant $(p=.10 ; 95 \% \mathrm{Cl}[.48, .66])$. Forthe GPS-iv, a cutoff score of $\geq 3$ maximizes the sensitivity and specificity. The results indicated a sensitivity of .78 and a specificity of .65 (see Table 3). AUC for the GPS-iv showed fair diagnostic accuracy $(.77 ; 95 \% \mathrm{Cl}[.69, .84] ; p<.00$ 
Table 3. Diagnostic validity statistics for the GPS-pv and the GPS-iv and for the most predictive tems of the GPS-pv ${ }^{1}$ and the GPS-iv

\begin{tabular}{cccccccc}
\hline & Sens & Spec & PPP & NPP & OCC & IPPP & INPP \\
\hline GPS-pv & & & & & & & \\
\hline Cutoff $\geq 00$ & 1.00 & .00 & .15 & .90 & .15 & .00 & .05 \\
Cutoff $\geq 01$ & .83 & .27 & .17 & .88 & .36 & .02 & .04 \\
Cutoff $\geq 02$ & .59 & .57 & .20 & .85 & .57 & .04 & .00 \\
Cutoff $\geq 03$ & .30 & .71 & .16 & .86 & .65 & .01 & .01 \\
Cutoff $\geq 04$ & .22 & .84 & .20 & .86 & .75 & .05 & .01 \\
Cutoff $\geq 05$ & .17 & .91 & .26 & .85 & .80 & .11 & .00 \\
Cutoff $\geq 06$ & .07 & .95 & .19 & .85 & .82 & .04 & .00 \\
Cutoff $\geq 07$ & .04 & .97 & .20 & .85 & .83 & .05 & .00 \\
Cutoff $\geq 08$ & .04 & .98 & .33 & .85 & .84 & .18 & .00 \\
Cutoff $\geq 09$ & .02 & 1.00 & .50 & .85 & .85 & .35 & .00 \\
Cutoff $\geq 10$ & .00 & 1.00 & & & .85 & & \\
\hline GPS-iv & & & & & & & \\
\hline Cutoff $\geq 00$ & 1.00 & .00 & .15 & .96 & 15 & .00 & .11 \\
Cutoff $\geq 01$ & .94 & .25 & .18 & .96 & .35 & .03 & .11 \\
Cutoff $\geq 02$ & .89 & .47 & .23 & .94 & .54 & .08 & .10 \\
Cutoff $\geq 03$ & .78 & .65 & .28 & .91 & .67 & .13 & .60 \\
Cutoff $\geq 04$ & .59 & .79 & .33 & .90 & .76 & .18 & .05 \\
Cutoff $\geq 05$ & .44 & .88 & .39 & .89 & .81 & .24 & .05 \\
Cutoff $\geq 06$ & .39 & .91 & .45 & .88 & .83 & .30 & .03 \\
Cutoff $\geq 07$ & .26 & .96 & .52 & .86 & .85 & .37 & .01 \\
Cutoff $\geq 08$ & .11 & .98 & .56 & .86 & .85 & .40 & .01 \\
Cutoff $\geq 09$ & .09 & 1.00 & 1.00 & .86 & .86 & .85 & .01 \\
Cutoff $\geq 10$ & .07 & 1.00 & 1.00 & .85 & .86 & .85 & .00 \\
Cutoff $\geq 11$ & .00 & 1.00 & & & .85 & & \\
\hline GPS-pv 1 & & & & & & & \\
\hline Cutoff $\geq 00$ & 1.00 & .00 & .15 & .89 & .15 & .00 & .04 \\
Cutoff $\geq 01$ & .44 & .84 & .32 & .85 & .78 & .17 & .00 \\
Cutoff $\geq 02$ & .02 & .99 & .33 & & .84 & .18 & \\
\hline GPS-iv ${ }^{2}$ & & & & & & & \\
\hline Cutoff $\geq 00$ & 1.00 & .00 & .15 & .97 & .15 & .00 & .12 \\
Cutoff $\geq 01$ & .91 & .52 & .25 & .93 & .58 & .10 & .08 \\
Cutoff $\geq 02$ & .65 & .86 & .45 & .88 & .83 & .30 & .04 \\
Cutoff $\geq 03$ & .28 & .98 & .68 & .86 & .87 & .53 & .01 \\
Cutoff $\geq 04$ & .07 & 1.00 & 1.00 & & .86 & .85 & \\
\hline & & & & & & \\
\hline
\end{tabular}

Note. Base rate of PD is $15.23 \%(46 / 302): 1$ most predictive items of the GPS-pv are HAB4 and $\mathrm{BIO} ;{ }^{2}$ mos predictive items of the GPS-iv are HAB2, HAB4, HAB6 and BIO1

Predictive validity

Logistic regression was performed to assess the impact of the GPS items on the kelihood that the older adult had a PD. The model for the GPS-pv contained all 16 items as predictor variables. A total of 302 cases were analyzed, and the full model significantly predicted PD status (omnibus chi-square $=32.88$; $\mathrm{df}=16 ; p<.008$ ) The model accounted for between $10.3 \%$ and $18.0 \%$ of the variance in PD status, and successfully predicted $98.4 \%$ of the older adults without PDs. However, only $8.7 \%$ of the predictions of older adults with PDs were accurate Overall, $84.8 \%$ of the predictions were correct. Table 4 gives the coefficients, Wald statistic, associated degrees of freedom, and probability values for each of the predictor variables. These show that only the items HAB4 and BIO5 reliably predicted PD status. The value of the coefficient for HAB4 reveals that older adults who gave a positive response to this item were eight and a half times more likely to have a PD than those who gave a negative response. Older adults who agreed with item $\mathrm{BIO} 5$ were approximately three times more likely to have a PD than those who disagreed.

A logistic regression analysis was performed with PD status as the dependent variable and the 16 GPS-iv items as predictor variables. The full model containing al predictors was statistically significant $(n=302$; omnibus chi-square $=71.80 ; \mathrm{df}=16 ; p$ $<.000$ ), indicating that the model was able to distinguish between informants who did and did not report the presence of a PD in their older adults. The model as a whole explained between $21.2 \%$ and $36.9 \%$ of the variance in PD status, with an overall correct classification of $88.7 \%$. Of the older adults without a PD, $98.4 \%$ was accurately predicted. However, only slightly more than one-third $(34.8 \%)$ of the predictions of the presence of a PD were correct. As shown in Table 4, four out of 16 items made a unique, statistically significant contribution to the model (HAB2, HAB4, HAB6 and BIO1). The coefficients of these four items all show that if the informant responded positively to them, older adults were four to five times more likely to have a PD.

For both the GPS-pv and GPS-iv, additional analyses were performed. These consisted of logistic regression analyses using the likelihood ratio test for testing the difference between two nested models ${ }^{\left({ }^{41}\right)}$ and the calculation of endorsement rates. For both questionnaires, these analyses identified the same items as the biggest contributors to PD predictions, except for $\mathrm{BIO} 5$ on the GPS-pv, which failed to show a large distinction.

Logistic regression analyses identified GPS-pv items HAB4 and BIO5 and GPS-iv items $\mathrm{HAB} 2, \mathrm{HAB} 4, \mathrm{HAB} 6$, and $\mathrm{BIO} 1$ as those with the most predictive value. Validity statistics were also calculated for these items. Table 3 shows the classical diagnostic validity statistics for the shortened GPS-pv and GPS-iv assessments, given different cutoff scores.

The validity statistics for the two GPS-pv items show that although these combined items insufficiently identified older adults with PDs, they were able to detect older adults without PDs. In contrast to the original GPS-pv, the short version had a significant $(p=00)$ AUC $(.64 ; 95 \% \mathrm{Cl}[.51, .73])$. The validity statistics for the four GPS-iv items indicate that a cutoff score of $\geq 1$ provides optimal screening for PDs given a sensitivity of .91 and a specificity of .52. The AUC was .82 (95\% Cl $[.75, .89])$ and was significant at $p=.00$. 
Table 4. Logistic regression analyses predicting the likelihood of having a PD based on the GPS items

\begin{tabular}{|c|c|c|c|c|c|c|}
\hline & B & S.E. & Wald & $p$ & Odds ratio & $95 \% \mathrm{Cl}$ \\
\hline \multicolumn{7}{|l|}{ GPS-pv } \\
\hline HAB1 & -1.06 & 0.89 & 1.44 & .23 & 0.35 & {$[0.06,1.96]$} \\
\hline HAB2 & 0.07 & 0.49 & 0.02 & .89 & 1.07 & {$[0.41,2.80]$} \\
\hline HAB3 & -0.23 & 0.48 & 0.22 & .64 & 0.80 & {$[0.31,2.06]$} \\
\hline HAB4 & 2.14 & 0.52 & 16.89 & .00 & 8.51 & {$[3.06,23.62]$} \\
\hline HAB5 & -0.33 & 0.38 & 0.76 & .38 & 0.72 & {$[0.34,1.51]$} \\
\hline HAB6 & -0.31 & 1.45 & 0.05 & .83 & 0.73 & {$[0.04,12.51]$} \\
\hline HAB7 & -0.54 & 0.61 & 0.78 & .38 & 0.59 & {$[0.18,1.92]$} \\
\hline $\mathrm{BIO} 1$ & 0.75 & 0.49 & 2.38 & .12 & 2.12 & {$[0.82,5.49]$} \\
\hline $\mathrm{BIO} 2$ & -1.34 & 1.29 & 1.07 & .30 & 0.26 & {$[0.02,3.32]$} \\
\hline $\mathrm{BIO} 3$ & -0.10 & 1.09 & 0.84 & .36 & 0.37 & {$[0.04,3.10]$} \\
\hline $\mathrm{BIO} 4$ & 0.89 & 0.49 & 3.32 & .07 & 2.42 & {$[0.94,6.28]$} \\
\hline BIO5 & 1.13 & 0.50 & 5.07 & .02 & 3.09 & {$[1.16,8.24]$} \\
\hline $\mathrm{BIO6}$ & 0.53 & 1.37 & 0.15 & .70 & 1.70 & {$[0.12,24.77]$} \\
\hline $\mathrm{BIO}$ & 1.17 & 0.79 & 2.21 & .14 & 3.22 & {$[0.69,15.01]$} \\
\hline $\mathrm{BIO} 8$ & -0.89 & 0.68 & 1.74 & .19 & 0.41 & {$[0.11,1.54]$} \\
\hline $\mathrm{BIO9}$ & -1.44 & 1.01 & 2.03 & .16 & 0.24 & {$[0.03,1.72]$} \\
\hline Constant & -2.03 & 0.27 & 56.07 & .00 & 0.13 & \\
\hline \multicolumn{7}{|l|}{ GPS-iv } \\
\hline HAB1 & -0.26 & 0.61 & 0.18 & .67 & 0.77 & {$[0.24,2.56]$} \\
\hline HAB2 & 1.52 & 0.45 & 11.56 & .00 & 4.55 & {$[1.90,10.91]$} \\
\hline HAB3 & 0.02 & 0.48 & 0.00 & .96 & 1.02 & {$[0.40,2.61]$} \\
\hline HAB4 & 1.35 & 0.50 & 7.32 & .01 & 3.85 & {$[1.15,10.24]$} \\
\hline HAB5 & 0.17 & 0.41 & 0.16 & .69 & 1.18 & {$[0.53,2.63]$} \\
\hline HAB6 & 1.56 & 0.50 & 9.70 & .00 & 4.75 & {$[1.78,12.66]$} \\
\hline HAB7 & 0.37 & 0.51 & 0.53 & .47 & 1.45 & {$[0.54,3.93]$} \\
\hline $\mathrm{BIO} 1$ & 1.64 & 0.46 & 12.48 & .00 & 5.14 & {$[2.07,12.76]$} \\
\hline $\mathrm{BIO} 2$ & -1.08 & 1.04 & 1.09 & .28 & 0.34 & {$[0.05,2.58]$} \\
\hline $\mathrm{BIO} 3$ & -1.56 & 0.96 & 2.65 & .10 & 0.21 & {$[0.03,1.38]$} \\
\hline $\mathrm{BIO} 4$ & 0.19 & 0.45 & 0.18 & .67 & 1.21 & {$[0.50,2.94]$} \\
\hline $\mathrm{BIO} 5$ & 0.82 & 0.65 & 1.61 & .21 & 2.23 & {$[0.64,8.13]$} \\
\hline $\mathrm{BIO} 6$ & 1.87 & 1.48 & 1.59 & .21 & 6.46 & {$[0.36,117.57]$} \\
\hline $\mathrm{BlO} 7$ & -0.07 & 0.63 & 0.01 & .92 & 0.94 & {$[0.27,3.23]$} \\
\hline $\mathrm{BIO}$ & -0.56 & 0.57 & 0.97 & .33 & 0.57 & {$[0.19,1.75]$} \\
\hline BIO9 & -0.45 & 0.72 & 0.39 & .53 & 0.64 & {$[0.16,2.61]$} \\
\hline Constant & -3.64 & 0.43 & 72.42 & .00 & 0.03 & \\
\hline
\end{tabular}

Note. $d f=1$.

\section{Discussion}

Empirical research on PDs in older adults is a young field, particularly in the area of general practice. This is the first study to assess the value of a screening instrument for PDs in older adults (the GPS) in Dutch general practice. The test-retest reliability of the GPS subscales and the total scale was strong and yielded significance for both versions. Based on the diagnostic accuracy statistics, the GPS-iv is preferable to the GPS-pv; sensitivity and specificity were $78 \%$ and $65 \%$, respectively, for the GPS-iv and $83 \%$ and $27 \%$, respectively, for the GPS-pv. This might be due to the nature of the applied reference criterion, which is purely informant-based and relies on just one diagnostic source. It is plausible that the GPS-pv would have performed better if the reference criterion also had included self-report. Thus, there is an urgent need for the development of a self-report reference criterion. Additionally, six GPS items (HAB4 and $\mathrm{BIO} 5$ from the GPS-pv and HAB2, HAB4, HAB6, and BIO1 from the GPS-iv) yielded the most predicted validity. However, the diagnostic accuracy of these items needs cross-validation in community-dwelling older adult populations.

The present results differ from those of van Alphen and colleagues ${ }^{(20)}$. They found that the diagnostic accuracy of the GPS-pv was better than that of the GPS-iv. However, that study differed from the present study with respect to target population (psychiatric elderly outpatients versus community-dwelling older adults) and informants (exclusively children versus diverse, related informants). Another important difference relates to the reference criterion. In the present study, the GPS was validated with an informant-based instrument, whereas in van Alphen et al. (20), the presence or absence of PD was based on a clinical diagnosis, which is independent of both the older adult's and the informant's perspectives.

The results of the present study speak to the value of involving multiple sources of information because it included informant information in addition to self-report in the assessment of PDs in older adults. Relying solely on self-report has serious limitations e.g. 18, 19). By including informant information, some of the limitations can be overcome. First, use of informant data solves issues related to the older adults' motivation and ability to report PDs. Individuals, including older adults, may be consciously or unconsciously driven to present themselves more favorably as a result of the socially undesirable characteristics associated with PDs ${ }^{(44)}$. In addition, they may be unaware of their maladaptive behaviors due to the distorted self-perceptions that characterize many PDs ${ }^{(6)}$ or the ego-syntonic nature of PDs ${ }^{(19)}$. Second, older adults may lack the insight needed to accurately report their personality and their interpersonal relationships as a result of cognitive decline (including dementia) and unfamiliarity with assessment situations ${ }^{\left({ }^{18)}\right.}$. Third, informant data minimize the cognitive and somatic load associated with frailty in older adults. In addition, in general practice, usage of informant information is becoming more acceptable as a way to screen for dementia in older adults (45). The GPS-iv could have a similar role in the detection of PDs.

There are several limitations to this study. First, there was a low response rate. Although over 3,500 older adults were invited to participate, only $30.4 \%$ returned the reply, and, of those, only $38.5 \%$ were willing to participate. Consequently, the results may not be representative of the target population. Nonetheless, recruitment of older 
adults in research studies is often difficult ${ }^{(46)}$. The low response rate in the present study is comparable to that in studies that used similar methods (e.g., ${ }^{47)}$

Second, we used the HAP as reference criterion. This instrument is solely based on informant information, and, therefore, is not ideal for validating a self-report screening instrument, such as the GPS-pv. However, when the current study began, no selfreport-based reference criterion that specifically addresses older adults by taking the aging process and environmental-related changes into account was available ${ }^{(48)}$. The HAP is one of the few validated and reliable instruments that addresses older adults' personality and uses age-neutral items to consider age-related issues ${ }^{(32)}$. Moreover the HAP is a promising instrument for the measurement of PDs as defined by the DSM-5; an expert study showed that the HAP items largely adhered to the DSM- 5 criteria ${ }^{(49)}$

Third, collateral information was not used to confirm a clinical diagnosis. The PD construct is complex because PDs are multi-faceted. Moreover, from a practical poin of view, the presence of a clinical diagnosis of PDs in older adults is rare in genera practice. A longitudinal, expert, and all data (LEAD) standard (52) for the assessment of PDs is preferable ${ }^{(50)}$. The LEAD standard uses longitudinal data to ultimately reach a consensus diagnosis among clinicians. The longitudinal data are gathered from observational, biographic, informant, test, and file data sources and from staff experiences with the patient. Although LEAD standards are implemented in menta healthcare services, they are difficult to use in general practice. Thus, our use of the HAP as a reference criterion for a general practice population was based on practical considerations. However, it would be interesting to include other data, such as the frequency of GP attendance or history of mental-health consultations, as possible features of PDs in future studies ${ }^{(10)}$.

Fourth, there was heterogeneity of informants with respect to nature and duration of their relationships to the patient. Although the majority of the patients in the present study selected their spouses as informants, some chose other people, such as their (grand-) children or children-in-law. The difference in generations and the nature and duration of the relationship between the patient and informant could influence the agreement levels; in other words, observations by the various informants may be drawn from non-equivalent perspectives or sources. An analysis of these differences would be interesting.

Fifth, the internal consistency of the GPS-pv, and to a lesser degree GPS-iv, was limited. Although the homogeneity of the GPS was also measured with AIC, which is preferable to Cronbach's a when using a small-scaled instrument ${ }^{(33)}$, the GPS-pv total score did not reach the .15 criterion. This is likely due to the abstract and multi-facetted nature of the PD construct. Nevertheless, the other scales did reach sufficient AIC.
Sixth, there was relatively low specificity of both GPS versions when a cutoff score with good sensitivity was suggested. However, when using opportunistic screening or a case-finding instrument (such as the GPS), relatively higher sensitivity is preferred over specificity. Moreover, currently there are no alternative brief instruments for screening PDs in older adults. Thus, it is not realistically to expect both high sensitivity and specificity when screening of PDs in older adults. Similar research in young adults, using more comprehensive instruments, was unable to do so because of the complexity of the PD construct ${ }^{(51)}$

Seventh, the GPS is intended as a screening-process tool for GPs. It can only be used to screen for the presence or absence of a PD based on the atheoretical model of DSM-5. Specific DSM-5 PDs cannot be screened with the GPS.

Thus, additional research is needed to further validate the utility of the GPS in general practice, especially for the GPS-pv. There is a high need to replicate both the present study and that of van Alphen and colleagues (2006), once a criterion that allows both self and informant scoring is available for older adults. It would also be worthwhile to further investigate the predictive value of the GPS items (HAB4 and BIO5 for the GPS-pv; HAB2, HAB4, HAB6 and BIO1 for the GPS-iv). Research on GPS implementation in general practice is also warranted. Moreover, in future research, it is important to be even more attentive to recruitment issues for the target population. Hand delivering, rather than mailing, participant invitations may increase the response rate ${ }^{(47)}$.

This first attempt to provide GPs an age-specific screening instrument for PDs is innovative. This research represents an important step forward for GPs who intend o screen for PDs in their older adult patients but who lack the resources and time to systematically conduct extended diagnostic procedures (e.g., the LEAD standard). Screening for PDs in older adults that is based on the general DSM- 5 criteria is an important first step for general practice. 


\section{References}

1. American Psychiatric Association. Diagnostic and statistical manual of mental disorders. 5th ed. Arlington, VA: American Psychiatric Publishing; 2013

2. Widiger T, Trull T. Plate tectonics in the classification of personality disorder: Shifting to a dimensional model. American Psychologist. 2007;62:71-83.

3. American Psychiatric Association. Diagnostic and statistical manual of mental disorders. 4th; text revision ed. Washington DC: Author; 2000.

4. Agronin ME, Maletta G. Personality disorders in late life: Understanding and overcoming the gap in research. American Journal of Geriatric Psychiatry. 2000;8(1):4-18.

5. Oltmanns TF, Balsis SMA. Personality disorders in later life: Questions about measurement, course, and impact of disorders. Annual Review of Clinical Psychology. 2011;7:321-49.

6. Segal DL, Coolidge FL, Rosowsky E. Personality disorders and older adults: Diagnosis, assessment and treatment. New Jersey: John Wiley \& Sons Inc; 2006.

7. Balsis SMA, Woods CM, Gleason MEJ, Oltmanns TF. Overdiagnosis and underdiagnosis of personality disorders in older adults. American Journal of Geriatric Psychiatry 2007;15:742-53.

8. van Alphen SPJ, Dijk v, S, Videler AC, Rossi G, Dierckx E, Bouckaert F, et al. Personality disorders in older adults: Emerging research issues. Current Psychiatric Reports. 2015;17:538-45.

9. van Alphen SPJ, Derksen JLL, Sadavoy J, Rosowsky E. Features and challenges of personality disorders in late life. Aging and Mental Health. 2012;16(7):805-10.

10. Jackson HJ, Burgess PM. Personality disorders in the community: Results from the Australian national survey of mental health and well-being part III. Social Psychiatry and Psychiatric Epidemiology. 2004;39:765-76

11. Stevenson J, Brodaty H, Boyce P, Byth K. Personality disorder comorbidity and outcome: Comparison of three age groups. Australian and New Zealand Journal of Psychiatry. 2011:45(9):771-9.

12. Condello C, Padoani W, Uguzzoni U, Caon F, De Leo D. Personality disorders and selfperceived quality of life in an elderly outpatient population. Psychopathology. 2003;36:78-83.

13. Frankenburg FR, Zanarini MC. Personality disorders and medical comorbidity. Curren Opinion in Psychiatry. 2006;19(4):428-31.

14. Weissman MM. The epidemiology of personality disorders: A 1990 update. Journal of Personality Disorders. 1993;7(Suppl 1):44-62.

15. Ames A, Molinari V. Prevalence of personality disorders in community living elderly. Journal of Geriatric Psychiatry and Neurlogy. 1994;7(3):189-94.

16. Smith Silberman C, Roth L, Segal DL, Burns WJ. Relationship between the Millon Clinica Multiaxial Inventory-II and Coolidge Axis II Inventory in chronically ill older adults: A pilot study. Journal of Clinical Psychology. 1997;53(6):559-66.
17. Edelstein BA, Woodhead EL, Segal DL, Heisel MJ, Bower EH, Lowery AJ, et al. Older adult psychological assessment. Clinical Gerontologist. 2007:31(3):1-34.

18. American Psychological Association. Guidelines for psychological practice with older adults. American Psychologist. 2014;69(1):34-65.

19. Klonsky ED, Oltmanns TF, Turkheimer E. Informant-reports of personality disorder Relation to self-reports and future research directions. Clinical Psychology: Science and Practice. 2002;9:300-11

20. van Alphen SPJ, Engelen GJJA, Kuin Y, Hoijtink HJA, Derksen JLL. A preliminary study of the diagnostic accuracy of the Gerontological Personality disorders Scale (GPS). International Journal of Geriatric Psychiatry. 2006;21(9):862-8.

21. Tummers JHA, Hoijtink JHA, Penders KAP, Derksen JLL, van Alphen SPJ. Screening items for personality disorders in older adults: A multi-center study of psychiatric inpatients and outpatients in the Netherlands. Clinical Gerontologist. 2011;34(1):34-44.

22. Folstein MF, Folstein SE, McHugh PR. Mini-mental state. A practical method for grading the cognitive state of patients for the clinician. Journal of Psychiatric Research. 1975;12:189-98

23. Yesavage JA, Brink TL, Rose TL, Lum O, Huang V, Adey M, et al. Development and validation of a Geriatric Depression screening Scale: A preliminary report. Journal of Psychiatric Research. 1983;17(1):37-49.

24. Babor TM, Higgings-Biddle JC, Saunders JB, Monteiro MG. AUDIT the Alcoho Use Disorders Identification Test. Guidelines for use in primary care. World Health Organization, Department of Mental Health and Substance Dependence; 2001. Report No.: WHO/MSD/MSB/01.6a Contract No.: WHO/MSD/MSB/01.6a.

25. De Beurs E. Brief Symptom Inventory handleiding. Leiden, The Netherlands: PITS B.V. 2008

26. CBS list [Internet]. Available from: http://www.cbs.nl/.

27. Gómez A, Conde A, Santana JM, Jorrín A, Serrano IM, Medina R. The diagnostic usefulnessof the AUDIT and the AUDIT-C for detecting hazardous drinkers in the elderly. Aging and Mental Health. 2006;10(5):558-61.

28. van Alphen SPJ. Diagnostiek van persoonlijkheidsstoornissen bij ouderen. Een bijdrage aan de ontwikkeling van een screeningsinstrument. [diagnosis of personality disorders in older adults. A contribution to the contruction of a screening instrument]: Radboud Universiteit Nijmegen; 2006

29. Barendse H. Thissen T. H.A.P. Hetero-Anamnestische Persoonlijkheidsvragenlijs handleiding. Schijndel:Barendse \& Thissen; 2006.

30. Millon T. Personality prototypes and their diagnostic criteria. In: Millon T, Kierman GL, editors. Contemporary directions in psychopathology: Towards the DSM-IV. New York: Guilford Press; 1996. p. 671-712.

31. Millon T, Everly GS. Personality and its disorders: A biosocial learning approach. New York: Wiley-Interscience;1985. 
32. Barendse H, Thissen AJC, Oei TI, Rossi G, van Alphen SPJ. Psychometric proporties of an informant personality questionnaire (the HAP) in a sample of older adults in the Netherlands and Belgium. Aging and Mental Health. 2013;31(1):1-7.

33. Clark LA, Watson D. Constructing validity. Basic issues in objective scale development. Psychological Assessment.1995;7(3):309-19.

34. Cohen J. Differences between proportions. Statistical power analysis for the behavioral science. 2nd ed. Hillsdale, NJ: Lawrence Erlbaum Associates; 1988. p. 179-213.

35. Hsu LM. Diagnostic validity statistics and the MCMI-III. Psychological Assessment. 2002;14(4):410-22.

36. Meehl P, Rosen A. Antedecent probability and the efficiency of psychometric signs, patterns, or cutting points. Psychological Bulletin. 1955;52(3):194-216.

37. Rossi G, Sloore H. Diagnostic efficiency of the Dutch language version of the Millon Clinical Multiaxial Inventory-III. In: Halvorsen I, Olsen S, editors. New research on personality disorders: Nova Science Publishers Inc.,; 2008.

38. Streiner DL. Diagnosing tests: Using and misusing diagnostic and screening tests. Journal of Personality Assessment. 2003;81(3):209-19.

39. Agresti A. An introduction to categorical data analysis.2nd ed. New York: Wiley; 2002.

40. Bewick V, Cheek L, Ball J. Statistic review 13: Receiver operating characteristic curves. Critical Care. 2004;8(6):508-12.

41. Garson DG. Logistic regression: Binary \& multinomial [Ebook]. Asheboro, USA: Statistica Associates Publishing; 2013. Available from: www.statisticalassociates.com.

42. DeVellis RF. Scale development: Theory and application. 2nd ed. Thousand Oaks, California: Sage; 2003

43. Cohen J. The significance of a product moment rs. Statistical power analysis for the behavioral science. 2nd ed. Hillsdale, NJ: Lawrence Erlbaum Associates; 1988. p. 75-108.

44. Cooper LD, Balsis SMA, Oltmanns TF. A longitudinal analysis of personality disorder dimensions and personality traits in a community sample of older adults: Perspectives from selves and informants. Journal of Personality Disorders. 2014;28(1):151-65.

45. Brodaty $\mathrm{H}$, Pond D, Kemp N, Luscombe G, Harding L, Berman K, et al. The GPCOG: A new screening test for dementia designed for general practice. Journal of American Geriatrics Society. 2002:50(3):530-4

46. Gregson BA, Smith M, Lecouturier J, Rousseau N, Rodgers H, Bond J. Issues of recruitment and maintaining high response rates in a longitudinal study of older hospital patients in England-pathways to care study. Journal of Epidemiology and Community Health. 1997:51(5):541-8.

47. Edelman LS, Yang R, Guymon M, Olson LM. Survey methods and response rates among rural community dwelling older adults. Nursing Research. 2013;62(4):286-92.

48. Rossi G, van den Broeck J, Dierckx E, Segal D, van Alphen SPJ. Personality assessment among older adults: The value of personality questionnaires unraveled. Aging and Menta Health. 2014:1-4.
49. Barendse H, Rossi G, van Alphen SPJ. Personality disorders in older adults: Expert opinion as a first step toward evaluating the criterion validity of an informant questionnaire (HAP). International Psychogeriatrics. 2014;26(1):173-4.

50. van Alphen SPJ, Bolwerk N, Videler AC, Tummers JHA, van Royen RJJ, Barendse H, et al. Age-related aspects and clinical implications of diagnosis and treatment of personality disorders in older adults. Clinical Gerontologist. 2012;35(1):27-41.

51. Tyrer P, Coombs N, Ibrahimi F, Mathilakath A, Bajaj P, Ranger M, et al. Critical developments in the assessment of personality disorder. The British Journal of Psychiatry. 2007:190(49):S51-S9

52. Spitzer, C. Psychiatric diagnosis: Are clinicians still necessary? Comprehensive Psychiatry. 1983;24:399-411. 


\section{4}

Mapping the nomological network of the Gerontological Personality disorders Scale (GPS) by the HiTOP approach

Submitted

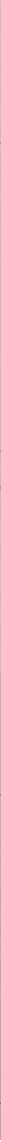




\section{Abstract}

\section{Purpose}

While the Gerontological Personality disorders Scale (GPS) can aid in detecting personality disorders (PDs) in older adults in general practice, its availability does not guarantee its use. This study therefore aimed to examine the feasibility and acceptability of the GPS from an older adult, informant and professional perspective.

\section{Methods}

A convergent parallel mixed methods study was conducted. Qualitative data were collected through semi-structured interviews with four general practitioners and fou nurse practitioners and were analyzed thematically. Quantitative data were collected through a 5-item questionnaire completed by 329 older adults and 329 informants.

\section{Results}

The thematic analysis revealed five major themes regarding feasibility and acceptability according to the professionals: 'taboo to ask intimate questions,' 'quite unfamilia with these disorders,' 'assets,' 'PDs are a topic of interest in general practice' and 'preconditions.' Descriptive statistics showed that most older adults and informants found the GPS items to be clearly phrased, easy to understand, non-confrontational or not unpleasant to answer.

\section{Conclusions}

The GPS is a feasible and acceptable instrument for detecting PDs in older adults in general practice. Educating professionals about PDs in older adults and the GPS is important prior to its use in daily practice and might further increase its acceptability.

\section{Keywords}

personality disorders, older adults, general practice, feasibility, acceptability, mixed methods research.

\section{Introduction}

Recently, interest in personality disorders (PDs) in older adults (>60 yrs.) has increased because of the rapidly growing aging population and the serious consequences of PDs for both patients and their environment. The prevalence rate is substantial at approximately $8 \%$ in the older adult general population ${ }^{(1)}$. PDs are associated with various negative effects such as decreased physical functioning ${ }^{(2)}$, increased health service utilization and use of medical resources ${ }^{(2-4)}$, poor treatment outcomes of comorbid psychiatric disorders ${ }^{(5)}$, and increased mortality rates due to suicide and other causes ${ }^{(6)}$. Fortunately, findings have consistently indicated that PDs in older adults are treatable to some extent ${ }^{(7-8)}$.

PDs often remain unrecognized even though they are severe disorders, and both general practitioners (GPs) and nurse practitioners (NPs) ${ }^{1}$ may experience many (interpersonal) difficulties with older adults with PDs such as treatment rejection and non-compliance with somatic and mental care ${ }^{(9)}$. Under-recognition might be due to several factors including ageism ${ }^{(10)}$, deviating phenomenological manifestation ${ }^{\left({ }^{11}\right)}$, a complex clinical picture because of comorbidity of psychiatric and/or somatic disorders (1) and the scarcity of accurate instruments to detect PDs in older adults ${ }^{(12-13)}$.

To fill this gap, the diagnostic accuracy of the Gerontological Personality disorders Scale (GPS; ${ }^{14)}$ was recently evaluated in general practice ${ }^{(15)}$. The results of that study were promising in providing an adequate tool to GPs who want to take a first step in detecting PDs in their older adult patients but lack the skills and time to systematically conduct extended diagnostic procedures.

Improving the detection of PDs in general practice is of importance because it enables GPs and NPs to take personality functioning into account when considering their approach and communication to optimize older adults' treatment compliance. Furthermore, it allows GPs to make faster and more specific referrals to mental health settings where further diagnostic assessments and treatment options are available.

While the GPS may aid in detecting PDs in general practice, the availability of the instrument does not guarantee that it will be used. New instruments are often not easily implemented (16) Successful implementation depends on multiple factors including the characteristics of the innovation and of the professionals applying the innovation, as well as patient characteristics ${ }^{(17-18)}$

1 The nurse practitioners in this study are doctors' assistants who received a 2-year posgraduate higher professional education and are trained to provide health promotion and maintenance through the diagnosis and treatment of acute illnesses and chronic conditions. 
To facilitate the development of effective strategies to implement the GPS in general practice, the feasibility and acceptability of this instrument was examined from the perspective of older adults, informants, GPs, and NPs using a mixed methods design.

\section{Methods}

\section{Design and context}

As optimizing patient care is an interplay between clinical practice and research (19), this study took a pragmatic stance that highlighted the research question by using diverse methods that best suited the study's purpose ${ }^{(20)}$. This mixed methods study occurred in the context of a psychometric analysis of the GPS as described in previous article ${ }^{(15)}$. A convergent parallel design ${ }^{(21)}$ with equal priority was used to ensure the comprehensiveness and triangulation of the results. The perspectives of the GPs and NPs (qualitative data) and those of the older adults and informants (quantitative data) contributed to a more integrated understanding of the feasibility and acceptability of the GPS in general practice. Figure 1 depicts both a flowchart and the study design, including the sequence of data collection and analysis for the qualitative and qualitative strands.

The Medical Ethical Review Commission of the Maastricht University Medical Center (MUMC+) in the Netherlands granted ethics approval (approval no. MEC 094-060).

\section{Participants}

In total, 704 participants were included. For information on dropout, see Figure 1.

\section{Qualitative strand}

The participants were approached by telephone and purposively selected based on their profession (GP; $n=4$ or NP; $n=4$ ) in the general practices that provided the patients who participated in the quantitative strand. All but one (refusal because of high workload) of these practices consented to participate Next, one GP and NP per participating practice were asked to use the GPS during a medical encounter the following month to gain experience with this instrument, after which an interview was planned at a time and date of their choosing.

All the GPs were male. Their average age was 61.3 years (range $=59-64, S D=2.1$ ) with a mean of 32.5 years of work experience (range $=31-34, S D=1.3$ ). All the NPs were female with an average age of 36 years (range $=28-43, S D=6.8$ ). Their work experience ranged from four to ten years (mean $=8.3, S D=2.9$ ).

Quantitative strand

The participants consisted of both older adults ( $n=348$ of which 329 were retained in the analyses) and informants $(n=329)$, all of whom had previously participated in a psychometric study on the GPS ${ }^{(15)}$. In that study, the older adults were nonrandomly sampled from five general practices in the south of the Netherlands. The recruitment was limited to Dutch-speaking patients of 60 years or older who had an Dutch-speaking informant who was also willing to participate. Older adults with florid psychiatric disorders, cognitive dysfunctions, and major attentional problems as a result of sedation and/or alcohol use, intellectual disabilities, or a life expectancy of less than three months were excluded. The older adults assigned their informants. No other specifications or conditions were provided.

Approximately half of the older adults were male $(n=149)$. The average age was 69.9 years (range $=60-91, S D=7.4$ ). They were screened for psychiatric disorders using 1) the Alcohol Use Disorders Identification Test (22), 2) the Geriatric Depression Scale (23), 3) the Brief Symptom Inventory (24), and 4) a Dutch informant questionnaire on personality ${ }^{(25-26)}$. Based on this screening, $7.3 \%$ of the older adults were identified as at risk of being harmful alcohol users, $8.5 \%$ were indicated as having mild to severe depression, $18.5 \%$ had (very) high levels of somatic complaints, $7.6 \%$ had (very) high levels of (subjective) cognitive problems, $8.5 \%$ had (very) high levels of interpersonal sensitivity, $16.7 \%$ had (very) high levels of anxiety, $13.4 \%$ had (very) high levels of hostility, $10.9 \%$ had (very) high levels of phobia, $10.0 \%$ had (very) high levels of paranoid thoughts, $8.8 \%$ had (very) high levels of psychoticism, and $17.0 \%$ were identified as having a PD.

Of the 329 informants, 138 were male. Their average age was 64.4 years (range $=25-89, S D=11.8$ ). Table 1 shows the demographic information. 
Figure 1. Convergent parallel mixed methods design: qualitative / quantitative study arms with data collection and analysis procedures
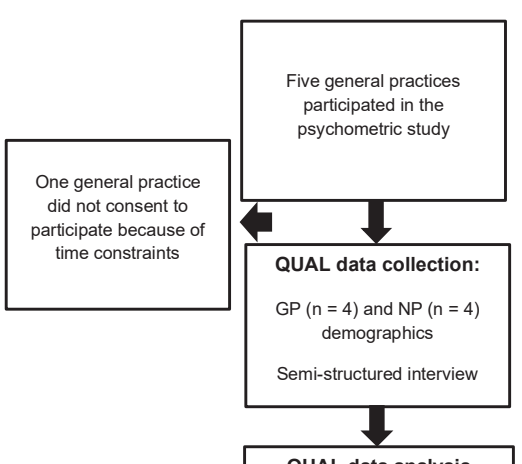

\begin{tabular}{|l|}
\hline $\begin{array}{c}\text { QUAL data analysis } \\
\text { (Nvivo): }\end{array}$ \\
Thematic analysis: \\
- Data familiarization \\
- Initial coding \\
- Theme searching \\
- Themes reviewing \\
- Defining and naming \\
themes \\
- Producing report
\end{tabular}

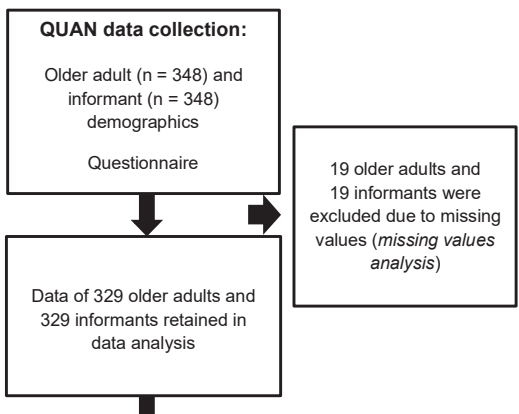

1
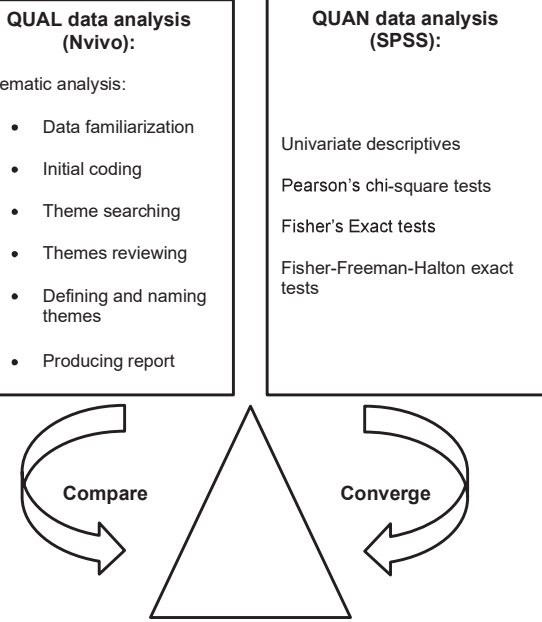

Triangulation
Table 1. Demographic features of older adults and informants

\begin{tabular}{|c|c|c|}
\hline & Older adults & Informants \\
\hline \multicolumn{3}{|l|}{ Age } \\
\hline Years $(S D)$ & $69.9(7.4)$ & $64.4(11.8)$ \\
\hline Range & $61-91$ & $25-89$ \\
\hline \multicolumn{3}{|l|}{ Gender (\%) } \\
\hline Men & $149(45.3)$ & $138(41.9)$ \\
\hline Women & $180(54.7)$ & $191(58.1)$ \\
\hline \multicolumn{3}{|l|}{ Marital status (\%) } \\
\hline Single & $14(4.3)$ & - \\
\hline Married / Civil partnership & $249(75.7)$ & - \\
\hline Cohabit & $7(2.1)$ & - \\
\hline Two household family (LAT) & $7(2.1)$ & - \\
\hline Divorced & $9(2.7)$ & - \\
\hline Widowed & $43(13.1)$ & - \\
\hline \multicolumn{3}{|l|}{ Housing (\%) } \\
\hline Dwelling-house & $323(98.2)$ & - \\
\hline Sheltered accommodation & $1(0.3)$ & - \\
\hline Elderly home & $2(0.6)$ & - \\
\hline Other & $3(0.9)$ & - \\
\hline \multicolumn{3}{|l|}{ Educational level (\%) } \\
\hline Elementary school & $36(10.9)$ & $20(6.1)$ \\
\hline School of domestic science/trade school & $141(42.9)$ & $107(32.5)$ \\
\hline Sr secondary vocational ED & $64(19.5)$ & $98(29.8)$ \\
\hline Sr general secondary ED/pre- university ED & $12(3.6)$ & $10(3.0)$ \\
\hline Higher professional ED & $60(18.2)$ & $68(20.7)$ \\
\hline University & $16(4.9)$ & $26(7.9)$ \\
\hline \multicolumn{3}{|l|}{ Nature of relationship (\%) } \\
\hline Partner & \multicolumn{2}{|c|}{$251(76.3)$} \\
\hline Sibling & \multicolumn{2}{|c|}{$9(2.7)$} \\
\hline Child & \multicolumn{2}{|c|}{$44(13.4)$} \\
\hline Grandchild & \multicolumn{2}{|c|}{$1(0.3)$} \\
\hline Brother/sister-in-law & \multicolumn{2}{|c|}{$1(0.3)$} \\
\hline Friend & \multicolumn{2}{|c|}{$9(2.7)$} \\
\hline Son/daughter-in-law & \multicolumn{2}{|c|}{$2(0.6)$} \\
\hline Other & \multicolumn{2}{|c|}{$12(3.7)$} \\
\hline
\end{tabular}


Table 1. Continued

\begin{tabular}{lc}
\hline \multicolumn{3}{l}{ Older adults } & Informants \\
\hline Duration of relationship in years (\%) & $10(3.0)$ \\
\hline $1-5$ & $9(2.7)$ \\
$6-10$ & $7(2.1)$ \\
$11-15$ & $8(2.4)$ \\
$16-20$ & $11(3.3)$ \\
$21-25$ & $8(2.4)$ \\
$26-30$ & $17(5.2)$ \\
$31-35$ & $40(12.2)$ \\
$36-40$ & $49(15.0)$ \\
$41-45$ & $59(18.0)$ \\
$46-50$ & $46(14.0)$ \\
$51-55$ & $35(10.6)$ \\
$56-60$ & $14(4.3)$ \\
$61-65$ & $4(1.2)$ \\
$66-70$ & $1(0.3)$ \\
$71-75$ & $0(0.0)$ \\
$76-80$ & $0(0.0)$ \\
$81-85$ & $1(0.3)$ \\
$86-90$ & $10(3.0)$ \\
Missing data
\end{tabular}

Note. - = data were not obtained.

Measures

Qualitative strand

The semi-structured interview was specifically developed for this study and consisted of 44 (mainly) open-ended questions covering the GPs' and NPs' attitudes towards PDs in older adults, their experience with the GPS and study participation (Table 2). The questions addressing experience with the use of the GPS were based on the quality criteria formulated by the Dutch Committee on Testing ${ }^{(27)}$ of the Dutch Institute of Psychologists (NIP) regarding test material.

Quantitative strand

The Gerontological Personality disorders Scale (Table 3) is a 16-item age-specific screening instrument designed to detect PDs in older adult inpatients ${ }^{(14)}$, which is now also available for general practice ${ }^{(15)}$. It consists of a self-report version (GPS patient version; GPS-pv) and an informant version (GPS-iv). To minimize method variance, the only difference between the self- and informant-report version is that the self-report items are worded in the first person (e.g., "I hope that others solve my problems"), and the informant-report items are worded in the third person (e.g., "He/she hopes that others solve his/her problems"). The 16 statements, which are derived from the PD diagnostic criteria of the fourth edition of the Diagnostic and Statistical Manual of Mental Disorders (DSM-IV; ${ }^{28)}$, assess both habitual behaviors (HAB) and biographical information (BIO; i.e., life characteristics), and these statements are endorsed as being either true or false. The GPS manual states that the presence of severe psychiatric disorders such as dementia, psychosis or major depression may negatively affect the reliability and validity of the instrument and therefore suggests not using the GPS-pv in such cases. However, the GPS-iv can be used in such circumstances by instructing the informant to answer the questions with the patient in mind when he or she does not suffer from the present psychopathology.

To date, two studies have addressed the psychometric properties of the GPS in different settings. In the older adult inpatient population (i.e., receiving care at an ambulatory department of geriatric psychiatry), the GPS-pv had moderate (HAB scale) to excellent (BIO scale) test-retest reliability with reasonable sensitivity and specificity (approximately $70 \%$ ) for both subscales ${ }^{(14)}$. The informant version had low sensitivity $(45 \%)$ and a good score for specificity (78\%). Recently, the diagnostic accuracy of the GPS was assessed in Dutch general practice ${ }^{(15)}$. The test-retest reliability of the GPS subscales and the total scale was strong (GPS-pv: $r_{\mathrm{s}}=.56[\mathrm{HAB}], r=.67[\mathrm{BIO}]$ $r_{\mathrm{s}}=.66$ [total] and the GPS-iv: $r_{\mathrm{s}}=.52$ [HAB], $r_{\mathrm{s}}=.65$ [BIO], $r_{\mathrm{s}}=.68$ [total]). Based on statistics related to diagnostic accuracy, the GPS-iv is preferable to the GPS-pv; the sensitivity and specificity were $78 \%$ and $65 \%$ for the GPS-iv, respectively, and $83 \%$ and $27 \%$ for the GPS-pv, respectively.

The 5-item self-report questionnaire was specifically developed for this study and consisted of items addressing the feasibility and acceptability of the GPS from the perspectives of older adults and informants (Table 4). 
Table 2. Semi-structured interview for general practitioners and nurse practitioners

\section{Attitude towards personality disorders in older adults}

What is your professional attitude towards personality disorders in older adults?

Is this something that has your attention (interested in, actively ...)?

What is your attitude towards detection of personality disorders in older adults?

Is detection of personality disorders in older adults necessary?

If yes; why?

If not; why?

Is (should) detection of personality disorders in older adults (be) a task of the general practitioner?

If yes; why?

If not; why?

s (should) detection of personality disorders (be) a task of the nurse specialist?

If yes; why?

If not; why?

Experience with the administration of the GPS

The GPS starts with an introductory text. Is this text clear (enough)?

Did you deviate from this text?

If yes; why?

How did the patients react to the introductory text?

Was the GPS easy to fit in your consult?

If yes; why?

If not; how did you deal with this?

How do you judge the scoring method of the GPS?

Did you find the items comprehensible?

If not; which items weren't?

What made them less comprehensible?

Did you find the items unambiguous?

If not; which items weren't?

What made them ambiguous?

Did you find the items concise?

If not: which items weren't?

What made them elaborate?

Did you have to explain certain items?

If so; what items?

And how did you explain them?
Table 2. Continued

How do you judge the format and layout of the GPS?

How do you judge the number of GPS items, from your own perspective?

How do you judge the number of GPS items, from the patient's perspective?

How went the administration of the GPS?

How do you judge the usage of the GPS?

What are the strengths of the GPS?

What are the weaknesses of the GPS?

Does the GPS has an added value in your practice?

If yes; in what way?

If not; why not?

Do you intend to use the GPS?

If yes; for what reason?

In which patients you will and in in which patients you won't use it?

If not; why not?

Do you judge the GPS to be a useful instrument to detect personality disorders in older adults?

If yes; why?

If not: why?

\section{Experience with participation in study}

How did you experience your participation in the current study?

Did your participation in the current study change your opinion and/or attitude toward personality disorders in older adults?

If yes; how and what did it change?

If not; why?

Note. Originally, these questions were in Dutch- they are translated for this publication 
Table 3. Items of the Gerontological Personality disorders Scale-patient version (GPS-pv)

\begin{tabular}{llcc}
\hline The Gerontological Personality disorders Scale-patient version (GPS-pv) & Yes & No \\
\hline & Habitual behavior & & \\
\hline $\mathbf{1}$ & I don't like growing older because I become less attractive & 1 & 0 \\
$\mathbf{2}$ & I often worry about my health & 1 & 0 \\
$\mathbf{3}$ & I'm often concerned about my memory & 1 & 0 \\
$\mathbf{4}$ & I hope that others solve my problems & 1 & 0 \\
$\mathbf{5}$ & I'm often afraid of losing those who care for me, such as members of the family or my & 1 & 0 \\
& partner & & \\
$\mathbf{6}$ & I'm often taken advantage of by others & 1 & 0 \\
$\mathbf{7}$ & I find it difficult to fend for myself & 1 & 0 \\
\hline & Biographical information & & \\
\hline $\mathbf{1}$ & In my life I've been to see the doctor for many vague physical complaints & 1 & 0 \\
$\mathbf{2}$ & I have sometimes said to my family or friends that I don't want to live any longer & 1 & 0 \\
$\mathbf{3}$ & In the past I've been admitted to a psychiatric institution because of nerves & 1 & 0 \\
$\mathbf{4}$ & At important times in my life, I experienced high levels of nervousness, stress or & 1 & 0 \\
& sadness & & \\
$\mathbf{5}$ & In the past I've already had treatment from a psychiatrist or psychologist & 1 & 0 \\
$\mathbf{6}$ & I have sometimes tried to end my life & 1 & 0 \\
$\mathbf{7}$ & At the most I've only had 1 acquaintance or friend in my life & 1 & 0 \\
$\mathbf{8}$ & In my life I've not been very interested in sexual contact & 1 & 0 \\
$\mathbf{9}$ & In the past I've often taken tranquilizers and/or sleeping pills & 1 & 0 \\
\hline
\end{tabular}

Table 4. The 5-item questionnaire: Questions regarding the Gerontological Personality disorders Scale (GPS) for older adults and informants

\begin{tabular}{l} 
1. How do you judge the number of GPS questions? \\
$\square$ too many \\
$\square$ many \\
$\square$ good \\
$\square$ few \\
$\square$ too few \\
\hline 2. How do you judge the language level of the GPS questions? \\
$\square$ difficult \\
$\square$ normal \\
$\square$ easy \\
\hline 3. Did you find the GPS questions comprehensive? \\
$\square$ yes \\
$\square \quad$ no \\
\hline 4. Did you find the GPS questions unpleasant to answer? \\
$\square \quad$ yes \\
$\square \quad$ no \\
\hline 5. Did you find the GPS questions confronting to answer? \\
$\square \quad$ yes \\
$\square \quad$ no \\
\hline Remarks and/or comments: \\
\hline
\end{tabular}

\section{Data collection}

\section{Qualitative strand}

Data on the GPs' and NPs' experiences with the GPS and their opinions on its feasibility and acceptability were collected using semi-structured interviews (Table 2). The first author conducted the interviews in the general practice of the participants between 2012 and 2013, and they lasted between 19 to 44 minutes each. All the interviews were audio recorded with the participants' consent.

\section{Quantitative strand}

The first author collected data on the older adults' and informants' perspectives on the feasibility and acceptability of the GPS during a 10- to 20-minute home visit (for data collection purposes only) at a date and time of the participants' choosing between 2009 and 2012. First, she administered the GPS to the older adults followed by the 
self-report questionnaire (Table 3). In the meantime, the informants completed their GPS version and subsequently completed the 5 -item questionnaire (Table 4).

Data analysis

\section{Qualitative strand}

One of the two independent research assistants transcribed the recordings verbatim. The first author checked the transcripts against the original recordings and complemented them when needed. The qualitative data management software, NVivo version 9 was used ${ }^{(29)}$. Two authors with different professional backgrounds KP a PhD student/psychologist and EvZ a social worker/legal expert/health service researcher) read and analyzed the transcripts independently using Braun and Clarke's inductive thematic analysis ${ }^{(30}$, see Table 5 ). Throughout the last phase of analysis, the findings were translated from Dutch to English. During the analysis, discrepancies and disagreements were discussed until consent was reached.

Quantitative strand

All statistical tests were performed using SPSS Windows version 20.0 (31). Prio formal analysis, Missing Value Analysis (MVA) was conducted to identify missing values. Based on the MVA, which revealed that the amount of missing data was low $(<5 \%)$ and seemed to be random as well as the fact that the measurement of the items complicated estimating the missing values, cases with missing values and their matched older adult or informant were omitted from further analysis $(n=38)$. Next, descriptive statistics were used to summarize the participants' characteristics and responses to the questionnaire.

The triangulation of methods (quantitative and qualitative data), different sources (older adults, informants, GPs and NPs), varying professional backgrounds (GP, health service researcher/epidemiologist, psychologist and social worker/legal expert/health service researcher), reflexivity (reflexive journal) and the creation of an audit trail contributed to the trustworthiness of the study. Transparency in analysis and reporting was achieved by providing extensive verbatim quotations.
Table 5. Overview of data analysis based on Braun \& Clarke's phases of thematic analysis

Phase Description of the process

1. Start data-immersion by actively (re-) reading data and listening audio recordings. Note initial ideas.

2. Generate initial codes by collating data relevant to each code across the complete data set.

3. Generate potential themes by collating codes and gathering all data relevant to each potential theme.

4. Review and refine the themes by checking there is a coherent pattern across both data extracts and the entire data set.

5. Define and name themes after ongoing analysis in which a clear conceptual idea arises of the various themes and how they fit together.

6. Provide an illustration of the themes with quotations presenting vivid and lucid examples of the point being made, making links to the research questions and literature.

Note. This analysis is a dynamic and recursive process, moving back and forth between phases.

\section{Results}

Qualitative results

Five major themes emerged from the thematic analysis. The themes all related to the feasibility and/or acceptability of the GPS.

'Taboo to ask intimate questions'

All the professionals described the GPS as having some sensitive items that can form a barrier to its administration. For example, $\mathrm{GP}_{3}$ identified these items and explained sensitivity as follows: "[..]...there are questions that may embarrass people a little. Especially older adult patients. Questions about suicide and sexuality. Well, then you have an 82-year-old sitting in front of you, yeah, they are just not used to these (questions)." The transcripts, especially those of the NPs, gave the impression that there was more to the response, as illustrated in the following excerpt from NP: "I did find them (questions) clear, yeah. However, I did find some questions (about suicide and sexuality) difficult to ask...[..]...the people responded very normal, but as a person you sometimes find it hard to ask such questions." This response suggested that there might be some kind of taboo related to asking intimate questions. This was supported by the following response by $\mathrm{NP}_{2}$ : "[......the question about sexual contact was difficult... [..]...I thought to myself, 'can I flat out (bluntly) ask this question?', whereas you also ask diabetics whether they experience sexual problems. It can be related to diabetes, and you therefore explain it." 
'Quite unfamiliar with these disorders'

This theme emerged when discussing the sensitivity related to asking intimate questions and comparing the responses of the professionals. All of the NPs independently expressed a lack of knowledge concerning PDs in older adults. $\mathrm{NP}_{2}$ said, "Well..., of course I am not totally familiar with the whole PDs-business, like what information you need to detect it in a person...." NP ${ }_{1}$ responded, "As for myself, I just know too little about it." This knowledge gap may have contributed to the sensitivity and the reluctance to asking intimate questions.

'Assets'

As opposed to the barriers, all the professionals described the GPS as having assets including plain and brief questions, a clear and concise introduction, and being smooth and easy to administer. Another addressed asset was its administration time. For instance, $\mathrm{NP}_{4}$ said, "It does not take much time. Therefore, I think it should be possible (to fit in a consultation)." Similarly, GP added, "It went swiftly and fast." Both the GPs and NPs also voiced that the GPS had added value. $\mathrm{GP}_{2}$ described the awareness of PDs in older adults created by the use of the GPS. He explained, "..........you immerse yourself...that alone is enough to increase the level of knowledge, which initially was $5 \%$ to $25 \%$ That alone provides new glasses to look through. Then, you look more carefully, and pick them out more easily." It may also provide surprising new insights, as NP put it, "Well, by asking these questions, you gain more insight into how people think. I was surprised by some people because I had a completely different view of them. When they answered the questions, I thought 'oh, I totally did not expect that from you.' Therefore, I certainly find that meaningful." GP found that using the GPS may also trigger reflection. He expressed the following: "This (the GPS) draws your attention to questions that make you think, 'hey, what exactly is the situation?', so it gives you a little pause for thought."

\section{'PDs are a topic of interest in general practice'}

In all the transcripts, the professionals expressed that PDs in older adults was hot issue in their daily practice. The professionals, especially the GPs, considered recognizing and dealing with these disorders to be part of their job responsibilities. "You try to be attentive to whether PDs play a role when people get into trouble", GP said. Their interest in this topic may also be due to the complicating effect that PDs are believed to have on their tasks. GP ${ }^{3}$ stated that recognizing PDs is difficult and that they negatively affect treatment options. He said, "You do not recognize a PD very easily. In addition, it is even harder because of multimorbidity; I would almost say it gets bogged down...[... ...Yeah, and then you do not recognize it, but it does sometimes make your treatment ineffective."
PDs also seemed to require some professional flexibility. As $\mathrm{NP}_{2}$ put it, "In consultations, you are often confronted with patients with PDs. This just complicates your working method. You must approach these people very differently than people without PDs. Because of it (PD), you sometimes really get stuck in communication A PD complicates things. Then, you will be facing very different things...[......You just have to change your approach completely." $\mathrm{GP}_{2}$ 's response illustrated that, aside from complicating the care for the patient, their sensitivity to PDs might also be emotionally bound. He voiced, "After 34 years, you certainly have... of course they are not all new patients...you regularly encounter the same problem. 'Goddamn it, has he not mastered it by now? Does he still not get it?' [..] and there are people with whom you ALWAYS end up in a discussion [... ...There is always something happening. In addition, then you think 'for God's sake, I am not talking about that!', people who agitate or provoke you personality-wise." He continued, "I think, as for myself, it would be good to know more about it and have some tools to know how to address certain personalities. That I could leave my emotions aside [..] that I will not take the easy way out, because it keeps dragging on...I would like to have some tools." In line with this, $\mathrm{GP}_{3}$ stated "How can you address it (PDs), so that it affects both general practitioners and patients the least?" Another professional, $\mathrm{NP}_{2}$, said, "How do you make it intelligible, how do you recognize it? How do you address it? Additionally, what kind of tools or resources are available?" These excerpts illustrate the need for resources to both recognize and address PDs, which seems to be commonplace among professionals.

\section{'Preconditions'}

This theme connoted the professionals' feelings that there were certain requirements to facilitate the use of the GPS. According to the professionals, available time, a clear indication for administration, a validated instrument and a contribution to the service provided in general practice are preconditions that must be met. Additionally, receiving education on PDs in older adults and how to use the GPS is needed, as expressed by $\mathrm{NP}_{2}$ as follows: “...[... ...also the question about 'I have only had one acquaintance'...[..]. . quite some people responded with 'yes, I do not have more,' then you think 'oh dear, do I have to go into greater depth, or not...?" In addition to the professionals' need for more knowledge, they stated the importance of properly informing the patients about the GPS, as illustrated by the following excerpt from $\mathrm{GP}_{2}$ : "For every patient, I think the introduction is key to the instrument." 
Quantitative results

Responses to the questionnaire and comparison of the participants' responses.

Overall, most older adults and informants judged the GPS to have a good number of comprehensive and normal language items. Nearly all the older adults and informants did not find the items unpleasant or confrontational to answer (Table 6). The inter-rater reliability was calculated with $\mathrm{AC}$ statistics whose validity does not depend on the hypothesis of independence between raters ${ }^{(32)}$. Table 6 shows that the agreement between the older adults' and informants' responses ranged from 'moderate' (language level) to 'almost perfect' (comprehensive questions), according to Landis and Koch ${ }^{(33)}$ Kappa benchmark scale.

Table 6. Older adults' and informants' responses regarding the Gerontological Personality disorders Scale (GPS)

\begin{tabular}{|c|c|c|}
\hline & Older adults (\%) & Informant (\%) \\
\hline \multicolumn{3}{|l|}{ How do you judge the number of GPS questions? } \\
\hline Too many & $1(0.3)$ & $1(0.3)$ \\
\hline Many & $12(3.7)$ & $48(14.6)$ \\
\hline Good & $306(93.0)$ & $257(78.1)$ \\
\hline Few & $9(2.7)$ & $21(6.4)$ \\
\hline Too few & $1(0.3)$ & $2(0.6)$ \\
\hline $\mathrm{AC}_{1}$ & \multicolumn{2}{|c|}{.73} \\
\hline$S E$ & \multicolumn{2}{|c|}{.03} \\
\hline $\mathrm{Cl}$ & \multicolumn{2}{|c|}{$.68-.79$} \\
\hline \multicolumn{3}{|c|}{ How do you judge the language level of the GPS questions? } \\
\hline Difficult & $1(0.3)$ & $2(0.6)$ \\
\hline Normal & $221(66.7)$ & $263(79.5)$ \\
\hline Easy & $109(32.9)$ & 66 (19.9) \\
\hline $\mathrm{AC}_{1}$ & \multicolumn{2}{|c|}{.55} \\
\hline$S E$ & \multicolumn{2}{|c|}{.04} \\
\hline $\mathrm{Cl}$ & \multicolumn{2}{|c|}{$.48-.62$} \\
\hline \multicolumn{3}{|l|}{ Did you find the GPS questions comprehensive? } \\
\hline Yes & $329(99.4)$ & $330(99.7)$ \\
\hline No & $2(0.6)$ & $1(0.3)$ \\
\hline $\mathrm{AC}_{1}$ & \multicolumn{2}{|c|}{.99} \\
\hline$S E$ & \multicolumn{2}{|c|}{.01} \\
\hline $\mathrm{Cl}$ & \multicolumn{2}{|c|}{$.98-1.00$} \\
\hline
\end{tabular}

Table 6. Continued

\begin{tabular}{|c|c|c|}
\hline & Older adults (\%) & Informant (\%) \\
\hline \multicolumn{3}{|c|}{ Did you find the GPS questions unpleasant to answer? } \\
\hline Yes & $13(4.0)$ & $11(3.3)$ \\
\hline No & $316(96.0)$ & $318(96.7)$ \\
\hline $\mathrm{AC}_{1}$ & & \\
\hline$S E$ & & \\
\hline $\mathrm{Cl}$ & & \\
\hline \multicolumn{3}{|c|}{ Did you find the GPS questions confronting to answer? } \\
\hline Yes & $30(9.1)$ & $31(9.4)$ \\
\hline No & $299(90.9)$ & $298(90.6)$ \\
\hline $\mathrm{AC}_{1}$ & & \\
\hline$S E$ & & \\
\hline $\mathrm{Cl}$ & & \\
\hline
\end{tabular}

Note. For the agreement between patient and informant responses (inter-rater reliability), we executed Gwet's $\mathrm{AC}_{1}$ statistics (2008)

Responses to GPS items and judgments about the GPS.

As the professionals identified GPS items $\mathrm{BIO} 2$ (suicide ideation), $\mathrm{BIO6}$ (suicide attempt) and $\mathrm{BIO} 8$ (hyposexuality) to be 'sensitive questions' that may have been potentially unpleasant and/or confrontational to answer for older adults and informants, we took a closer look at these items.

Both the older adults and informants who found the GPS to be unpleasant and/or confrontational to complete predominantly answered 'no' to $\mathrm{BIO} 2$ (93\%; 97.6\%), BIO6 (97.7\%; 95.2\%) and $\mathrm{BIO}$ (81.4\%; 88.1\%). Conversely, most of the older adults and informants who dealt with verbalized suicide ideation $(n=17 ; n=18)$, suicide attemp $(n=12 ; n=22)$ or hyposexuality $(n=98 ; n=78)$ did not find the GPS questions to be unpleasant and/or confrontational (91.2\%; 97.2\%, 91.7\%; 90.0\%, 91.8\%; 93.6\%, respectively).

To check whether there was an association between the described findings above, Pearson's chi-square tests and Fisher's exact tests were executed. The tests showed no significant associations between judging the GPS items to be either unpleasant to answer or confrontational and the actual response to the 'sensitive' GPS items (see Table 7) 
Table 7. Association between unpleasantness/confrontingness of GPS items and responses on 'sensitive' GPS items

\begin{tabular}{|c|c|c|c|c|}
\hline & \multicolumn{2}{|c|}{$\begin{array}{c}\text { Item: } \\
\text { Unpleasant questions }\end{array}$} & \multicolumn{2}{|c|}{$\begin{array}{c}\text { Item: } \\
\text { Confronting questions }\end{array}$} \\
\hline & Yes & No & Yes & No \\
\hline \multicolumn{5}{|l|}{ Response on GPS item BIO2 (suicide ideation) } \\
\hline \multicolumn{5}{|l|}{ All participants } \\
\hline Confirmative response on GPS item & 0 & 35 & 4 & 31 \\
\hline Negative response on GPS item & 24 & 599 & 57 & 562 \\
\hline Fisher's Exact test (two-tailed) & \multicolumn{2}{|c|}{.63} & \multicolumn{2}{|c|}{.56} \\
\hline Phi & \multicolumn{2}{|c|}{-.05} & \multicolumn{2}{|c|}{.02} \\
\hline \multicolumn{5}{|l|}{ Older adults } \\
\hline Confirmative response on GPS item & 0 & 17 & 3 & 14 \\
\hline Negative response on GPS item & 13 & 299 & 27 & 285 \\
\hline Fisher's Exact test (two-tailed) & \multicolumn{2}{|c|}{1.00} & \multicolumn{2}{|c|}{.19} \\
\hline Phi & \multicolumn{2}{|c|}{-.05} & \multicolumn{2}{|c|}{.07} \\
\hline \multicolumn{5}{|l|}{ Informants } \\
\hline Confirmative response on GPS item & 0 & 18 & 1 & 17 \\
\hline Negative response on GPS item & 11 & 300 & 30 & 281 \\
\hline Fisher's Exact test (two-tailed) & \multicolumn{2}{|c|}{1.00} & \multicolumn{2}{|c|}{1.00} \\
\hline Phi & \multicolumn{2}{|c|}{-.05} & \multicolumn{2}{|c|}{-.03} \\
\hline \multicolumn{5}{|l|}{ Response on GPS item BIO6 (suicide attempt) } \\
\hline \multicolumn{5}{|l|}{ All participants } \\
\hline Confirmative response on GPS item & 1 & 16 & 2 & 15 \\
\hline Negative response on GPS item & 23 & 618 & 59 & 578 \\
\hline Fisher's Exact test (two-tailed) & \multicolumn{2}{|c|}{.47} & \multicolumn{2}{|c|}{.67} \\
\hline Phi & \multicolumn{2}{|c|}{.02} & \multicolumn{2}{|c|}{.01} \\
\hline \multicolumn{5}{|l|}{ Older adults } \\
\hline Confirmative response on GPS item & 0 & 6 & 1 & 5 \\
\hline Negative response on GPS item & 13 & 310 & 29 & 294 \\
\hline Fisher's Exact test (two-tailed) & \multicolumn{2}{|c|}{1.00} & \multicolumn{2}{|c|}{.44} \\
\hline Phi & \multicolumn{2}{|c|}{-.03} & \multicolumn{2}{|c|}{.04} \\
\hline \multicolumn{5}{|l|}{ Informants } \\
\hline Confirmative response on GPS item & 1 & 10 & 1 & 10 \\
\hline Negative response on GPS item & 10 & 308 & 30 & 288 \\
\hline Fisher's Exact test (two-tailed) & & & & \\
\hline Phi & & & & \\
\hline
\end{tabular}

Table 7. Continued

\begin{tabular}{|c|c|c|c|c|}
\hline & \multicolumn{2}{|c|}{$\begin{array}{c}\text { Item: } \\
\text { Unpleasant questions }\end{array}$} & \multicolumn{2}{|c|}{$\begin{array}{c}\text { Item: } \\
\text { Confronting questions }\end{array}$} \\
\hline & Yes & No & Yes & No \\
\hline \multicolumn{5}{|l|}{ Response on GPS item BIO8 (hyposexuality) } \\
\hline \multicolumn{5}{|l|}{ All participants } \\
\hline Confirmative response on GPS item & 5 & 83 & 8 & 80 \\
\hline Negative response on GPS item & 19 & 547 & 53 & 513 \\
\hline Fisher's Exact test (two-tailed) & \multicolumn{2}{|c|}{.35} & \multicolumn{2}{|c|}{1.00} \\
\hline $\mathrm{Phi}$ & \multicolumn{2}{|c|}{.04} & \multicolumn{2}{|c|}{.00} \\
\hline \multicolumn{5}{|l|}{ Older adults } \\
\hline Confirmative response on GPS item & 3 & 46 & 5 & 44 \\
\hline Negative response on GPS item & 10 & 269 & 25 & 254 \\
\hline Fisher's Exact test (two-tailed) & \multicolumn{2}{|c|}{.42} & \multicolumn{2}{|c|}{.79} \\
\hline $\mathrm{Phi}$ & \multicolumn{2}{|c|}{.05} & \multicolumn{2}{|c|}{.02} \\
\hline \multicolumn{5}{|l|}{ Informants } \\
\hline Confirmative response on GPS item & 2 & 37 & 3 & 36 \\
\hline Negative response on GPS item & 9 & 278 & 28 & 259 \\
\hline Fisher's Exact test (two-tailed) & \multicolumn{2}{|c|}{.63} & \multicolumn{2}{|c|}{1.00} \\
\hline $\mathrm{Phi}$ & \multicolumn{2}{|c|}{.04} & \multicolumn{2}{|c|}{.-02 } \\
\hline
\end{tabular}

\section{Discussion}

While previous research has shown that the GPS may aid in the detection of PDs in older adults in general practice ${ }^{(15)}$, its availability does not guarantee its use. To facilitate the development of effective implementation strategies of the GPS in this setting, the present mixed methods study examined the feasibility and acceptability of this instrument from an older adult, informant and professional perspective. The experience of all the participants with the GPS was overall very positive; it was judged to be a feasible and acceptable instrument for detecting PDs in older adults in general practice.

Further, this study revealed that the professionals experienced reluctance asking some of the more intimate GPS items addressing verbalized suicide ideation, suicide attempt and hyposexuality. This is in line with previous research identifying suicidal ideation, sexual activity and other mental illness among others to be sensitive topics to discuss in the health care context ${ }^{(34-36)}$. Concerns about their own knowledge and expertise in the field are commonly reported barriers in discussing these topics ${ }^{(37-38)}$ as was expressed in the present study. 
Although the professionals were preoccupied with violating the privacy of the older adults and informants, as they expressed feeling some sort of barrier to asking the intimate questions on the GPS, the vast majority of both older adults and informants did not find the GPS items unpleasant to answer or confrontational. The fact that this questionnaire was only seen by themselves and the researcher as well as the fact that the items were verbally administered might have contributed to this, as research indicates that factors such as third-party presence ${ }^{(39-40)}$ and admitting to emotional problems ${ }^{(39)}$ on paper instead of talking about them decrease the willingness to disclose sensitive topics. Furthermore, several studies note that patients are generally willing to answer psychiatric questionnaires in general practice settings ${ }^{(39,41)}$.

The minority of older adults and informants who found the GPS to be unpleasant and/or confrontational were predominantly those who had not dealt with these subjects themselves. In addition, older adults and informants who had dealt with verbalized suicidal ideation and/or attempt or hyposexuality did not find the GPS to be confrontational or unpleasant. Thus, perhaps having no experience with these behaviors may have caused them to feel caught off guard and insulted if they were not appropriately informed about the type of questions prior their inquiry. This might be overcome by using specific communication techniques such normalizing, transparency and asking permission ${ }^{(36)}$ when introducing the GPS.

The strengths of this study include examining both the feasibility and acceptability of the GPS from various perspectives. By taking the perceptions of older adults and informants into account in addition to those of professionals, the study is able to obtain a more complete and holistic picture of the factors that might play a role in the implementation of the GPS. Additionally, using both quantitative and qualitative data enables greater depth in the results and provides new insight into this complex phenomenon. Moreover, the variety of backgrounds of the authors (family medicine, psychology, physical therapy, social work, law) provides an innovative triangulation of perspectives when analyzing the data.

However, some limitations are worth noting. First, in the qualitative strand, GPs and NPs from four out of five practices were willing to participate. Although small(er) sample sizes are common in qualitative research, we are not completely certain that we reached data saturation. Interviewing more professionals would have been preferable; however, because of time constraints, this was not possible. Nevertheless, it is reassuring that despite differences in ages, genders, professions and years of work experience, their responses were very similar, even more so within professions.

Second, it is possible that factors such as interest in PDs, gender, level of training and/or education and years of work experience affected the current findings. Professionals (three GPs and two NPs) from three out of four practices expressed having great interest in PDs in older adults, and some of them were even initiating PDrelated research or participating in refresher courses. However, their responses were similar to those who did not express a strong interest in PDs. Gender, level of education and years of work experience (and inherent age) might also have affected the findings Although they were nearly the same within professional disciplines, gender, level of education and years of work experience greatly differed between GPs and NPs, which may have affected the results.

Third, the NPs in the present study had 'somatic training' instead of 'mental health training,' which may explain why they were not quite familiar with PDs. However, at the time the study occurred, the participating practices did not have NPs with a mental health background.

Fourth, as the aim was for professionals to gain experience with using the GPS in their daily practice, they were free to use the instrument in any manner they chose. It turned out that all the professionals used the GPS somewhat randomly and during appointments when there was remaining time to do so. Hence, they employed the GPS in ways other than that for which it is intended, namely to use it when the presence of PDs is suspected. It is therefore possible that their experience regarding its feasibility would have been different if they had used the GPS as intended.

Although the detection of PDs in general practice is important and should also be feasible in other countries, future research is suggested including (larger sample) cross-validation studies of these findings across the Netherlands as well as in other countries and cultures because findings may differ. It is conceivable that in certain cultures, discussing sensitive topics in a direct manner, as is the case with the GPS, is not conventional or even appropriate, and therefore, professionals might respond differently to the feasibility and acceptability of the GPS. Larger samples may circumvent potential selection bias for reasons such as including only those professionals who have a clear interest in PDs, and they may also provide greater heterogeneity with respect to years of work experience.

It would also be worthwhile to include NPs with a mental health background, as these professionals (given their training and line of work) might encounter and address older adults with PDs more often than NPs with a somatic background.

Moreover, in future research, it would be valuable to instruct the professionals on when to employ the GPS before gaining experience with the instrument. By providing these instructions, the feasibility and acceptability of the GPS can be assessed in situations that more closely resemble daily practice. Other suggestions for further work include the implementation of the GPS in general practice on a larger scale. Another research topic is the influence of existing psychopathology on self- and informant 
ratings on the GPS. As PDs and other psychiatric and/or somatic disorders often cooccur and greatly affect one another reciprocally, understanding these mechanisms as well as their effect on the GPS is essential when assessing PDs in general practice.

To conclude, we are convinced that our findings have important implications. From this study, we have determined that the GPS can easily be incorporated in general practice, as professionals, older adults, and informants find it feasible and acceptable for use in this setting. However, it is recommended that as part of its implementation by professionals, especially NPs, they receive training concerning PDs (recognition and how to address them) as well as background information on the GPS and how to use it. Additionally, adequately informing older adults and informants about the GPS (e.g., type of questions, aim of questionnaire) when planning to use it may further lower the barrier to asking intimate questions. As $\mathrm{GP}_{2}$ eloquently stated, "For every patient, I think the introduction is key to the instrument."

Hence, in addition to its ability to assist in the detection of PDs in older adults ${ }^{(15)}$, the GPS now also proves to be a feasible and acceptable tool for general practice. It may assist GPs and NPs in objectifying the presence of a PD and thereby enable them to adapt treatment to accommodate the specific needs of individual patients by taking their PD into account. This may enhance the odds of a positive treatment response, avoid dropout, and possibly improve doctor-patient interactions. In addition, it may aid in their responsibility "to lead the way in destigmatizing" PDs ${ }^{\left({ }^{4} 2\right)}$.

\section{References}

1. Schuster JP, Hoertel N, Le Strat Y, Manetti A, Limosin F. Personality disorders in older adults: Findings from the national epidemiologic survey on alcohol and related conditions. American Journal of Geriatric Psychiatry. 2013;21(8):757-68.

2. Powers AD, Oltmanns TF. Personality disorders and physical health: A longitudina examination of physical functioning, healthcare utilization, and health-related behaviors in middle-aged adults. Journal of Personality Disorders. 2012;26(4):524-38.

3. Twomey CD, Baldwin DS, Hopfe M, Cieza A. A systematic review of the predictor of health service utilisation by adults with mental disorders in the UK. BMJ Open. 2015;5:e007575.

4. Lawton EM, Oltmanns TF. Personality pathology and mental health treatment seeking in a community sample of older adults. Personality and Mental Health. 2013;7:203-12.

5. Stevenson J, Brodaty H, Boyce P, Byth K. Personality disorder comorbidity and outcome: Comparison of three age groups. Australian and New Zealand Journal of Psychiatry. 2011;45(9):771-9.

6. Björkenstam E, Björkenstam C, Holm H, Gerdin B, Ekselius L. Excess cause-specific mortality in in-patient-treated individuals with personality disorder: 25-year nationwide population-based study. The British Journal of Psychiatry. 2015;207(4):339-45.

7. Videler AC, Rossi G, Schoevaars M, van der Felz C, Alphen SJPv. Effects of schema group therapy in older outpatients: A proof of concept study. International Psychogeriatrics. 2014;26:1709-17.

8. Lynch TR, Cheavens JS, Cukrowicz KC, Thorp SR, Bronner L, Beyer J. Treatment of older adults with co-morbid personality disorder and depression: A dialectical behavio therapy approach. International Journal of Geriatric Psychiatry. 2007;22:131-43.

9. van Alphen SPJ, Derksen JLL, Sadavoy J, Rosowsky E. Features and challenges of personality disorders in late life. Aging and Mental Health. 2012;16(7):805-10.

10. Nelson TD. Ageism: Stereotyping and prejudice against older persons. Nelson TD, editor. Cambridge, MA: MIT press Itd; 2004

11. van Alphen SPJ, Bolwerk $N$, Videler AC, Tummers JHA van Royen RJJ, Barendse $H$, et al. Age-related aspects and clinical implications of diagnosis and treatment of personality disorders in older adults. Clinical Gerontologist. 2012;35(1):27-41.

12. Rossi G, Van den Broeck J, Dierckx E, Segal D, Van Alphen SJP. Personality assessmen among older adults: The value of personality questionnaires unraveled. Aging and Menta Health. 2014:18(8):936-40

13. Oltmanns TF, Balsis SMA. Personality disorders in later life: Questions about measurement, course, and impact of disorders. Annual Review of Clinical Psychology. 2011;7:321-49.

14. van Alphen SPJ, Engelen GJJA, Kuin Y, Hoijtink HJA, Derksen JLL. A preliminary study of the diagnostic accuracy of the Gerontological Personality disorders Scale (GPS). International Journal of Geriatric Psychiatry. 2006:21(9):862-8. 
15. Penders KAP, Rossi G, Metsemakers JFM, Duimel-Peeters IGP, Alphen SPJv. Diagnostic accuracy of the Gerontological Personality disorder Scale (GPS) in Dutch general practice. Aging and Mental Health. 2016;20(3):318-28

16. Grol R, Wensing M. Implementatie. Effectieve verbetering van de patientenzorg: Reed Business; 2011.

17. Grol R. Implementing guidelines in general practice care. Quality in Health Care 1992;1(3):184-91.

18. Wensing M, Bosch M, Grol R. Developing and selecting interventions for translating knowledge to action. Canadian Medical Association Journal. 2010;182(2):E85-E8.

19. Grol R, Wensing M. Implementatie van verbeteringen in de zorg: Een complex probleem. In: Grol R, Wensing M, editors. Implementatie effectieve verbetering van de patientenzorg. Doetinchem: Reed Business; 2011. p. 22-39.

20. Morgan D. Paradigms lost and pragmatism regained: Methodological implications of combining qualitative and quantitative methods. Journal of Mixed Methods Research. 2007;1(1):48-76.

21. Creswell JW. A concise introduction to mixed methods research. Thousands Oaks, California: SAGE Publications inc; 2015

22. Babor TM, Higgings-Biddle JC, Saunders JB, Monteiro MG. AUDIT the Alcohol Use Disorders Identification Test. Guidelines for use in primary care2001; (WHO/MSD/ MSB/01.6a):[1-40 pp.]. Available from: http://whqlibdoc.who.int/hq/2001/WHO_MSD_ MSB_01.6a.pdf.

23. Yesavage JA, Brink TL, Rose TL, Lum O, Huang V, Adey M, et al. Development and validation of a Geriatric Depression screening Scale: A preliminary report. Journal of Psychiatric Research. 1983;17(1):37-49.

24. De Beurs E. Brief Symptom Inventory handleiding [brief symptom inventory manual] Leiden, The Netherlands: PITS B.V.; 2008.

25. Barendse H, Thissen T. H.A.P. Hetero-Anamnestische Persoonlijkheidsvragenlijs handleiding. Schijndel: Barendse \& Thissen; 2006.

26. Barendse H, Thissen AJC, Oei TI, Rossi G, van Alphen SPJ. Psychometric proporties of an informant personality questionnaire (the HAP) in a sample of older adults in the Netherlands and Belgium. Aging and Mental Health. 2013;17(5):623-9.

27. Dutch Committee on Testing. Cotan beoordelingsysteem voor de kwaliteit van testen 2010. Available from: http://www.psynip.nl/tests_cotan/cotan-beoordeling/beoordelingssysteem. html.

28. American Pstchiatric Association. Diagnostic and statistical manual of mental disorders. 4th; text revision ed. Washington DC: Author; 2000.

29. QSR International Pty Ltd. Nvivo qualitative data analysis software. 9 for Windows edition 2010.

30. Braun V, Clarke V. Using thematic analysis in psychology. Qualitative Research in Psychology. 2006;3(2):77-101.

31. IBM Corp. IBM SPSS statistics for windows. 23.0 ed. Armonk, New York: IBM Corp; 2015
32. Gwet KL. Computing inter-rater reliability and its variance in the presence of high agreement. British Journal of Mathematical and Statistical Psychology. 2008:61:29-48.

33. Landis JR, Koch GG. The measurement of observer agreement for categorical data. Biometrics. 1977;33(1):159-74.

34. Roberts R. Importance of the sexual dimension in psycho-social assessment. Australian Social Work. 1992;45:37-42.

35. Mellor R, Greenfield S, Dowswell G, Sheppard J, Quinn T, McManus R. Health care professionals' view on discussing sexual wellbeing with patients who have had a stroke: Qualitative study. PLoS ONE. 2013;8(10):1-9.

36. McBride R. Talking to patients about sensitive topics: Techniques for increasing the reliability of patient self-report [handout]. Medical School and Residency Program Curriculum Resources on drug abuse and addiction; The University of North Dakota, School of Medicine \& Health Sciences2010.

37. Hordern A, Street A. Communicating about patient sexuality and intimacy after cancer: Mismatched expectations and unmet needs. Medical Journal of Australia. 2007;186:224-7.

38. Humphery S, Nazareth I. GPs' views on their management of sexual dysfunction. Family Practice. 2001;18(5):516-8

39. Wood F, Pill R, Prior L, Lewis G. Patients' opinions of the use of psychiatric case-finding questionnaires in general practice. Health Expectations. 2002;5(4):282-8.

40. Tourangeau R, Yan T. Sensitive questions in surveys. Psychological Bulletin 2007;133(5):859-83.

41. Dorwick C, Leydon G, McBride A, Howe A, Burgess H, Clarke P, et al. Patients' and doctors' views on depression serverity questionnaires incentivised in UK quality and outcomes framework: Qualitative study. British Medical Journal. 2009;338:1-6.

42. Horton R. Rethinking personality disorders. Lancet. 2015;385: 664 . 


\section{7}

General discussion

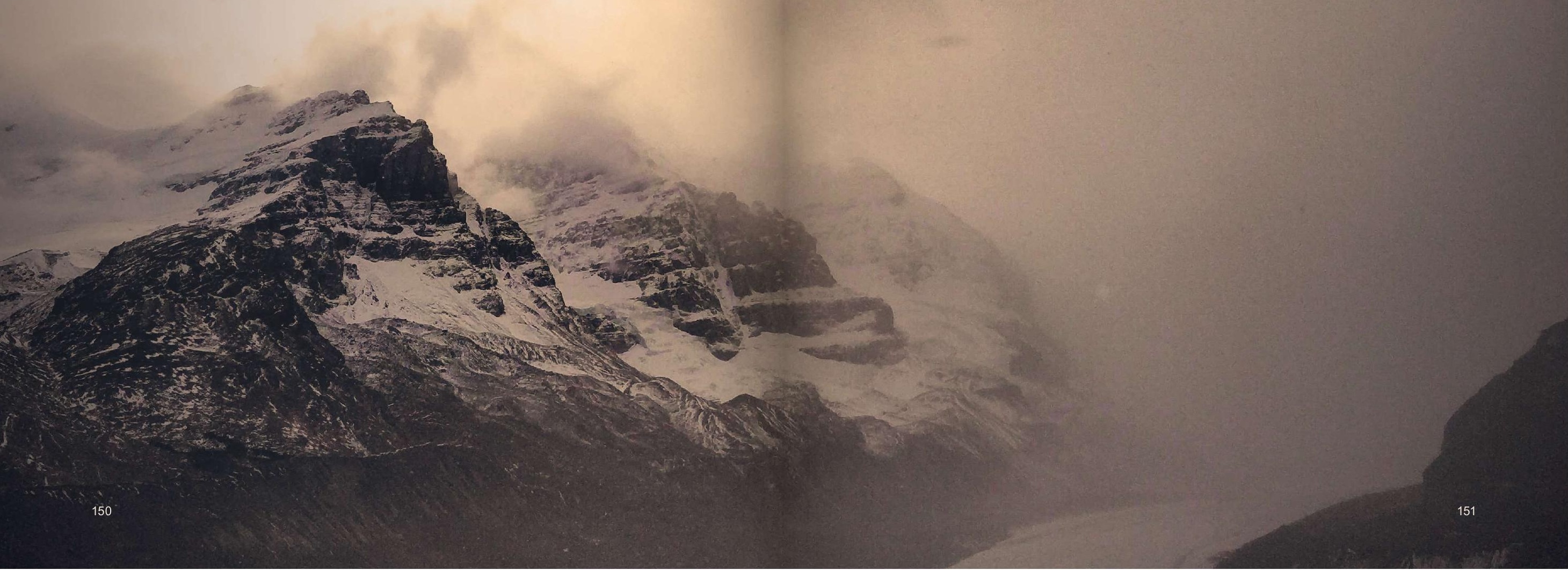




\section{Introduction}

General practitioners (GPs) are frequently consulted by older adults ( $\geq 60 \mathrm{yrs}$.) with personality disorders (PDs), although this is generally not the (key) reason for consultation given its ego-syntonic nature. These prevalent and disabling disorders, however, often remain unrecognized. The lack of adequate instruments severely complicates the detection of PDs in late life in general practice. Therefore, the main goal of the work presented in this dissertation was to evaluate and validate the Gerontological Personality disorders Scale (GPS), a brief and age-specific instrument developed for detecting PDs in elderly psychiatric outpatients, in general practice. Accordingly, the individual studies in this dissertation described: 1) the current status of PDs in older adults with respect to epidemiology, assessment and treatment, 2) the reliability and diagnostic accuracy of the GPS in general practice, 3) the convergent and divergent validity of GPS in general practice, 4) the concordance of the selfand informant-report version of the GPS in general practice, and what factors may contribute to the level of concordance, and 5) the feasibility and acceptability of the GPS in general practice according to professionals, older adults, and their informants.

This general discussion gives an overview of the major findings of the studies presented in this thesis. Next, it reflects on the findings and discusses the strength and limitations. Finally, implications for general practice and suggestions for further research are presented.

\section{Main findings}

PDs in late life is an understudied field (1), in which research initiatives are steadily growing, mainly focusing on the prevalence and assessment. Our literature review (chapter 2) confirmed the underexplored nature of this research area, as the number of (relevant) studies was limited. It revealed that PDs are prevalent in older adults, ranging from $10.6-57.8 \%$ depending on setting, and that there are now a handful of instruments available that are suitable for the assessment of PDs in late life. A number of these instruments is based on the DSM-5's alternative model of PDs, a hybrid dimensionalcategorical model that is more true to the nature of PDs than the prevailing categorica system, and therefore may hold a more realistic view on personality pathology (2) Moreover, there is initial evidence of treatment effectiveness, although more rigorous studies are clearly warranted. Besides these findings, our study revealed that the construct of PDs in late life might be not that clear or straightforward, which is obviously a downside of a young field. Conversely, one might argue that this holds opportunities as this underexplored research area deserves to blossom.
In order to determine whether the GPS was an adequate tool for detecting of PDs in older adults in general practice, various aspects were assessed.

The evaluation of the reliability and diagnostic accuracy of the self and informantreport versions of the GPS yielded diverse results (chapter 3 ). The GPS-pv showed limited internal consistency for the HAB subscale as well as for the total scale. Its testretest reliability, with an interval of one month, was strong. Unfortunately, there was no optimal cutoff score with both adequate sensitivity and specificity. For the informantreport version, both subscales were homogeneous, while the total scale had limited internal consistency. The test-retest reliability was good. For the GPS-iv, with a cutoff of $\geq 3,78 \%$ of the older adults with PDs will be identified as such while $65 \%$ of the non-cases will be classified accordingly. Based on its current psychometric properties; the informant version is preferred over the GPS self-report, and is an adequate tool for making an initial assessment of PDs in older adults in general practice.

With respect to the nomological network encompassing convergent validity (i.e. measures of theoretically-related constructs should be highly correlated) and discriminant validity (i.e. measures of theoretically less related constructs should be slightly correlated; chapter 4), both versions of the GPS showed similar correlation patterns to normative personality traits (as measured with the HAP) and psychopathology (as measured with the GDS, AUDIT and BSI). However, with respect to personality, the magnitude of the correlations was larger for the informant-report GPS than it was for the GPS-pv, which might be the results of shared method variance. There appeared to be meaningfully (positive) association with psychopathology, except for alcohol use disorders which showed small negative correlations. When linking the GPS to a new and promising empirical-based classification system, the Hierarchical Taxonomy of Psychopathology (HiTOP; ${ }^{3)}$ which conceptualizes psychopathology multiple dimensions organized into increasingly broad, transdiagnostic spectra the GPS corresponds the most to the P-factor, the somatoform spectrum and the internalizing spectrum. Conversely, the GPS seems to be less related to the HiTOP's externalizing spectra (both antagonistic and disinhibited). These findings are in line with previous research revealing a more atypical presentation of PDs in late life, with more internalizing and somatoform features ${ }^{(4)}$

As to self-informant concordance (i.e. the level of agreement between a person's self-appraisal and an informant's judgment on the same matter; chapter 5), the agreement between the GPS-pv and GPS-iv ranged from moderate (HAB scale) to high (BIO scale) with good agreement on the total GPS. When comparing both sources, informants reported significantly more pathology than the older adults did. The items HAB2 (He/she often worries about his/her health) and HAB5 $(\mathrm{He} / \mathrm{she}$ is often afraid of losing those who care for him/her, such as family members or his/ her partner) appeared to be less accessible to informants, which may be due to 
the intrapsychic nature of these items making this information less visible to others. Relational aspects such as relationship type and its quality were not associated with self-informant agreement when using the GPS. The level of congeniality (rated with a grade of 1-10) did seem to play a role in self-informant agreement; lower ratings on congeniality were associated with higher GPS-iv scores, implying more personality problems. The findings showed that self- and informant-report provide complementary perspectives.

In terms of feasibility and acceptability (chapter 6), both GPs and nurse practitioners (NPs; having higher vocational training in nursing or psychology, and working unde the supervision of the GP ${ }^{(5)}$ ) expressed that PDs in older adults is a relevant topic for general practice as recognition and management of these disorder is part of their job responsibilities for which they need resources. They were positive about their experiences with the GPS. Reported pros included having plain and short questions, having a clear and brief introduction as well as its' smooth and easy application Most professionals voiced that using the GPS went fast and could be completed during consultations. Using the GPS also increased awareness of PDs in older adults provided some surprising insights about some patients and triggered reflection. However, certain requirements, such as established diagnostic accuracy, a clear indication for use and having a contribution, would facilitate the use of the GPS in general practice. Education on PDs in older adults and how to use the GPS is needed as well prior its use. Furthermore, underlying study revealed that the professionals experienced some reluctance in asking the more intimate GPS items which seemed be the result of concerns about their own knowledge and expertise with these disorders. The majority of older adults and informants judged the GPS to have a good number of clearly phrased items, that were easy to understand, and mainly nonconfronting or not unpleasant to answer. Overall, the GPS appeared to be a feasible and acceptable instrument for detecting PDs in older adults in general practice which might be a first step in the assessment of PDs in late life. Using the GPS may lead to a more specified referral to specialized mental healthcare, where thorough assessment can be done resulting in a formal diagnosis and where various treatment options are available. However, educating professionals about PDs in late life as well as about the GPS is important prior using it in daily practice as it might increase the acceptability even more.

\section{Reflection on the main findings}

What is an acceptable reference standard?

One of the prerequisites when examining the concurrent validity of an instrument in another setting, is the availability of a gold standard, (i.e. a suitable criterion). However, a gold standard seldom exists ${ }^{(6-7)}$, particularly for mental disorders as these are latent, not direct measurable constructs. This is also the case for instruments assessing PDs, especially in late life since it is a challenging and underexplored field ${ }^{(1)}$. Moreover, it seems that the construct of PDs in late life hasn't been fully unraveled yet ${ }^{\left({ }^{8}\right)}$. In these instances, the decision what reference standard to use, is of major importance in the assessment of validity.

In contrary to the DSM criteria, PDs appear to be less stable in the course of life (9), and its manifestation in late life may differ compared to other life stages ${ }^{\left({ }^{(10}\right)}$. Ignoring the age-specific context in the assessment of PDs in older adults may therefore hamper its detection, and may negatively affect the validation of a new instrument. Barring this in mind, the HAP was chosen as reference criterion, as at that time, it was the only reliable and validated instrument addressing personality while being attentive to the aging process and environmental related changes ${ }^{(11)}$. In retrospect, our choice of using the HAP as a reference was even more empowered as a subsequent exper study showed that the HAP items were age neutral and adhered largely to the DSM-5 criteria for PDs ${ }^{122}$. However, unlike GPS, the HAP solely relies on informant-report which is not ideal for validating the self-report version of the GPS. Especially, since research repeatedly indicates that agreement between self- and informant-report in PD assessment is modest ${ }^{(13)}$.

Given the nature of our sample, formal PD diagnoses were not available and could therefore not be used as a reference. Alternative options for reference standards would be semi-structured and clinical interviews, which although considered the most robust, have an overall diagnostic accuracy of $71 \%{ }^{(14)}$. Examples of such instruments are the Structured Clinical Interview for DSM-IV Axis II Personality Disorders (SCIDII), Alcohol Use Disorder and Associated Disabilities Interview Schedule-DSMIV Version (AUDADIS-IV), and the Structured Interview for DSM-IV Personality (SIDP-IV) Another option is relying on questionnaires like the Assessment of DSM Personality disorders-IV (ADP-IV), and the Personality Disorders Questionnaire (PDQIV). Although, these interviews and questionnaires are commonly used in mental healthcare settings and/or research ${ }^{(8,15-16)}$, we judged them to be inappropriate for our study. First and foremost, these instruments are designed for adults and do not take the effects of aging into account. Besides, most of these instruments, although corroborated in various settings, haven't yet been validated in elderly populations. 
Also, these instruments, being based on the DSM-IV and addressing every single PD criterium, are likely to provide inadequate information as research points out that about $30 \%$ of the criteria incorporate measurement bias in late life ${ }^{(17-18)}$. Furthermore, these instruments can be quite straining and overwhelming for older adults, who often experience age-related dysfunctions, as they are rather lengthy (94-134 items), and its administration can take up to two hours ${ }^{(19)}$

In the absence of a gold standard, another alternative would be relying on a 'lead' standard, which stands for Longitudinal, Expert, All Data. This diagnostic model, which is indicated for complex mental disorders such as PDs, is commonly used in highly specialized mental healthcare for integrating information from multiple sources ${ }^{(20)}$. In this procedure various longitudinal information (i.e. clinical observations, and diagnostic conversations) is combined on which multiple experts will have to reach a consensus diagnosis. Even though diagnoses based on this procedure have more temporal and predictive stability compared to diagnoses based on semi-structured interviews (21), this procedure is very time-consuming and assigning the importance to each source of information is quite complex and not always unequivocal (22). Whilst the procedure has strength and opportunities, it was not feasible in the context of this research given the length, the complexity and the absence of appropriate data.

Considering all this, an acceptable reference criterion for PDs in late life, aside from a clinical diagnosis which is often not available, is preferably an age-specific or at leas an age-neutral instrument validated within these age group that has clear and simple items and is not too lengthy.

What is acceptable diagnostic accuracy for assessing PDs in older adults in general practice?

Criterion validity or the diagnostic accuracy of an instrument, that is the degree to which the scores of an instrument adequately reflects a gold standard (23), is often expressed in sensitivity and specificity ${ }^{(7)}$. Sensitivity is the ability of an instrument to correctly identify those with the condition (true positive rate), whereas instrument specificity is the ability of the instrument to correctly identify those without the condition (true negative rate; ${ }^{6}$ ). When the GPS would have perfect sensitivity, this indicates that the GP can be sure that all older adults with PDs will be correctly detected. When the GPS would reach perfect specificity, the GP can be confident that an older adult with a negative test result does not have a PD. Instruments with both $100 \%$ sensitivity and specificity, therefore being a genuine gold standard, hardly exist, and therefore classification errors occur. Often a compromise between sensitivity and specificity is required, by choosing a cutoff score which minimizes the occurrence of these errors (24). This can result in higher sensitivity at the expense of lower specificity and vice versa.
Whether an instrument is valid depends on its clinical purpose; conclusive criteria for determining sufficient validity are absent. Acceptable validity is subjective to the aim of the instrument, and the costs and benefits of correct and incorrect (either false positive or false negative) classifications ${ }^{(24)}$. The aim of the GPS is to facilitate the GP and/or NP with a first assessment tool in the detection of PDs in older adults. The choice between either high sensitivity or high specificity depends on, amongst others, the severity and the prevalence of PDs. As PDs are known to be highly impairing, affecting both the patient and his environment, healthcare utilization can be improved when older adults with PDs are correctly identified. One could argue that false negative results should be avoided where possible. Consequently, higher sensitivity with relatively lower specificity would be preferable. This would necessarily result in a higher number of false positives results. False positive results might be less problematic in the context of a first assessment, as in the second step (which will be corroborated in the implementation section) the professional could correct for the misclassification, whereby unnecessary classification and stigmatization can minimized. Furthermore, gaining more insight in one's personality (both adaptive and maladaptive traits) and interpersonal styles is valuable in light of patient-centered care as it helps the GP responding more attuned to the patient, thereby further improving the doctor-patient relationship.

In conclusion, given the detrimental effects that PDs have on the older adult himself, his loved one's and healthcare, an instrument used for a first assessment of PDs in late life in general practice should favor sensitivity over specificity to be acceptable. Consequently, the GPS is an acceptable instrument for a first assessment of PDs in older adults in general practice.

\section{Improving the GPS}

In the development of an instrument, the formulation of adequate items is a challenging task which is accompanied with recurrent item reformulations ${ }^{(25)}$. When going over some of the basic rules of item formulation ${ }^{(26)}$, the GPS items (see Table 1 for item content) show some potential for improvement.

Although professionals as well as older adults and informants judged the GPS items to be comprehensible and easy to understand (chapter 6), some items contain terms that have multiple meanings. Nine items out of the 16 items (HAB2 HAB3, HAB5, $\mathrm{HAB} 6, \mathrm{BIO} 1, \mathrm{BIO} 2, \mathrm{BIO} 4, \mathrm{BIO}$, and $\mathrm{BIO}$ ) use such highly subjective and debatable terms as 'often', 'sometimes', 'vague', 'at important times', ' a lot', 'not very interested', which may be interpreted differently by respondents, and thereby potentially creating bias. Also, in older adults, more specifically those with limited formal education, this might be even more tricky, as they are often less familiar with testing and may be more reluctant in responding ${ }^{(27)}$. Consequently, these items might be improved by specifying 
these terms more clearly. The challenge, however, will be to formulate tangible items, while keeping them as concise as possible to remain comprehensible to the target population irrespective of their level of education and without adding too many items to the questionnaire, as its brevity is one of its strengths.

When formulating items, it is also important to avoid items with multiple questions, as it may cause confusion for the respondent. As such $\mathrm{BIO} 4$ addresses multiple feelings (nervousness, stress, sadness) at once, which might make it hard to respond to this item when only one or two of these feelings resonates to the older adult or informant. It might therefore be more appropriate to break this item down in three items.

Furthermore, items containing negative wording are known to complicate respondence ${ }^{(26)}$. For example, item $\mathrm{BIO}$ (In his/her life, he/she has not been very interested in sexual contact) might therefore be harder to answer, which parallels the professionals' experience when addressing this item. They had the impression that the item was not always understood correctly and believed that it was (due to negative wording) too 'modestly/cautiously' formulated. Hence, this item might amend from reformulation avoiding negative wording.

Aside from these basic rules of item formulation, interviewing the professionals (chapter 6 ) as well as being highly involved in data collection, provided valuable insight which may enhance the GPS (even more). Some GPs noticed, while using the GPS, that one item in particular seemed to be difficult for older adults when they were the one who asked it. When addressing $\mathrm{BIO1}$, a number of older adults felt hesitant to answer and replied that the GP should answer this question while he, as being their GP for many years, would have a better view. HAB5 also appeared to be troublesome some older adults, as they felt it was not applicable any more since they lost (many) their loved ones already. Multiple participating professionals suggested that the (use of the) GPS would benefit from changing the order of the BIO subscale a little, so that $\mathrm{BIO} 2$ and $\mathrm{BIO} 6$ will be subsequent questions, given their similar content. In the current order, the difference of the two items was not always clear as older adults commonly reacted that $\mathrm{BIO} 6$ was a duplicate question. Furthermore, some GPs stated that this 'interruption' felt somewhat odd. When these items would succeed each other, the distinction might be more apparent and the sequence might be more logical thereby having a more natural flow.

Although the above described suggestions could improve the GPS, research is necessary to establish whether this is the case.
Table 1. Items of the Gerontological Personality disorders Scale (GPS)

\begin{tabular}{|c|c|c|c|}
\hline & The Gerontological Personality disorders Scale-informant version (GPS-iv) & Yes & No \\
\hline & \multicolumn{3}{|l|}{ Habitual behavior } \\
\hline 1 & He/she doesn't like growing older because he/she become less attractive & 1 & 0 \\
\hline 2 & He/she often worries about his/her health & 1 & 0 \\
\hline 3 & He/she is often concerned about his/her memory & 1 & 0 \\
\hline 4 & He/she hopes that others solve his/her problems & 1 & 0 \\
\hline 5 & $\begin{array}{l}\text { He/she often afraid of losing those who care for him/her, such as members of the } \\
\text { family or his/her partner }\end{array}$ & 1 & 0 \\
\hline \multirow[t]{3}{*}{6} & He/she is often taken advantage of by others & 1 & 0 \\
\hline & He/she finds it difficult to fend for his/herself & 1 & 0 \\
\hline & Biographical information & & \\
\hline & In his/her life he/she has been to see the doctor for many vague physical complaints & 1 & 0 \\
\hline 2 & $\begin{array}{l}\text { He/she has sometimes said to his/her family or friends that he/she doesn't want to } \\
\text { live any longer }\end{array}$ & 1 & 0 \\
\hline 3 & In the past he/she has been admitted to a psychiatric institution because of nerves & 1 & 0 \\
\hline & $\begin{array}{l}\text { At important times in his/her life he/she experienced high levels of nervousness, stress } \\
\text { or sadness }\end{array}$ & 1 & 0 \\
\hline 5 & In the past he/she has already had treatment from a psychiatrist or psychologist & 1 & 0 \\
\hline & He/she has sometimes tried to end his/her life & 1 & 0 \\
\hline & At the most he/she has only had 1 acquaintance or friend in his/her life & 1 & 0 \\
\hline 0 & In his/her life he/she has not been very interested in sexual contact & 1 & 0 \\
\hline & In the past he/she has often taken tranquilizers and/or sleeping pills & 1 & 0 \\
\hline
\end{tabular}

Implementation in general practice

While the GPS may assist in the detection PDs in late life (chapter 3), and seems sensitive to internalizing and somatoform (PD) features in particular (chapter 4), it is not self-implementing. There is not one ideal strategy for implementing an innovation in general practice, as a variety of factors and barriers are involved in the change process and both professionals and practices may differ with respect to experience, learning styles, and needs (28). A number of instrument features, as well as characteristics of patients and professionals applying it, which are believed to contribute to successful ${ }^{(28-29)}$, were explored, yielding the GPS to be feasible and acceptable within this setting (chapter 6). Although we didn't perform an implementation study, we do, however, have some suggestions (be)for(e) using the GPS in general practice.

Although the interviewed professionals were favorable about the characteristics of the GPS, had a positive attitude toward (their role in) detecting PDs in older adults, and expressed the need for resources for both detecting and dealing with these disorders in their elderly patients, they commented that certain preconditions would facilitate the use of the GPS. First and foremost, professionals stated that prior using the GPS, it's reliability and validity should be established within general practice. This precondition has been addressed. For now, based on the current psychometric properties (chapter 
3), we recommend that the professional when using the GPS outweighs the score of the GPS-iv over the GPS-pv; the score of the GPS-iv should be decisive. However a critical comment is in place, as the informant-based reference criterion is likely to have negatively affected the evaluation of the GPS-pv's accuracy. As, for now, the informant-report version is preferred, it might ask for a little different approach to which GPs and NPs may be accustomed to when addressing mental issues, namely including an informant instead of solely relying on the patient. However, an informantbased approach may be particularly suited within this setting, since at least GPs often provide health care to the entire family and/or caregivers which are potential informants. Furthermore with respect to certain disorders such as dementia, using collatera information is already common ground, as is the case in general practice ${ }^{(30)}$.

Another point that the GPs and NPs raised, was that having a clear indication to when to use the GPS would facilitate its implementation. In our view, the GPS should be considered to corroborate the professionals' gut feeling. It should therefore be employing strategically, as routine screening for PDs in general practice is not recommended ${ }^{(31)}$. These gut feelings might be triggered by excessive GP visits and care demands, non-compliance, an overly dependent attitude, (excessively) demanding specific or special treatment that is not necessary, resistance and premature termination of (medical) treatment, (chronic) treatment-resistant symptoms, multiple interpersonal conflicts, troubled doctor-patients relationship, heartsink feelings, as these are all (but not exhaustive) potential signs of underlying personality pathology (31-34). These signs could therefore serve as a kind of guideline with which to use the GPS.

A last recommendation concerns education. Our feasibility study (chapter 6 ) revealed that all professionals experienced some reluctance when addressing the more intimate GPS items regarding verbalized suicide ideation, suicide attempt and hyposexuality, while older adults and informants didn't seem to mind these. This disinclination presumably stems of their concerns about their own knowledge and expertise in the field, which are commonly reported barriers in discussing sensitive topics ${ }^{\left({ }^{35}\right)}$. Educating the professionals about PDs in later life, and providing handson experience with the GPS as well as training sessions addressing communication techniques including normalizing, being transparent and asking permission ${ }^{(36)}$ are therefore recommended as it builds their knowledge and may boost their confidence in addressing the sensitive GPS items. The hands-one sessions with the GPS should include: practicing with the instrument, information about its indication for use as well as potential signs to be attentive of. Furthermore, another aspect that should be addressed is how to introduce the instrument and some items as it may circumvent that the informant is caught off guard by the content of the items. On a more fundamental level, all healthcare professionals working with older adults would benefit if PDs in later life would have a more pronounced position in medical curricula and training programs.

\section{Methodological considerations}

The findings of the studies presented in this dissertation need to be interpreted in the context of some methodological considerations. This section addresses general methodological issues, since study-specific strengths and limitations have already been discussed in the preceding chapters.

Strengths

This is one of the first studies to explore an age-specific instrument for detecting PDs in older adults with both a self and informant-report version in general practice. First of all, the setting of this study, i.e. general practice, makes the study unique and particularly valuable, as tools for the recognition of PDs in older adults are known to be scarce (37) and were completely absent within this setting. Also, research on PDs in older adults in general practice is virtually nil. One of the tasks of the GP, who plays a central role in (Dutch) healthcare, is to identify physical and mental health problems, and therefore PDs, at an early stage. A lack of instruments makes detection of PDs, especially in older adults, quite difficult. PDs can easily be overlooked or misinterpreted, as patients may not ask for help, and are likely to be unaware of the origins of their problems and the effect of their behavior on others. In combination with multimorbidity whether or not with polypharmacy ${ }^{(38)}$, and a less prototypical expression $(4,10)$, the absence of instruments severely complicates recognition. Hence, resources are urgently needed. The GPS is a first PD tool, adequate for general practice.

Secondly, evaluating an age-specific instrument in the assessment of PDs in late life is a strength. Having an instrument that is attentive to the aging context is of importance as it may objectify PDs in older adults more adequately by accounting for the atypical manifestations of traits, as is thought to be the case in late life $(4,10)$. Furthermore, the necessity of using multiple methods, including both self and informant-report in assessing PDs becomes more and more apparent ${ }^{(13)}$. PDs are not seldomly accompanied by a poor self-sense ${ }^{(39)}$, little understanding of one own's internal state ${ }^{(40)}$, and a limited awareness of the effect of their behavior on others ${ }^{(41)}$. Distorted cognitions, one of the hallmarks of a PD ${ }^{(42)}$, might also impair accurate self-report, as well as the tendency for individuals to be driven to present themselves excessively positive or negative ${ }^{(43)}$. In late life, cognitive impairments but also test characteristics such as a large number of items, their complexity due to abstract language, cluttered lay-out and the use of small font ${ }^{(44)}$, may further comprise self-report. A more valid view 
on PD symptoms might be retrieved from including information from family members, friend and/or acquaintances as well ${ }^{(13)}$. The GPS-iv can be used to get an informant's perspective.

Thirdly, another strength was the quite large number of included older adults and informants in our research compared to other studies using the same instrument ${ }^{(45)}$ or focusing on similar populations and setting ${ }^{(46-47)}$ in the field of test validation. The sample size (ranging from $\mathrm{N}=604$ to $\mathrm{N}=658$ of which half were older adults and half were informants) is even more commendable as recruitment of older adults in research is known to be challenging ${ }^{(48)}$

Fourthly, a more overarching strength of this dissertation concerns the careful and in-depth evaluation of the GPS with respect to both its psychometric properties as well as it practical use. By exploring the GPS's internal consistency, test-retest-reliability, diagnostic accuracy, convergent validity, discriminant validity, self-informant agreement and combining it with an examination of its feasibility and acceptability, this dissertation provides a comprehensive overview of this instrument in general practice. It offers a clinically useful and easy-to-use measure for a setting where no alternatives are available.

Lastly, the dissertation draws attention to an important and relatively young field of research, PDs in late life, in a setting in which this is completely virgin territory.

\section{Limitations}

Although one of the strengths of our research was the rather large sample size participant enrollment endured a high non-response, as only $11.7 \%$ of all 3,518 approached older adults, consented to participate. This might be the result of socalled research fatigue. At the time of recruitment, multiple other studies with the same target population with respect to age as ours started as well, thereby appealing to the same general practices and older adults. As the grant supporting our research was region-specific, it wasn't possible to recruit elsewhere.

Given the low response rate, the study population's representativeness is at risk Besides, the participants were overall the young-old to middle-old adults $(30.2 \% 60-64$ yrs., $39.7 \% 65-74$ yrs., $26.4 \% 75-84$ yrs., and $3.7 \% \geq 85$ yrs.). As we did not explore the reasons for the non-respondence, selection bias can't be ruled out. However we do believe that our sample was quite representative of the target population. The prevalence of PDs in our studies ranged for $15.0-17.3 \%$, which is slightly higher than the rates found in the general older adult population ${ }^{(8)}$. However, those studies predominantly used non-age specific or non-age neutral instruments, which may have resulted in underestimated prevalence rates ${ }^{(18)}$. Alternatively, the higher prevalence rates in our studies could also be the result of using an informant-based reference criterion, as this perspective often reveals more pathology than self-report or clinica judgement does ${ }^{(49)}$

Low response rates might bias results, as non-respondents might differ from respondents with respect to essential characteristics ${ }^{(48)}$. The study of Rockwood (50) showed, that non-respondents, especially those of 85 years and older, used significantly more medical services than participants, and had a higher number of hospital admissions. Reasoning from these finding, it could be that the nonrespondents in our research were the ones with PD pathology, as PDs are related to increased healthcare consumption and use of medical resources ${ }^{(51-53)}$. Furthermore individuals with maladaptive personality traits such as suspiciousness, and a lack of interest in interpersonal contact (cluster $\mathrm{A}$ and $\mathrm{C}$ ) are likely to refuse to cooperate with research studies ${ }^{(4)}$. On the other hand, other types of PDs thrive on attention (cluster $\mathrm{B})$ and older adults with such pathology might be therefore more willing to participate in scientific research.

Aside from age and PD features, other factors in our research might explain why potential eligible participants declined participation. Most importantly, PDs being the topic of research, might have been a barrier in participating, as disclosing about one's personality might be intimidating because PDs are still stigmatizing disorders ${ }^{(54)}$. In order to minimize this factor, we avoided where possible the term 'PD' and 'personality pathology' in the written information included in the invitation and used 'personality characteristics' instead. However, it was impossible to completely circumvent these terms as the GPS itself contains the term PD.

Another limitation pertains to the internal consistency of the GPS. The HAB scale of the GPS-pv and the total scale of both GPS versions lack sufficient internal consistency, which does not seem to be specific to our population, as studies using the GPS in geropsychiatric inpatients ${ }^{(55)}$ and geriatric medicine outpatients ${ }^{(45)}$ reveal limited homogeneity as well. A first plausible explanation might be that it is a demonstration of the tension between the abstract and multi-faceted nature of the PD construct on the one hand, and the aim of constructing a brief and feasible instrument that, given the target population, is as little constraining as possible on the other hand.

A second explanation relates to the type of measurement model. The construct of PDs is non-observable and can therefore not be measured directly. Such a construct consists of latent variables ${ }^{\left({ }^{56}\right)}$. How these variables will be measured depends on conceptual framework, and the ensuing model being either reflective or formative ${ }^{(57)}$. In case of the GPS, it might be that a formative approach has been chosen. In a formative model, the construct (in this case PDs in late life) is the result of the presented items. Hence, each item contributes a part of the construct, and together the items form the 
whole construct. Consequently, the items do not necessarily correlate with each other, which is the case for the HAB subscale. Furthermore, for multi-item instruments based on a formative model, there are no well-known measurement theories, which doesn't imply that there is no theory at all underlying formative models, but rather that the theories are less well developed ${ }^{(58)}$.This might apply to PDs in late life as it is a rather young and underexplored field ${ }^{(1)}$.

It is interesting nonetheless that although $\mathrm{HAB}$ and $\mathrm{BIO}$ are both small subscales consisting respectively of seven and nine items, the latter consistently proves to be more coherent and doesn't have internal consistency issues. One might argue that the above described tension and model choice would be applicable to both subscales. In that line of reasoning, both subscales would be likely to have either good or limited homogeneity. Perhaps how both scales were constructed might explain this contrast. The GPS is constructed out of an item pool consisting of 52 items based literature review, case-studies and expert opinion via a Delphi-study ${ }^{(60)}$, which ultimately resulted in the 16-item version with two subscales used in this dissertation. In the tables of their article, van Alphen and colleagues ${ }^{(59)}$ reported to which DSM-IV-TR PD criteria (i.e. $A, B, C$, or general criteria) the items adhere. For the HAB scale, one item belongs to cluster $A$ (HAB6), one to cluster $B$ (HAB1), one to both cluster $B$ and $C$ (HAB2), and 4 items address cluster $C$ (HAB3, HAB4, HAB5, and HAB7). The items of the $B I O$ scale reveal a less fragmented composition; one item addresses cluster $A(B \mid O 8)$, one cluster $\mathrm{B}(\mathrm{BIO} 2)$, one to both cluster $\mathrm{B}$ and $\mathrm{C}(\mathrm{BIO} 1)$, and the remaining 6 items adhere to the general criteria of $\mathrm{PDs}(\mathrm{BIO} 3, \mathrm{BIO} 4, \mathrm{BIO} 5, \mathrm{BIO}$, $\mathrm{BIO}$, and $\mathrm{BIO}$ ). With the majority of the $\mathrm{BIO}$ items tapping to the general criteria, which probably form more one whole than a compilation of various cluster-specific criteria, this might explain the contrast in internal consistency between the GPS subscales.

\section{Implications for general practice}

Several overall implications of the studies presented in this dissertation are notable. On a fundamental level, this dissertation contributes to the available knowledge base addressing PDs in older adults. It reveals that PDs in late life is a research field in its infancy, especially in general practice were both research and resources for recognizing and managing these disorders in elderly patients are lacking.

The GPS offers the GP and NP a tool that facilitates and marks the start for PD assessment in general practice, which improves the detection of PDs in elderly patients. Using the GPS may assist in attenuating the GPs and/or NPs frustration by recognizing PDs and increasing understanding of the elderly patient, and thereby explaining issues such as non-response to treatment or difficulty engaging in otherwise "straightforward" self-management ${ }^{(60)}$. Detecting PDs in his elderly patients by using the GPS, enables the professional to adjust his interpersonal style to the needs of their patient, which may restore and improve the doctor-patient relationship thereby possibly preventing issues as non-compliance and premature treatment termination.

Besides, it allows the professional to spend less time assessing and excluding cases, and it enables more cost-effective referrals to specialists when necessary (61) or by consulting a specialized (mental) healthcare professional in general practice (socalled 'anderhalvelijnszorg'). In this consultation, PD assessment can be continued leading to guidelines for the GP and/or NP in dealing with the maladaptive behavio of the older adult. Depending on whether (severe) personality pathology is present as well as whether there is a demand for care (stemming from the either the elderly patient or others), referral to specialized mental healthcare is possible where thorough assessment can be executed leading to a formal diagnosis which informs treatment options (i.e. personality-changing treatment, adaptation-enhancing treatment, and supporting-structuring treatment; ${ }^{62}$. These referrals can be more specified by including GPS scores which might further increase the collaboration between general practice and specialized mental healthcare settings.

Summarizing, the GPS supports the professional by 1) aiding in the recognition of a potential PD, 2) initiating further personality assessment leading to strategies to optimize interpersonal contact with the patient, and 3) enabling a more precise referral to mental healthcare

\section{Further research}

As discussed in chapter 1, research addressing PDs in late life in general practice is very scant. Consequently, this un(der)explored area holds countless research opportunities. Based on the studies in this dissertation, we suggest the research initiatives as discussed below.

Using an informant-based reference criterion to validate a self-report measure is far from ideal. It is therefore likely that this has negatively impacted our findings of the GPS-pv. Since the start of our study, when there were no suitable self-report reference instruments, the amount of research addressing the assessment of PDs in late life grew steadily, resulting in multiple validated and age neutral personality measures for older adults $(55,63-65)$. Potential self-report reference instruments for validating the GPS-pv could be the Assessment of DSM-IV Personality Disorders (ADP-IV; ${ }^{66)}$, addressing the symptoms of the DSM-IV PDs criteria, or the Severity Indices of Personality Problems-Short Form (SIPP-SF; ${ }^{67}$ ), assessing core domains of 
(mal)adaptive personality functioning (criterion A) according the DSM-5's alternative model of PD which is the counterpart of DSM's general criteria for PDs. We therefore suggest investigating the diagnostic accuracy of the GPS-pv while using either of these instruments as a reference criterion.

Our study showed that the GPS is an adequate, feasible an acceptable instrument for making a first step in assessing PDs in late life in general practice, however it may benefit from adjusting some items as we discussed earlier in this chapter. Further research should address whether these suggested adjustments do indeed improve the instrument.

We believe that using the GPS in general practice could improve patient care. However, research should be conducted on how to implement or position the GPS in the assessment of PDs in late life starting in general practice. One way could be by adopting a stepped approach for detecting PDs in older adults. Research is necessary to develop such an approach and to examine whether this is feasible and (cost-)effective.

Aside from instruments in aiding in the detection of PDs in late life in genera practice, professionals also voiced the need for resources in managing elderly patients with such pathology. The Cognitive Model for Behavioral Interventions (CoMBI; ${ }^{68)}$, which is specifically developed for managing older adults with PDs, might be a an appropriate tool for dealing PDs in general practice too. This model is based on the assumption that as the patient's core needs remain unfulfilled because of a triggering event, both his maladaptive self-image and perceptions of others will be confirmed, resulting in problematic behavior. However, by anticipating the patient's core needs, the triggering event can be circumvented, and the problematic behavior will decrease. It would be worthwhile to explore the potential of the CoMBI within general practice.

\section{Case description Mr. Johnson}

Let's go back to the case of Mr. Johnson, presented in the general introduction (chapter 1). What could be the impact of using the GPS in doctor Petersen's general practice? While reflecting on his relationship with Mr. Johnson, doctor Petersen noticed recurring interpersonal conflicts and his heartsink feelings. As his relationship with Mr. Johnson was troublesome for a long time, he decided to check his gut feeling of PD problems by using the GPS during the next consultation (for which he asked Mr. Johnson to bring his spouse). Six of the 16 GPS-iv items (HAB2, HAB4, HAB5, BIO5, BIO7, and $\mathrm{BIO9}$ ) were answered confirmatory, suggesting the presence of PD. Based on this score, doctor Peterson asked for a consult with a mental healthcare professional (by means of 'anderhalvelijnszorg'). This consultation revealed that the HAP scores were indicative of obsessive-compulsive PD with schizoid and paranoid traits, which therefore was used as a preliminary or working diagnosis. The HAP profile revealed $\mathrm{Mr}$ Johnson's strong need for recognition, clear interpersonal boundaries, predictability the opportunity to control the situation, self-determination and receiving clear and unambiguous information, which could be used in drafting guidelines informing interpersonal contact.

Next, the CoMBI model, which can be used with both PDs or maladaptive traits, could be employed to further manage the obsessive-compulsive PD behavior of Mr. Johnson. According to this model Mr. Johnson's sees himself a responsible and independent man, while viewing others as irresponsible, incompetent and intrusive. His urge to control the situation is triggered by uncontrollability and failure (such as doctor Petersen's denial of his request to change medication), as his core needs are autonomy and avoiding failure.

The consultation resulted in the following guidelines for doctor Petersen when dealing with Mr. Johnson's behavior 1) give him as much control as possible, 2) include him in the process of decision making/encourage patient participation in treatment 3) provide thorough explanations, and 4) be punctual and polite while being attentive to practical matters. 


\section{References}

1. Oltmanns TF, Balsis SMA. Personality disorders in later life: Questions abou measurement, course, and impact of disorders. Annual Review of Clinical Psychology. 2011;7:321-49.

2. Krueger RF, Markon KE. The role of the DSM-5 personality trait model in moving toward a quantitative and empirically based approach to classifying personality and psychopathology. Annual Review of Clinical Psychology. 2014;10:477-501.

3. Kotov R, Krueger RF, Watson D, Achenbach TM, Althoff RR, Bagby RM, et al. The Hierarchical Taxonomy of Psychopathology (HiTOP): A dimensional alternative to traditional nosologies. Journal of Abnormak Psychology. 2017;126(4):454-77.

4. Agronin ME, Maletta G. Personality disorders in late life: Understanding and overcoming the gap in research. American Journal of Geriatric Psychiatry. 2000;8(1):4-18.

5. Magnée T, de Beurs DP, de Bakker DH, Verhaak PF. Consultations in general practices with and without mental health nurses: An observational study from 2010 to 2014. BM Open. 2016;6:1-10.

6. Knottnerus JA, van Weel C, Muris JWM. Evaluation of diagnostic procedures. British Medical Journal. 2002;324:477-80.

7. De Vet HCW, Terwee CB, Mokkink LB, Knol DL. Validity. Measurement in medicine: A practical guide to biostatistics and epidemiology. New York: Cambridge University Press: 2011. p. 150-201.

8. Penders KAP, Peeters IGP, Metsemakers JFM, van Alphen SPJ. Personality disorders in older adults: A review of epidemiology, assessment, and treatment. Current Psychiatry Reports. 2020;22:1-14.

9. Penders KAP, Dierickx S, Steenhaut P, Dierckx E, Rossi G. Persoonlijkheidsstoornissen bij ouderen: Epidemiologische aspecten. Tijdschrift voor Gerontologie en Geriatrie. 2020;51(2):1-26.

10. Mroczek DK, Hurt SW, Berman WH. Conceptual and methodological issues in the assessment of personality disorders in older adults. In: Rosowsky E, Abrams RC, Zweig RA, editors. Personality disorders in older adults: Emerging issues in diagnosis and treatment. Mahwah, NJ: Erlbaum; 1999. p. 135-52.

11. Barendse H, Thissen AJC, Oei TI, Rossi G, van Alphen SPJ. Psychometric proporties of an informant personality questionnaire (the HAP) in a sample of older adults in the Netherlands and Belgium. Aging and Mental Health. 2013;17(5):623-9.

12. Barendse H, Rossi G, van Alphen SPJ. Personality disorders in older adults: Exper opinion as a first step toward evaluating the criterion validity of an informant questionnaire (HAP). International Psychogeriatrics. 2014;26(1):173-4

13. Klonsky ED, Oltmanns TF, Turkheimer E. Informant-reports of personality disorder: Relation to self-reports and future research directions. Clinical Psychology Science and Practice. 2002;9:300-11
14. Tyrer $\mathrm{P}$, Coombs N, Ibrahimi F, Mathilakath $\mathrm{A}$, Bajaj $\mathrm{P}$, Ranger $\mathrm{M}$, et al. Critical developments in the assessment of personality disorder. The British Journal of Psychiatry. 2007;190(49):S51-S9.

15. Widiger TA, Samuel DB. Evidence-based assessment of personality disorders. Psychological Assessment. 2005;17:278-87.

16. van Dijk SDM, Derksen JJL, Bouckaert F, van Alphen SPJ. Descriptive en structurele diagnostiek. In van Alphen SPJ, Oude Voshaar, R C, Bouckaert, F \& Videler, A C, editor. Handboek persoonlijkheidsstoornissen bij ouderen. Utrecht: De Tijdstroom; 2018.

17. Balsis S, Gleason MEJ, Woods CM, Oltmanns TF. An item response theory analysis of DSM-IV personality disorder criteria across younger and older age groups. Psychology and Aging. 2007;22(1):171-85.

18. Balsis SMA, Woods CM, Gleason MEJ, Oltmanns TF. Overdiagnosis and underdiagnosis of personality disorders in older adults. American Journal of Geriatric Psychiatry. 2007; 15:742-53

19. Beatson J, Broadbear JH, Sivakumaran H, George K, Kotler E, Moss F, et al. Missed diagnosis: The emerging crisis of borderline personality disorder in older people. The Australian and New Zealand Journal of Psychiatry. 2016;50(12):1139-45.

20. Spitzer C. Psychiatric diagnosis: Are clinicians still necessary? Comprehensive Psychiatry. 1983;24:399-411.

21. Verheul R, van den Brink W, Spinhoven P, Haringsma R. Richtlijnen voor klinische diagnostiek van DSM-IV persoonlijkheidsstoornissen. Tijdschrift voor Psychiatrie. 2000;42:409-22.

22. Verheul R, van den Brink W. Persoonlijkheidsstoornissen. In: Ormel J, van den Brink, W, Wiersma, D, editor. Leerboek psychiatrische epidemiologie. Utrecht: de Tijdstroom; 1999 p. 347-78.

23. Mokkink LB, Terwee CB, Patrick DL, Alonso J, Stratford PW, Knol DL, et al. The COSMIN study reached international consensus on taxonomy, terminology, and definitions of measurement properties for health-related patient-reported outcomes. Journal of Clinical Epidemiology. 2010;63:737-45.

24. Smits N, Smit F, Cuijpers P, de Graaf R. Using decision theory to derive optimal cutoff scores of screening instruments: An illustration explicating costs and benefits of mental health screening. International Journal of Methods in Psychiatric Research. 2007;16(4):219-29

25. De Vet HCW, Terwee CB, Mokkink LB, Knol DL. Development of a measurement instrument. Measurement in medicine: Practical guides to biostatistics and epidemiology. New York: Cambridge University Press; 2011. p. 30-64.

26. Bradburn N, Sudman S, Wansink B. Asking questions: The definitive guide to questionnaire design - for market research, political polls, and social and health questionnaires. Revised edition. San Fransico: Jossey-Bass, A Wiley Imprint; 2004.

27. APA Working Group on the Older Adults. What practitioners should know about workin with older adults. Professional Psychology: Research and Practice. 1998;29(5):413-27.

28. Grol R. Implementing guidelines in general practice care. International Journal for Quality in Health Care 1992:1(3):184-91. 
29. Wensing M, Bosch M, Grol R. Developing and selecting interventions for translating knowledge to action. Canadian Medical Association Journal. 2010;182(2):E85-E8.

30. Harrison JK, Fearon P, Noel-Storr AH, McShane R, Stott DJ, Quinn TJ. Informant questionnaire on cognitive decline in the elderly (iqcode) for the diagnosis of dementia within a general practice (primary care) setting. Cochrane Database Systematic Reviews. 2014(7).

31. Combs G, Oshman L. Pearls for working with people who have personality disorder diagnoses. Primary Care. 2016;43(2):263-8.

32. van Alphen SPJ, Derksen JLL, Sadavoy J, Rosowsky E. Features and challenges of personality disorders in late life. Aging and Mental Health. 2012;16(7):805-10.

33. Schafer S, Nowlis D. Personality disorders among difficult patients. Archives of Family Medicine. 1998;7:126-9

34. Huprich SK. Personality pathology in primary care: Ongoing needs for detection and intervention. Journal of Clinical Psychology in Medical Settings. 2018;25(1):43-54.

35. Hordern A, Street A. Communicating about patient sexuality and intimacy after cancer: Mismatched expectations and unmet needs. Medical Journal of Australia. 2007;186:224-7.

36. McBride R. Talking to patients about sensitive topics: Techniques for increasing the reliability of patient self-report [handout]. Medical School and Residency Program Curriculum Resources on drug abuse and addiction; The University of North Dakota, School of Medicine \& Health Sciences2010.

37. Rossi G, van den Broeck J, Dierckx E, Segal D, van Alphen SPJ. Personality assessment among older adults: The value of personality questionnaires unraveled. Aging and Mental Health. 2014;18(8):936-40

38. Junius-Walker U, Theile G, Hummers-Pradier E. Prevalence and predictors of polypharmacy among older primary care patients in Germany. Family Practice. 2007;24:14-9.

39. Linehan MM. Cognitive behavioral teatment of borderline personality disorder. New York, NY: Guilford Press; 1993.

40. Ebner-Priemer UW, Kuo J, Schlotz W, Kleindienst N, Rosenthal MZ, Detterer L, et al. Distress and affective dysregulation in patients with borderline personality disorder: A psychophysiological ambulatory monitoring study, the Journal of Nervous and Mental psychophysiological ambulatory

41. Carlson EN, Oltmanns TF. The role of metaperception in personality disorders: Do people with personality problems know how others experience their personality? Journal of Personality Disorders. 2015;29(4):449-67.

42. American Psychiatric Association. Diagnostic and statistical manual of mental disorders. $5^{\text {th }}$ ed. Arlington, VA: American Psychiatric Publishing; 2013.

43. Balsis S, Loehle-Conger E, Busch AJ, Ungredda T, Oltmanns TF. Self and informant report across the borderline personality disorders spectrum. Personality Disorders: Theory, Research, and Treatment. 2018;9(5):429-36.
44. van Alphen SPJ, Dijk v, S, Videler AC, Rossi G, Dierckx E, Bouckaert F, et al. Personality disorders in older adults: Emerging research issues. Current Psychiatric Reports. 2015;17:538-45.

45. Meeuwissen-van Pol E, Rossi G, De Weerd-Spaetgens C, van Alphen SPJ. Screening of personality disorders in a geriatric medicine population. European Geriatric Medicine. 2020;11:289-95.

46. Arthur A, Jagger C, Lindesay J, Clarke M. Using an annual over- 75 health check to screen for depression: Validation of the short Geriatric Depression Scale (GDS15) within genera practice. International Journal of Geriatric Psychiatry. 1999;14(6):431-9.

47. Pirani A, Brodaty $\mathrm{H}$, Martini E, Zaccherini D, Neviani F, Neri M. The validation of the Italian version of the GPCOG (GPCOG IT): A contribution to cross-national implementation 2010;22(1):82-90

48. Gregson BA, Smith M, Lecouturier J, Rousseau N, Rodgers H, Bond J. Issues of recruitment and maintaining high response rates in a longitudinal study of older hospital patients in england-pathways to care study. Journal of Epidemiology and Community patients in england-pathways.

49. Oltmanns TF, Rodrigues MM, Weinstein Y, Gleason MEJ. Prevalence of personality disorders at midlife in a community sample: Disorders and symptoms reflected in interview, self, and informant reports. Journal of Psychopathology and Behavioral Assessment. 2014;36:177-88.

50. Rockwood K, Stolee P, Robertson D, Shillington ER. Response bias in a health status survey of elderly people. Age and Ageing. 1989;18(3):177-82.

51. Powers A, Strube MJ, Oltmanns TF. Personality pathology and increased use of medica resources in later adulthood. American Journal of Geriatric Psychiatry. 2014:22(12):147886.

52. Lawton EM, Oltmanns TF. Personality pathology and mental health treatment seeking in a community sample of older adults. Personality and Mental Health. 2013;7(3):203-12.

53. Twomey CD, Baldwin DS, Hopfe M, Cieza A. A systematic review of the predictor of health service utilisation by adults with mental disorders in the UK. BMJ Open. 2015;5:e007575.

54. Sheehan L, Nieweglowski K, Corrigan P. The stigma of personality disorders. Current Psychiatry Reports. 2016;18:1-7.

55. Debast I, Rossi G, van Alphen SPJ. Age-neutrality of a brief assessment of the section III alternative model for personality disorders in older adults. Assessment. 2018:1-14.

56. Spirtes P. Latent structure and causal variables. International Encyclopedia of the Social \& Behavioral Sciences. 2001:8395-400

57. de Vet HCW, Terwee CB, Mokkink LB, Knol DL. Concepts, theories and models, and types of measurements Measurement in medicine: Practical guides to biostatistics and epidemiology. New York: Cambridge University Press; 2011. p. 7-29.

58. Edwards JR, Bagozzi RP. On the nature and direction of relationships between constructs and measures. Psychological Methods. 2000;5(2):155-74. 
59. van Alphen SPJ, Engelen GJJA, Kuin Y, Hoijtink HJA, Derksen JJL. Constructie van een schaal voor de signalering van persoonlijkheidsstoornissen bij ouderen. Tijdschrift voor Gerontologie en Geriatrie. 2004;35(5):186-95.

60. Devens M. Personality disorders. Primary Care. 2007;34:623-40.

61. Ferrer RL, Hambidge SJ, Maly RC. The essential role of generalists in health care systems. Annals of Internal Medicine. 2005;142(8):691-9.

62. Videler AC, Van der Feltz-Cornelis CM, Rossi G, van Royen RJJ, Rosowsky E, van Alphen SPJ. Psychotherapeutic treatment levels for personality disorders in older adults. Clinica Gerontologist. 2015;38(4):325-41.

63. Debast I, Rossi G, van Alphen SPJ, Pauwels E, Claes L, Dierckx E, et al. Age neutraility of categorically and dimensionally measured DSM- 5 section II personality disorder symptoms. Journal of Personality Assessmenty. 2015;97(4):321-9.

64. Debast I, Rossi G, van Alphen SPJ. Construct validity of the DSM- 5 section III maladaptive trait domains in older adults. Journal of Personality Disorders. 2017;31(5):671-88.

65. Rossi G, Debast I, van Alphen SPJ. Measuring personality functioning in older adults; construct validity of the Severity Indices of Personality Problems-Short Form (SIPP-SF) Aging and Mental Health. 2017;21(7):703-7-11.

66. Schotte CKW, de Doncker D. ADP-IV vragenlijst [ADP-IV questionnaire]. Antwerp, Belgium: Universitair Ziekenhuis Antwerpen; 1994.

67. Verheul R, Andrea $\mathrm{H}$, Berghout CC, Dolan C, Busschbach JJ, van der Kroft PJ, et al. Severity indices of personality problems (sipp-118): Development, factor structure, reliability, and validity. Psychological Assessment. 2008:20:23-34.

68. Osterloh JWSA, Videler AC, Rossi GPM, van Alphen SPJ. Cognitive model for behavioura Rorders in older adults: A nursing approach. Tijdschrift voor Gerontologie en Geriatrie. 2018; 49·210-212. 


\section{Addenda}

\section{Summary}

Samenvatting

\section{Valorisation}

Gerontologische Persoonlijkheidsstoornissen Schaal

Informant versie
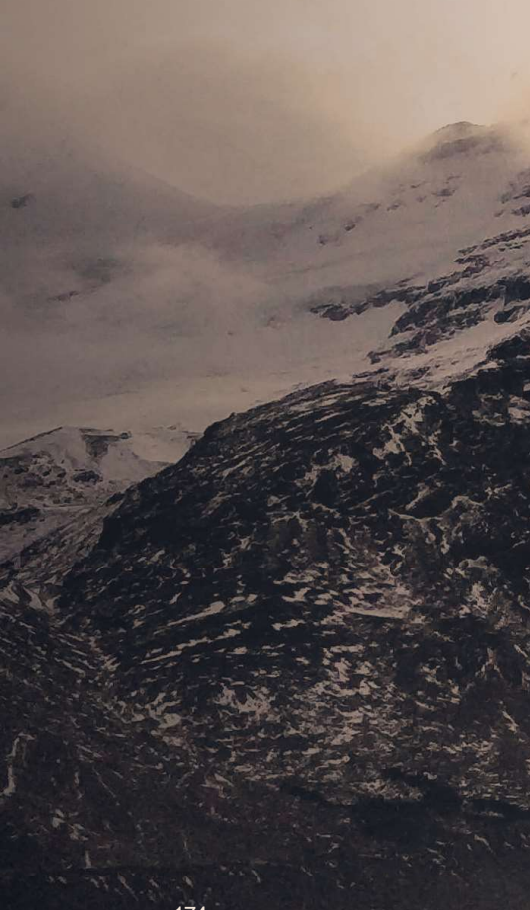

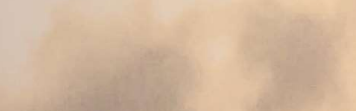
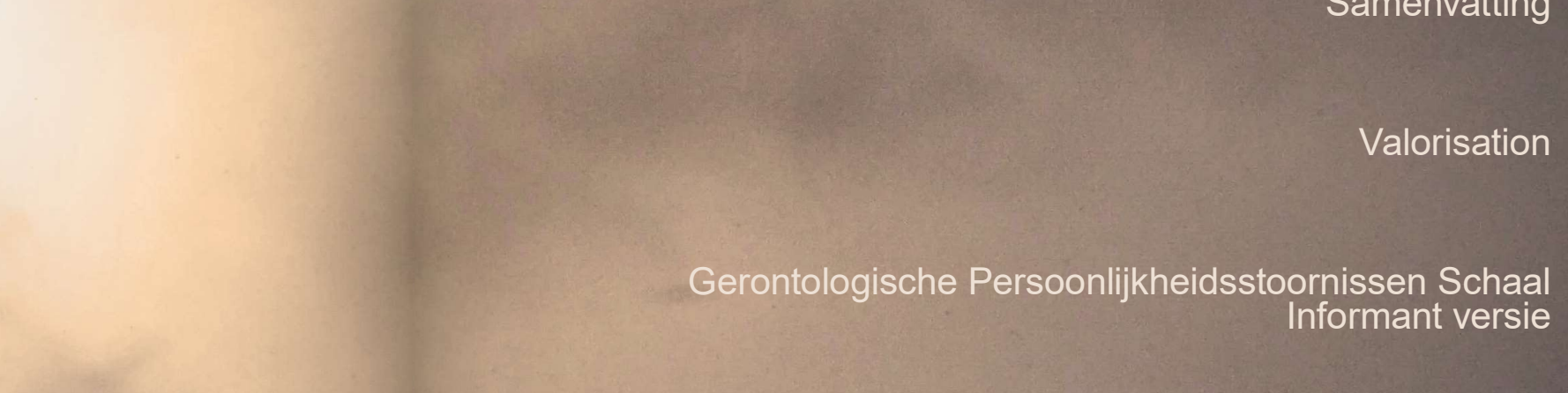

\section{Dankwoord}

About the author 


\section{Summary}

Chapter 1 introduces the theme and setting of the studies presented in this dissertation with a case description of Mr. Johnson, a 70-year old man who displays rather distinctive behavior. Next, personality disorders (PDs) are defined and its prevalence in older adults is discussed in the context of the aging population. It addresses the challenges for general practitioners (GPs) in dealing with PDs in their elderly patients and elaborates on the detection of these disorders being compromised by the absence of resources in general practice.

This chapter ends with the main objective, that is evaluating and validating the Gerontological Personality disorders Scale (GPS) - a short and age-specific instrument for detecting PDs in older adults- in general practice. The following research questions are addressed in this dissertation:

1. What is the current status of PDs in older adults with respect to epidemiology, assessment and treatment?

2. What is the reliability and diagnostic accuracy of the GPS in general practice?

3. What is the convergent and divergent validity of GPS in general practice?

4. What is the concordance of the self- and informant-report version of the GPS in general practice, and what factors may contribute to this?

5. What is the feasibility and acceptability of the GPS according to professionals as well as older adults and their informants?

In chapter 2 the current status of PDs in older adults ( $\geq 55 \mathrm{yrs}$.) with respect to epidemiology, assessment and treatment will be given by presenting the results of a literature review focusing on primary empirical research.

Since 2015, 12 studies have been published; three addressing epidemiological aspects, six on assessment, two exploring both epidemiology and assessment and one examining treatment. The studies showed that PDs are rather prevalent in later life ranging from $10.6-14.5 \%$ in community-dwelling older adults, to $57.8 \%$ in nursing homeresiding older adults. The highest rates were found for obsessive-compulsive PD, while dependent PD was the least prevalent in late life. Research revealed that the Severity Indices of Personality Problems Short Form (SIPP-SF), the Gerontological Personality disorders Scale (GPS) and the Assessment of DSM Personality disorders-IV (ADP-IV) are promising (new) instruments for assessing PDs in later life. Furthermore, schema therapy seems to be a feasible and effective intervention for PDs in older adults.

While reviewing the eligibility of the articles, about $35 \%$ used inconsistent terminology, which may imply that the construct and/or definition of PDs in late(r) 
life might not be that clear or straightforward. Factors as different and more atypica clinical presentations, a more temporal-instable course and late(r) onset may have contributed to this. This inconsistency might also signal the importance of examining the full spectrum of personality functioning and traits, as the distinction between the presence and absence of a PD is rather arbitrary.

Despite promising findings, there is an urgent need for research addressing PDs in older adults, especially studies investigating epidemiological aspects and treatment options. Furthermore, an appeal is done for research examining PDs in other settings, and exploring behavioral counseling as intervention for PDs in late life. In sum (research on) PD in older adults should not be dismissed, but they hold the future.

Chapter 3 describes the reliability and diagnostic accuracy of both the self- and informant-report version of the Gerontological Personality disorders Scale (GPS), a 16-item age-specific instrument assessing the presence of absence of PDs, when compared to an informant-based personality questionnaire (the Hetero Anamnestische Persoonlijkheidsvragenlijst; HAP), in general practice.

Data of 348 older adults sampled from five general practices in the Netherlands, and 348 informants, were included in the analysis. As part of evaluating the reliability of the GPS, internal consistency, test-retest reliability and inter-rater reliability were examined. The validity was assessed by calculating classical diagnostic validity statistics such as sensitivity, specificity, positive predictive power, negative predictive power, and the overall correct classification. Additionally, the incremental validity of positive and negative test scores was calculated as well as which items were the most predictive of PD-status.

The internal consistency of the GPS self-report version, and to a lesser degree GPS informant-report, was limited. The test-retest reliability of the GPS was strong for both versions. The inter-rater reliability ranged from moderate (HAB) to good (BIO). Based on the diagnostic accuracy statistics, the GPS informant version is preferable to the GPS self-report. Furthermore, two items of the self-report version (HAB4; problem solving by other, and $\mathrm{BIO} 5$; previous psychological treatment) and four items of the informant-report version (HAB2; health-related worry, HAB4; problem solving by others, HAB6; being disadvantaged, and $\mathrm{BIO1}$; excessive GP visits) yielded the most predicted validity.

Based on its current psychometric properties; the informant version is preferred over the GPS self-report, and is an adequate tool for making an initial assessment of PDs in older adults in general practice.
Chapter 4 presents the results of the study addressing the nomological network of both the self- and informant-report version of the GPS, by considering its relationships to personality (as measured with the HAP) and psychopathology (as measured with the AUDIT, GDS and BSI). Furthermore, the GPS' relationship with the Hierarchical Taxonomy of Psychopathology (HiTOP), a promising new framework for an integrating empirical classification of mental disorders, was examined as well.

Data of 320 older adults and 320 informants were analyzed. Both versions of the GPS showed similar correlations patterns to normative personality traits and psychopathology. However, with respect to personality, the magnitude of the correlations was larger for the informant-report GPS than it was for the GPS-pv, which is likely the results of shared method variance. The GPS appeared to be meaningfully (positive) associated with psychopathology, except for alcohol use disorders which showed small negative correlations. With respect to the HiTOP model; the GPS corresponds the most to the P-factor, the somatoform spectrum and the internalizing spectrum. On the contrary, the GPS is the least related to the HiTOP's externalizing spectra (both antagonistic and disinhibited).

These findings show that aside from general PD features, the GPS might be especially sensitive to somatoform and internalizing features, which are known to be (atypical) manifestations of PDs in late life.

In chapter $\mathbf{5}$ the concordance between the GPS self- and informant-report version was explored, as well as potentially explanatory factors such as which perspective reports more pathology, item accessibility and relational aspects. In this cross-sectional study, data of 326 older adult-informant dyads were included.

Self-informant agreement on the GPS was found to range from moderate to good depending on whether habitual behavior or biographical information was being judged. Overall, informants seem to be more sensitive to pathological personality features than older adults were. Differential item functioning might also (partly) explain the level of self-informant disagreement, as the item accessibility of 2 of the 16 GPS items (HAB2 health-related worry, and HAB5; afraid of losing others) was different for selves and informants when reporting the same underlying level of problems in habitual behavior These items appeared to be more discriminative in self- than in informant-report. Lastly, relational aspects such as relationship type as well as the quality of the relationship were not associated with self-informant agreement when using the GPS. The level of congeniality (rated with a grade of 1-10) did seem to play a role in self-informan agreement; lower ratings on congeniality were associated with higher GPS-iv scores, implying more personality problems. 
The findings showed that self- and informant-report provide complementary perspectives.

In chapter 6 the feasibility and the acceptability of the GPS was examined from a professional, older adult, and informant perspective. In this convergent parallel mixed methods study, the qualitative data were collected through semi-structured interviews with four general practitioners (GPs) and four nurse practitioners (NPs) whereas the quantitative data were collected through a 5-item questionnaire completed by 329 older adults and 329 informants.

Thematic analysis of the qualitative data revealed that PDs in older adults is a topic of interest in general practice, as GPs and NPs experience that these disorders have a complicating effect, require professional flexibility and cause frustration. Furthermore, the professionals regarded recognizing and managing these disorders are a part of their job responsibilities in which they need resources. As for the GPS, both GPs and NPs were positive about their experience with the instrument, reporting favorable characteristics including plain and short questions, a clear and brief introduction, smooth, easy and quick administration. Using the GPS increased their awareness of PDs in later life, provided surprising new insights and triggered reflection. Al professionals felt some reluctance when addressing $\mathrm{BIO} 2$ (suicide ideation), $\mathrm{BIO}$ (suicide attempt) and $\mathrm{BIO} 8$ (hyposexuality) which seemed related to concerns about their own knowledge and expertise with PDs among the aged. Furthermore, being validated, having a clear indication for its use, contributing to the service provided in general practice, as well as receiving training on PDs in older adults and how to use the GPS, are preconditions that would facilitate the use of the GPS in general practice. Quantitative data showed that most older adults and informants reported the GPS items to be clearly phrased, easy to understand, non-confrontational and not unpleasant to answer.

Hence, the GPS appeared to be a feasible and acceptable instrument for detecting PDs in older adults in general practice. Educating professionals about PDs in older adults and the GPS is important prior to its use in daily practice and might further increase its acceptability even more.

Chapter $\mathbf{7}$ is the general discussion of this thesis. This final chapter gives an overview of the major findings of the studies presented in this thesis. Next, the context of these results will be considered, i.e., what is an acceptable reference standard, what is acceptable diagnostic accuracy for assessing PDs in late life in general practice how can the GPS be improved and implemented in general practice?

With respect to an acceptable reference criterion for PDs in late life, after considering various aspects, it is concluded that aside from a clinical diagnosis, an age-specific or at least an age-neutral instrument validated within an older adult population that has clear and simple items and is not too lengthy is a suitable reference instrument.

When considering the detrimental effects that PDs have on the older adult himself, his loved one's and healthcare, it is believed that an instrument used for a first assessment of PDs in late life in general practice should favor sensitivity over specificity to be acceptable. In this light, the GPS is an acceptable instrument for a first assessment of PDs in older adults in general practice.

As a number of GPS items contain highly subjective and debatable terms, cover multiple questions in a single item, or contain negative wording, it is hypothesized that the GPS might show potential for improvement. Furthermore, the GPS may benefit from changing the sequence of some items.

When reflecting on implementing the GPS in general practice, it is believed that now the GPS is validated within this setting and using it to corroborate the professionals' gut feeling, might facilitate its use. Furthermore, educating the professionals about PDs in later life, and providing hands-on experience with the GPS as well as training sessions addressing communication techniques are recommended prior the implementing the GPS in general practice.

Methodological considerations, such as strengths and limitations, have been addressed. Strengths include the innovative nature of the studies (addressing the underexplored field of PDs in late life, examining an age-specific instrument, and the setting), the rather large sample size, and the careful and in-depth evaluation of the GPS. The low response rate and the limited internal consistency of the GPS are considered to be limitations.

The implications of the studies in the dissertation are that the GPS supports the professional by 1) aiding in the recognition of a potential PD, 2) initiating further personality assessment leading to strategies to optimize interpersonal contact with the patient, and 3) enabling a more precise referral to mental healthcare.

Finally, suggestions for further research are presented, such as 1) examining the diagnostic accuracy of the GPS-pv while using recently validated self-report instruments as a reference criterion, 2) investigating whether the GPS does indeed benefit from the suggested adjustments, 3) conducting a implementation study, and 4) exploring the feasibility of the Cognitive Model for Behavioral Interventions as too for managing PDs in general practice. 


\section{Samenvatting}

Hoofdstuk 1 introduceert het thema en de setting waarin de studies zoals beschreven in deze dissertatie zich hebben afgespeeld, middels een casusbeschrijving van dhr. Johnson, een 70-jarige man die nogal opmerkelijk gedrag laat zien in de contacten met zijn huisarts. Vervolgens worden persoonlijkheidsstoornissen (PS) gedefinieerd en wordt de prevalentie ervan op latere leeftijd in de context van de vergrijzing geplaatst. Het hoofdstuk beschrijft de uitdagingen waarmee huisartsen geconfronteerd worden in de omgang met ouderen met persoonlijkheidsproblematiek en gaat in op he (belang van) signaleren van deze stoornissen hetgeen bemoeilijkt wordt door het ontbreken van adequate hulpmiddelen in de huisartsenpraktijk. Het hoofdstuk eindigt met het weergeven van 1) het hoofddoel, namelijk het evalueren en het valideren van de Gerontologische Persoonlijkheidsstoornissen Schaal (GPS) - een kort, leeftijdsspecifiek instrument ten behoeve van de signalering van PS bij ouderen - in de huisartsenpraktijk, 2) evenals de volgende onderzoeksvragen

1. Wat is de huidige stand van zaken betreffende PS bij ouderen in relatie tot epidemiologie, diagnostiek en behandeling?

2. Wat is de betrouwbaarheid en de diagnostische accuraatheid van de GPS wannee deze wordt ingezet in de huisartsenpraktijk?

3. Wat is de convergente en divergente validiteit van de GPS bij gebruik in de huisartsenpraktijk?

4. Wat is de mate van overeenstemming tussen de patiënt en informant versie van de GPS in de huisartsenpraktijk en welke factoren spelen hier mogelijk een rol in?

5. Hoe wordt de bruikbaarheid en acceptatie van de GPS beoordeeld door de professional, de oudere en diens informant?

Ten slotte biedt het hoofdstuk een overzicht van deze dissertatie.

In hoofdstuk 2 wordt de huidige stand van zaken betreffende PS bij ouderen ( $\geq$ 55 jaar) met betrekking tot epidemiologie, diagnostiek en behandeling weergegeven middels de resultaten van een literatuurstudie gericht op primaire wetenschappelijke studies.

Sinds 2015 zijn er 12 relevante publicaties verschenen; drie betroffen epidemiologisch onderzoek, zes waren assessment-gerelateerd, twee studies onderzochten zowel epidemiologische als assessment aspecten en slechts één behandelstudie werd gepubliceerd.

De studies toonden aan dat PS bij ouderen behoorlijk prevalent zijn en variëren van $10.6-14.5 \%$ in de algemene oudere bevolking tot $57.8 \%$ binnen de verpleeghuissetting. 
De dwangmatige persoonlijkheidsstoornis blijkt op latere leeftijd het meest voorkomend te zijn, in tegenstelling tot afhankelijke persoonlijkheidsproblematiek. De assessment studies duidden dat de Severity Indices of Personality Problems Short Form (SIPPSF), de Gerontologische Persoonlijkheidsstoornissen Schaal (GPS) en de Assessment of DSM Personality disorders-IV (ADP-IV) veelbelovende (nieuwe) instrumenten zijn voor het objectiveren van persoonlijkheidspathologie op latere leeftijd. Qua interventies blijkt schematherapie een haalbare en effectieve behandeling voor ouderen met persoonlijkheidspathologie.

Tijdens de beoordeling van potentieel relevante studies, bleek ongeveer $35 \%$ ervan inconsequente terminologie te hanteren, hetgeen mogelijk impliceert dat het construct en/of definitie van PS bij ouderen (nog) niet zo helder of eenduidig is. Factoren als andere en meer atypische klinische uitingsvormen op latere leeftijd, een meer instabie beloop en latere 'onset' hebben hier mogelijk aan bijgedragen. Tevens kan deze inconsistentie duiden op het belang van het onderzoeken van het volledige continuüm van persoonlijkheid(sstoornissen), aangezien de grens tussen de af- en aanwezigheid van deze problematiek arbitrair is.

Gezien het beperkt aantal, maar veelbelovende onderzoeksresultaten, is er een dringende behoefte aan studies naar PS bij ouderen, en in het bijzonder naa epidemiologische aspecten en behandelmogelijkheden. Bovendien is het van belang om het onderzoeksgebied uit te breiden, te denken aan andere settingen en mediatieve interventies. Kortom, onderzoek naar persoonlijkheidsstoornissen bij ouderen heeft de toekomst.

Hoofdstuk 3 beschrijft de betrouwbaarheid en diagnostische accuraatheid van zowel de zelfrapportage als de informant versie van de GPS (respectievelijk GPS-pv en GPS-iv), een 16-item tellend screeningsinstrument voor PS op latere leeftijd, afgezet tegen een persoonlijkheidsvragenlijst ingevuld door informanten (de Hetero Anamnestische Persoonlijkheidsvragenlijst; HAP), in de huisartsenpraktijk.

Data van 348 ouderen, geïncludeerd uit vijf Nederlandse huisartsenpraktijken en 348 informanten werden geanalyseerd. De betrouwbaarheid van de GPS werd beoordeeld aan de hand van interne consistentie, test-hertest- en interbeoordelaarsbetrouwbaarheid. De validiteit werd onderzocht middels het berekenen van klassieke diagnostische validiteitsstatistieken zoals sensitiviteit, specificiteit, positieve voorspellende waarde, negatieve voorspellende waarde en de totale correcte classificatie. Tevens werd de incrementele validiteit van positieve en negatieve testscores berekend evenals welke items het meest voorspellend waren in het signaleren van persoonlijkheidsproblematiek.
De interne consistentie van de GPS-pv, en in mindere mate van de GPS-iv, was beperkt. De test-hertest betrouwbaarheid van de beide versies van de GPS was goed. De interbeoordelaarsbetrouwbaarheid varieerde van matig (subschaal habitueel gedrag) tot goed (subschaal biografische gegevens). Afgaande op de diagnostische accuraatheid statistieken bleek de GPS-iv beter in staat PS in ouderen te detecteren dan de zelfrapportage van de GPS. Twee items van de zelfrapportage versie (HAB4; problemen oplossen door anderen \& BIO5; eerdere psychologische behandeling) en vier items van de GPS informant versie (HAB2; gezondheids-gerelateerde zorgen, HAB4; problemen oplossen door anderen, HAB6; benadeeld worden \& BIO1; veelvuldig huisartsbezoek) bleken de meest voorspellende waarde te hebben.

Op basis van de onderzochte psychometrische eigenschappen, geniet de GPS informant versie de voorkeur boven de zelfrapportage versie en blijkt het een adequaat instrument te zijn voor het maken van een initiële inschatting betreffende de aanwezigheid van PS op latere leeftijd in de huisartsenpraktijk.

Hoofdstuk 4 presenteert de bevindingen van de studie betreffende he nomologische netwerk van zowel de zelfrapportage als informanten versie van de GPS, middels het beoordelen van zijn relaties tot persoonlijkheid (gemeten met de HAP) en psychopathologie (gemeten met de AUDIT, GDS en BSI). Tevens wordt de relatie tussen de GPS en de Hierarchical Taxonomy of Psychopathology (HiTOP), een veelbelovend nieuw model voor een integratieve empirische classificatie voor psychische stoornissen, onderzocht.

Data van 320 ouderen en 320 informanten werden geanalyseerd. Beide versies van de GPS tonen vergelijkbare correlatiepatronen ten aanzien van normatieve persoonlijkheidstrekken en psychopathologie. Echter, ten aanzien van persoonlijkheid blijkt de sterkte van de correlaties aanzienlijk hoger te zijn voor de informant versie dan voor de GPS zelfrapportage, hetgeen waarschijnlijk het gevolg is van gemeenschappelijke methode variantie. De GPS blijkt aanzienlijk (positief) geassocieerd te zijn met psychopathologie, uitgezonderd stoornissen in alcoholgebruik alwaar lage negatieve correlaties werden gevonden. Met betrekking tot het HiTOP model blijkt de GPS het meest overeen te komen met de P-factor, het somatoforme en het internaliserende spectrum. De GPS blijkt daarentegen het minst overeen te stemmen met de externaliserende spectra (zowel antagonistisch als ongeremd) van het HiTOP model. Deze bevindingen duiden dat naast algemene PS kenmerken, de GPS ook gevoelig lijkt te zijn voor somatoforme en internaliserende kenmerken, die gekaderd kunnen worden binnen de atypische uitingsvormen van PS op latere leeftijd.

In hoofdstuk 5 wordt de zelf-informant concordantie van de GPS geëxploreerd, evenals mogelijk verklarende factoren, zoals wie rapporteert meer pathologie, 
itemtoegankelijkheid en relationele aspecten. In deze cross-sectionele studie werd gebruikt gemaakt van de data van 326 ouderen-informanten dyaden.

De mate van zelf-informant overeenstemming op de GPS varieerde van matig to goed, afhankelijk van het feit of habitueel gedrag of biografische gegevens werden bevraagd. Over het algemeen bleken informanten meer pathologie te rapporteren dan ouderen zelf deden. De mate van zelf-informant concordantie kan mogelijk deels verklaard worden vanuit het verschil in itemtoegankelijkheid, aangezien twee van de 16 items minder toegankelijk bleken voor informanten (HAB2; gezondheids-gerelateerde zorgen, en HAB5; angst om anderen te verliezen) wanneer er sprake was van een gelijke mate van onderliggende pathologie. Relationele aspecten zoals aard van de relatie evenals de kwaliteit ervan bleken nagenoeg geen rol te spelen in zelf-informant overeenstemming op de GPS. Aardigheid (weergegeven middels een cijfer van 1-10) bleek daarentegen wel een rol te spelen; lagere scores ten aanzien van aardigheid bleken gerelateerd aan hogere informant-gerapporteerde GPS scores, hetgeen meer persoonlijkheidsproblemen impliceert.

De resultaten van deze studie onderstrepen het belang van het gebruik van zowe zelf- als informantenrapportage binnen persoonlijkheidsonderzoek bij ouderen, dewij zelf en informant rapportage complementair is aan elkaar.

In hoofdstuk 6 wordt de bruikbaarheid en acceptatie van de GPS onderzoch vanuit zowel professioneel oogpunt als vanuit ouderen- en informanten-perspectief. In deze convergente parallelle mixed-methods studie werden kwalitatieve data verzameld middels semi-gestructureerde interviews bij vier huisartsen en vier praktijkondersteuners. Kwantitatieve data werden bij 329 ouderen en 329 informanten middels een vragenlijst verzameld.

Thematische analyse van de kwalitatieve data gaf blijk dat PS bij ouderen een belangrijk thema vormt binnen de huisartsenpraktijk, gezien deze stoornissen de zorg compliceren, professionele flexibiliteit vereisen en mogelijk leiden tot frustratie. Daarnaast gaven de professionals aan dat herkenning van en het omgaan met deze problematiek behoort tot hun taken en verantwoordelijkheden, waarin zij behoefte hebben aan hulpmiddelen. Ten aanzien van de GPS, waren zowel huisartsen als praktijkondersteuners positief aangaande hun ervaring met dit instrument. Hierbij werden meerdere pluspunten benoemd waaronder de duidelijke en korte vragen, de heldere en beknopte inleiding, de eenvoudige en soepele afname evenals de korte afnameduur. Het gebruik van de GPS maakte hen meer bewust van de problematiek leidde tot verrassende nieuwe inzichten over de patiënten en zette aan tot reflectie. Alle professionals ervoeren enige terughoudendheid bij de afname van item $\mathrm{BIO} 2$ (suïcide ideatie), $\mathrm{BIO6}$ (suïcidepoging), and $\mathrm{BIO} 8$ (verminderde seksuele interesse), hetgeen mogelijk het gevolg was van een gebrek aan kennis en expertise betreffende PS bij ouderen. Factoren als gevalideerd zijn, een duidelijke indicatie voor afname hebben, een bijdrage leveren aan de geboden service in de huisartsenpraktijk evenals het ontvangen van scholing en training over PS bij ouderen en het gebruik van de GPS, faciliteren mogelijk het gebruik van de GPS binnen deze setting. De kwantitatieve resultaten gaven blijk dat dat het merendeel ouderen en informanten de GPS items duidelijk geformuleerd, begrijpelijk en niet vervelend of confronterend vonden.

De GPS lijkt derhalve een bruikbaar en geaccepteerd instrument te zijn voor het signaleren van PS op latere leeftijd in de huisartsenpraktijk. Het scholen van professionals aangaande PS bij ouderen alsmede het gebruik van de GPS verhoogt de acceptatie ervan zo mogelijk nog meer.

Hoofdstuk 7 omvat de algemene discussie van dit proefschrift. Dit laatste hoofdstuk geeft een overzicht van de belangrijkste bevindingen. Vervolgens worden de resultaten in context geplaatst, zoals 1) wat is een acceptabele referentie standaard, 2) wat is acceptabele diagnostische accuraatheid in het signaleren van PS in ouderen 3) hoe kan de GPS mogelijk verbeterd en 4) geïmplementeerd worden binnen de huisartsenpraktijk.

Ten aanzien van een acceptabele referentie standaard voor PS op latere leeftijd wordt, na verschillende aspecten in overweging genomen te hebben, geconcludeerd dat, behalve een klinische diagnose, een niet te uitgebreid (groot aantal items) leeftijdsspecifiek of op zijn minst een leeftijdsneutraal instrument gevalideerd voor ouderen met duidelijke en eenvoudige item geschikt is als referentie criterium.

Rekening houdend met de ingrijpende effecten van de aanwezigheid van een PS op de oudere zelf, zijn naasten en de gezondheidszorg, is een screeningsinstrument in de huisartsenpraktijk met een hogere sensitiviteit dan specificiteit te prefereren. Op basis hiervan is de GPS een acceptabel instrument voor het maken van een eerste inschatting van de aanwezigheid van PS bij ouderen in deze setting.

Gezien een aantal GPS items subjectieve termen bevatten, meerdere vragen in een item omvatten en soms ontkennend zijn geformuleerd, wordt verondersteld dat met enkele aanpassingen de GPS mogelijk verbeterd zou kunnen worden. Daarnaast zou de GPS kunnen profiteren van het veranderen van de itemvolgorde.

Reflecterend op de implementatie van de GPS binnen de huisartsenpraktijk, word verwacht dat de huidige validering van het instrument evenals het helder hebben van de indicatie van inzet (te weten ter bevestiging van het niet-pluis gevoel van de professional) in positieve zin zal bijdragen hieraan. Tevens wordt aangeraden om de professionals te scholen ten aanzien van persoonlijkheidsproblematiek op latere leeftijd, 'hands-on' ervaringen te bieden betreffende het gebruik van de GPS, evenals 
training sessies te organiseren waarin specifieke communicatietechnieken worden behandeld, alvorens de GPS te implementeren in de huisartspraktijk.

Sterke punten omvatten het innovatieve karakter van de studies (het onderzoeken van het ontontgonnen onderzoeksgebied, het onderzoeken van een leeftijdsspecifiek instrument evenals de setting), de relatief grote steekproefgrootte en de zorgvuldige en diepgaande evaluatie van de GPS. De lage respons en de beperkte interne consistentie van de GPS worden beschouwd als beperkingen.

De implicaties van de studies in het proefschrift zijn dat de GPS de professiona ondersteunt door 1) het helpen bij het signaleren van een potentiële PS, 2) het initiëren van verdere persoonlijkheidsbdiagnostiek die leidt tot strategieën om interpersoonlijk contact met de patiënt te optimaliseren, en 3) een nauwkeurigere verwijzing naar de geestelijke gezondheidszorg mogelijk te maken.

Ten slotte worden suggesties voor verder onderzoek gepresenteerd, zoals 1) het onderzoeken van de diagnostische nauwkeurigheid van de GPS-pv middels het gebruik van onlangs gevalideerde zelfrapportage-instrumenten als referentiecriterium, 2) nagaan of de GPS inderdaad baat heeft bij de voorgestelde aanpassingen, 3) het uitvoeren van een implementatiestudie en 4) het verkennen van de haalbaarheid van het cognitieve model voor gedragsinterventies als instrument voor het omgaan met PS-en in de huisartspraktijk.

\section{Valorisation}

This valorisation addendum elaborates on the societal value of the research and how this scientific knowledge can be conveyed to and employed in (general) practice so that it can be used and/or is suitable for a broader public than the scientific community only. The societal value will be addressed from various perspectives: 1) relevance of the scientific findings for healthcare and general practice; 2) (non-)scientific stake-holders to whom the findings are relevant; 3 ) innovativeness of the GPS; and 4) dissemination of gathered information.

\section{Relevance for healthcare and general practice}

The scientific findings as presented in this dissertation are of major practical relevance. The detection of personality disorders (PDs) in older adults in general practice is important and can be facilitated by using the Gerontological Personality disorders Scale (GPS), a brief and age-specific instrument addressing PDs in older adults.

PDs, such as paranoid PD, narcissistic PD, and obsessive-compulsive PD, are known to be severely disabling, contributing to a high disease burden including psychosocial impairment, decreased physical and cognitive functioning, and an elevated suicide risk (1-5). Older adults with PDs are prone to both other mental disorders and medical conditions ${ }^{(6)}$ and pose a high economic burden on society, given the increased healthcare utilization, greater length of treatment, and higher rates of medication use ${ }^{(7-9)}$. PDs may also affect professionals in general practice as these disorders are notable to strain the doctor-patient relationship as a result of interpersonal difficulties, which is a hallmark of PDs ${ }^{(10)}$. Furthermore, PDs are linked to direct or indirect treatment rejection, non-compliance to somatic and mental care ${ }^{(8,11)}$, and may cause frustration and heartsink feelings ${ }^{(12)}$.

Besides these consequences, PDs are common in late life. In the general elderly population, the prevalence ranges from $10.6-14.5 \%{ }^{(13-15)}$, which means that viewed from a national perspective in $2019,351,284$ to 480,530 adults older than 65 years living in the Netherlands suffered from personality pathology (16) Given the aging of the population, which is expected to persist in the coming years ${ }^{(17)}$, the number of older adults with PDs will only further increase ${ }^{(18)}$

Fortunately, research gradually reveals effective and feasible treatment options for PDs in late life ${ }^{(19-23)}$. However, PDs in older adults can be missed or misinterpreted in general practice, because of its more atypical presentation in late life ${ }^{(24-25)}$, the 
lack of appropriate screening instruments ${ }^{(26)}$, or patients' limited insight into (the origins of) his difficulties thereby not expressing complaints ${ }^{(27)}$. Such restrictions may contribute to the under-recognition of PDs, which in turn may result in delay of receiving adequate treatment, little and/or incorrect referrals, and less of ineffective treatment ${ }^{(4,11)}$. Therefore, the detection of PDs in late life is important, in order to avoid aggravation of complaints, deterioration of the doctor-patient relationship and to enable that the elderly patients receive the appropriate treatment. With the GPS, the genera practitioner (GP) and nurse practitioner (NP) have an adequate instrument assisting in the detection of PDs in late life in general practice.

\section{Relevance for different stakeholders}

There are different stakeholders for whom the results of the studies in this dissertation can be considered relevant, those being older adults and informants (i.e. a person who provides privileged information about a person), GPs and NPs, mental healthcare professionals, insurance companies, and researchers.

\section{Older adults and informants}

Based on the findings of the feasibility study, the opinion of the older adults and informants with respect to the GPS was examined (28). We concluded that both older adults and informants evaluated the instrument to be feasible and acceptable. Overall, they reported the GPS items to be clearly phrased and easy to understand. Furthermore, they did not find the items confrontational and unpleasant to answer ${ }^{(28)}$ One of the advantages for the older adults, viewed from a societal perspective, is that potential personality pathology is (early) detected. Potentially, older adults can now be referred, in an early phase, to healthcare professionals (the NP, psychologist, or specialized mental healthcare) best suited for further assessment. Eventually, this may lead to more effective care, which is likely to increase the older adult's well-being and quality of life. Furthermore, it may decrease the number of healthcare consultations, ineffective treatment and relapse known to PDs. For informants, often loved ones, relatives or close friends of the older adults, the detection of a PD in which the GPS aids, may lead to a better understanding of the (problematic) behavior of the older adults which may improve their relationship.

By using the GPS in general practice, it offers more familiar surroundings, which might lower the threshold for disclosing personal information, as this setting might be perceived as less stigmatizing than a mental healthcare setting. It might also make a potential transition to specialized healthcare less unforeseen and overwhelming as may help familiarize older adults with discussing personal (potentially sensitive) information as well as with assessment. This might be especially important for older adults, as they are less used to assessment situations ${ }^{(29)}$

In some instances, informant-report is (even more) indispensable as older adults with insufficient understanding of the Dutch language, (severe) cognitive impairments, or severely limited reality testing or introspective capabilities may be unable to reflect and report on their behavior and personality. In such cases, the informant version of the GPS offers a solution.

\section{Professionals in general practice: GPs and NPs}

The GPS facilitates and marks the start for PD assessment in general practice, which improves the (early) detection of PDs. This may assist in attenuating the GPs and NPs frustration and increases understanding of the elderly patient, and of issues such as non-response to treatment or difficulty engaging in otherwise "straightforward" selfmanagement. It might help these professionals in adjusting their treatment strategies and communication by accounting for the personality pathology thereby improving the doctor-patient relationship.

The innovation also has a practical benefit. Our study pointed out that the GPS is an easy to use and short instrument suited for the fast-paced nature of general practice. It allows the professional to spend less time assessing and excluding cases, and it enables more cost-effective referrals to specialists when necessary ${ }^{(30)}$. This strengthens their gatekeepers' function. Additionally, these referrals can be more specified by including the GPS, which might further increase the collaboration between general practice and specialized mental healthcare settings.

\section{Mental healthcare professionals}

These professionals may also profit when the GPS is used in general practice, as they now may receive more specific information about the older adult. The score on GPS may guide further assessment, thereby providing focus which may contribute to faster and potentially a more cost-effective and efficient assessment.

\section{Insurance companies}

Insurance companies may also benefit from the conducted research and the GPS. When elderly patients with PDs are detected as such, appropriate proceeding steps can be taken which may reduce the healthcare costs. By optimizing the recognition of PDs in late life in general practice, a more specified referral is possible whereby adequate treatment can be provided. This may decrease the number of healthcare consultations, ineffective treatments, and unnecessary medical testing. 


\section{Dissemination}

The studies in this dissertation contributed to the important but underexplored field of PDs in late life and draws attention to the need for increasing its empirical research base. Our finding concerning self-and informant agreement, contribute to the current and still topical debate about including multiple sources in assessing PDs. Also, our findings linking the GPS to the HiTOP model (i.e. a new and promising empirical-based classification system, which conceptualizes psychopathology as multiple dimensions organized into transdiagnostic spectra) contribute to the growing knowledge base of transdiagnostic (classification and) research in older adults, and hopefully stimulates research initiatives to include aged samples.

On a more practical level, the careful scientific analysis of the validity of this instrument has led to much more insight into its strengths and weaknesses, which makes it possible to adjust the instrument where needed. Even more so, the studies in this dissertation, raise awareness of the GPS and therefore facilitates validation in other settings, countries and cultures.

\section{Innovativeness}

The studies in the dissertation hold various innovative aspects. First of all, these studies address the underexplored field of research of PDs in late life, and reveals that is a hot topic in general practice in which professionals express an urgent need for resources for recognizing these disorders ${ }^{(28)}$. Also, the GPS is unique in that it is a firs age-specific and brief instrument addressing PDs in older adults, in the Netherlands or even worldwide. In addition, this instrument is now also available to GPs (and NPs), who play a key role in the identification of (psychiatric) disorders, but who lack instruments for detecting PDs in late life.

Although, including collateral information in general practice is not new (e.g. is common in cognitive assessment), using informant-report for exploring potential personality problems within this setting is novel. Having two versions, the GPS enables to require both a self and an informant outlook on PD symptoms. Lastly, via the studies in this dissertation, the GPS has been examined thoroughly within general practice. In addition to the reliability and diagnostic accuracy of the GPS, self-informan concordance, feasibility and acceptability from multiple perspectives, as well as its nomological network was explored, thereby providing comprehensive overview of this instrument.
Next to the scientific value of this dissertation, of which most chapters have been published in peer-reviewed international journals, the results of this dissertation can be used to raise broad awareness for the importance of (detecting) PDs in late life. Therefore, the outcomes of the studies were and will be presented and discussed at different (inter)national conferences and symposia. In order to reach a broad audience, the attended conferences were chosen to be as diverse as possible while being relevant, ranging from conferences specifically for general practitioners (i.e. WONCA) to the largest conference of PDs worldwide (i.e. ISPPD).

Additionally, the acquired knowledge has also been made available to healthcare professionals from multiple disciplines, including psychologists, GPs, and NPs. An overview of the research was included in one of the first (Dutch) books on PDs in older adults ${ }^{(31)}$. Furthermore, the results from these studies are integrated in a handbook addressing PD in late life (32), in which chapter 20 is dedicated to general practice ${ }^{(33)}$ The findings concerning reliability and diagnostic accuracy of the GPS in genera practice are also included in the test manual of the GPS ${ }^{(34)}$ and thereby available for clinical practice.

In addition, future challenges will be to examine whether the GPS would benefit from adjusting some of the items and to further evaluate the diagnostic accuracy of the GPS-pv in general practice by using a self-report reference criterion. Furthermore a strategy how to position and implement the GPS in general practice will be developed. 


\section{References}

1. Condello C, Padoani W, Uguzzoni U, Caon F, De Leo D. Personality disorders and selfperceived quality of life in an elderly psychiatric outpatient population. Psychopathology. 2003;36:78-83

2. Frankenburg FR, Zanarini MC. Personality disorders and medical comorbidity. Curren Opinion in Psychiatry. 2006;19(4):428-31.

3. Jackson HJ, Burgess PM. Personality disorders in the community: Results from the Australian national survey of mental health and well-being part III. Social Psychiatry and Psychiatric Epidemiology. 2004;39:765-76.

4. Stevenson J, Brodaty H, Boyce P, Byth K. Personality disorder comorbidity and outcome: Comparison of three age groups. Australian and New Zealand Journal of Psychiatry. 2011;45(9):771-9.

5. Szücs A, Szanto K, Aubry JM, Dombrovski AY. Personality and suicidal behavior in old age: A systematic literature review. Frontiers in Psychiatry. 2018;9.

6. Schuster JP, Hoertel N, Le Strat Y, Manetti A, Limosin F. Personality disorders in older adults: Findings from the national epidemiologic survey on alcohol and related conditions. The American Journal of Geriatric Psychiatry. 2013;21(8):757-68.

7. Powers A, Strube MJ, Oltmanns TF. Personality pathology and increased use of medical resources in later adulthood. The American Journal of Geriatric Psychiatry. 2014;22(12):1478-86.

8. Powers AD, Oltmanns TF. Personality disorders and physical health: A longitudina examination of physical functioning, healthcare utilization, and health-related behaviors in middle-aged adults. Journal of Personality Disorders. 2012;26(4):524-38.

9. Lawton EM, Oltmanns TF. Personality pathology and mental health treatment seeking in a community sample of older adults. Personality and Mental Health. 2013;7:203-12.

10. American Psychiatric Association. Diagnostic and statistical manual of mental disorders. $5^{\text {th }}$ ed. Arlington, VA: American Psychiatric Publishing; 2013.

11. van Alphen SPJ, Derksen JLL, Sadavoy J, Rosowsky E. Features and challenges of personality disorders in late life. Aging and Mental Health. 2012;16(7):805-10.

12. Schafer $\mathrm{S}$, Nowlis $\mathrm{D}$. Personality disorders among difficult patients. Archives of Family Medicine. 1998;7:126-9.

13. Holzer KJ, Huang J. Physical health-related quality of life among older adults with personality disorders. Aging and Mental Health. 2019;23(8):1031-40.

14. Oltmanns TF, Rodrigues MM, Weinstein Y, Gleason MEJ. Prevalence of personality disorders at midlife in a community sample: Disorders and symptoms reflected in interview, self, and informant reports. Journal of Psychopathology and Behavioral Assessment. 2014;36:177-88

15. Reynolds K, Pietrzak RH, El-Gabalawy R, Mackenzie CS, Sareen J. Prevalence of psychiatric disorders in US. Older adults; findings from a nationally representative survey. World Psychiatry. 2015;14(1):74-81.
16. Centraal Bureau voor de Statistiek. Bevolking; kerncijfers 2019 [Available from: https:// opendata.cbs.nl/statline/\#/CBS/nl/dataset/37296ned/table?ts=1585835385306.

17. United Nations. World population prospects 2019. [Available from: https://population. un.org/wpp/Download/Standard/Population/.

18. Beard JR. The demography and emidemiology of population ageing. In: Pachana NA Laidlaw K, editors. The oxford handbook of clinical geropsychology. Oxford: UK: Oxford University Press; 2014. p. 26-39.

19. Lynch TR, Cheavens JS, Cukrowicz KC, Thorp SR, Bronner L, Beyer J. Treatment of older adults with co-morbid personality disorder and depression: A dialectical behavio therapy approach. International Journal of Geriatric Psychiatry. 2007;22:131-43.

20. Videler AC, Rossi G, Schoevaars M, van der Feltz-Cornelis CM, van Alphen SPJ. Effects of schema group therapy in older outpatients: A proof of concept study. International Psychogeriatrics. 2014;26(10):1709-17.

21. Videler AC, van Alphen SPJ, van Royen RJJ, van der Feltz-Cornelis CM, Rossi G, Arntz A. Schema therapy for personality disorders in older adults: A multiple-baseline study. Aging and Mental Health. 2018;22(738-747):1-10.

22. Videler AC, Van der Feltz-Cornelis CM, Rossi G, van Royen RJJ, Rosowsky E, van Alphen SPJ. Psychotherapeutic treatment levels for personality disorders in older adults. Clinical Gerontologist. 2015;38(4):325-41.

23. Videler AC, van Royen R, Heijnen-Kohl SMJ, Rossi GMP, van Alphen SPJ, Van de Feltz-Cornelis CM. Adapting schema therapy for personality disorders in older adults. International Journal of Cognitive Therapy. 2017;10(1):62-78.

24. Mroczek DK, Hurt SW, Berman WH. Conceptual and methodological issues in the assessment of personality disorders in older adults. In: Rosowsky E, Abrams RC, Zweig RA, editors. Personality disorders in older adults: Emerging issues in diagnosis and treatment. Mahwah, NJ: Erlbaum; 1999. p. 135-52.

25. Debast I, van Alphen SPJ, Rossi G, Tummers JHA, Bolwerk N, Derksen JJL, et a Personality traits and personality disorders in late middle and old age: Do they remain stable? A literature review. Clinical Gerontologist. 2014;37(3):253-71.

26. Rossi G, van den Broeck J, Dierckx E, Segal D, van Alphen SPJ. Personality assessment among older adults: The value of personality questionnaires unraveled. Aging and Menta Health. 2014;18(8):936-40.

27. Balsis S, Loehle-Conger E, Busch AJ, Ungredda T, Oltmanns TF. Self and informant report across the borderline personality disorders spectrum. Personality Disorders: Theory, Research, and Treatment. 2018;9(5):429-36.

28. Penders KAP, van Zadelhoff E, Rossi G, Duimel-Peeters IGP, van Alphen SPJ, Metsemakers JFM. Feasbility and acceptability of the Gerontological Personality disorders Scale (GPS) in general practice: A mixed methods study. Journal Personality Assessment. 2019;101(5):534-43

29. American Psychological Association. Guidelines for psychological practice with older adults. American Psychologist. 2014;69(1):34-65.

30. Ferrer RL, Hambidge SJ, Maly RC. The essential role of generalists in health care systems. Annals of Internal Medicine. 2005:142(8):691-9. 
31. van Alphen SPJ. Persoonlijkheidsstoornissen bij ouderen: Diagnostiek, behandeling en gedragsadvisering. Amsterdam, Nederland: Hogrefe; 2010.

32. van Alphen SPJ, Oude Voshaar RC, Bouckaert F, Videler AC. Handboek persoonlijkheidsstoornissen bij ouderen. Utrecht, Nederland: De Tijdstroom; 2018.

33. Barendse HPJ, Penders KAP, Metsemakers JFM, van Alphen SPJ. Huisartsenpraktijk en generalistische basis-ggz. In: van Alphen SPJ, Oude Voshaar RC, Bouckaert F, Videler AC, editors. Handboek persoonlijkheidsstoornissen bij ouderen. Utrecht, Nederland: De Tijdstroom; 2018. p. 280-7.

34. van Alphen SPJ, Engelen GJJA. Gerontologische Persoonlijkheidsstoornissen Schaal GPS. Loghum, Nederland: Bohn Stafleu van Loghum; 2018.

\section{Gerontologische Persoonlijkheidsstoornissen}

\section{Schaal (GPS)}

\section{Informant versie huisartsenpopulatie ouderen}

\begin{tabular}{|c|c|c|c|}
\hline & Habitueel gedrag (HAB) & Nee & Ja \\
\hline 1. & Hij/zij vindt ouder worden vervelend omdat hij/zij minder aantrekkelijk wordt & 0 & 1 \\
\hline 2. & Hij/zij maakt zich vaak zorgen over zijn/haar gezondheid & 0 & 1 \\
\hline 3. & $\mathrm{Hij/zij} \mathrm{is} \mathrm{vaak} \mathrm{bezorgd} \mathrm{over} \mathrm{zijn/haar} \mathrm{geheugen}$ & 0 & 1 \\
\hline 4. & $\mathrm{Hij/zij} \mathrm{hoopt} \mathrm{dat} \mathrm{anderen} \mathrm{zijn/haar} \mathrm{problemen} \mathrm{oplossen}$ & 0 & 1 \\
\hline 5. & $\begin{array}{l}\mathrm{Hij/zij} \mathrm{is} \mathrm{vaak} \mathrm{bang} \mathrm{om} \mathrm{degenen} \mathrm{die} \mathrm{voor} \mathrm{hem/haar} \mathrm{zorgen,} \mathrm{zoals} \mathrm{familieleden} \mathrm{of} \\
\text { partner, te verliezen }\end{array}$ & 0 & 1 \\
\hline 6. & Hij/zij wordt vaak benadeeld door anderen & 0 & 1 \\
\hline 7. & Hij/zij vindt het moeilijk om voor zichzelf op te komen & 0 & 1 \\
\hline & Biografische gegevens (BIO) & Nee & Ja \\
\hline 1. & $\begin{array}{l}\text { Hij/zij heeft gedurende het leven veel onduidelijke lichamelijke klachten gehad } \\
\text { waarvoor hij/zij bij de dokter is geweest }\end{array}$ & 0 & 1 \\
\hline 2. & $\begin{array}{l}\text { Hij/zij heeft wel eens tegen familie of bekenden gezegd een einde aan zijn/haar } \\
\text { leven te willen maken }\end{array}$ & 0 & 1 \\
\hline 3. & $\begin{array}{l}\mathrm{Hij/zij} \mathrm{is} \mathrm{in} \mathrm{het} \mathrm{verleden} \mathrm{opgenomen} \mathrm{geweest} \mathrm{in} \mathrm{een} \mathrm{psychiatrische} \mathrm{instelling} \mathrm{of} \\
\text { rustoord wegens zenuwen }\end{array}$ & 0 & 1 \\
\hline 4. & $\begin{array}{l}\text { Hij/zij heeft tijdens belangrijke momenten in het leven veel last gehad van zenuwen, } \\
\text { spanningen of somberheid }\end{array}$ & 0 & 1 \\
\hline 5. & $\begin{array}{l}\mathrm{Hij/zij} \mathrm{is} \mathrm{eerder} \mathrm{in} \mathrm{het} \mathrm{leven} \mathrm{behandeld} \mathrm{door} \mathrm{een} \mathrm{psychiater/} \mathrm{zenuwarts} \mathrm{of} \\
\text { psycholoog }\end{array}$ & 0 & 1 \\
\hline 6. & $\begin{array}{l}\text { Hij/zij heeft wel eens een poging gedaan om een einde aan zijn/haar leven te } \\
\text { maken }\end{array}$ & 0 & 1 \\
\hline 7. & Hij/zij heeft tijdens zijn/haar leven hooguit 1 kennis of vriend gehad & 0 & 1 \\
\hline 8. & $\mathrm{Hij/zij} \mathrm{heeft} \mathrm{in} \mathrm{zijn/haar} \mathrm{leven} \mathrm{weinig} \mathrm{belangstelling} \mathrm{gehad} \mathrm{voor} \mathrm{seksueel} \mathrm{contact}$ & 0 & 1 \\
\hline 9. & $\begin{array}{l}\text { Hij/zij heeft in het verleden vaak gebruik gemaakt van zenuwtabletten en/of } \\
\text { slaaptabletten }\end{array}$ & 0 & 1 \\
\hline
\end{tabular}

Penders, K.A.P., Rossi, G., Metsemakers, J.F.M., Duimel-Peeters, I.G.P., \& Van Alphen, S.P.J., (2016). The diagnostic accuracy of the Gerontological Personality disorder Scale (GPS) in Dutch general practice. Aging and Mental Health, 20(3), 318328. DOI: 10.1080/13607863.2015.1008989. 


\section{Personalia}

\section{Naam patiënt:}

Geboortedatum:

Naam informant:

\section{Relatie tot patiënt}

\section{Instructie}

Het informantgedeelte van de GPS bestaat uit twee subschalen, te weten Habitueel gedrag en Biografische gegevens. De beide subschalen worden bij de informan afgenomen met de volgende instructie:

Dit is een kort interview en duurt ongeveer 5 minuten. De bedoeling van dit interview is inzicht te krijgen in uw karakter van uw naaste. $U$ kunt op de vragen antwoorden met 'ja' of 'nee'. Zijn de volgende uitspraken van toepassing op naaste.

Indien momenteel sprake is van ernstige depressieve, psychotische en/of cognitieve problematiek dient, in het bijzonder bij de HAB-items, aan de informant vermeld te worden om deze vragen te beantwoorden toen er bij de patiënt nog geen sprake was van een psychiatrisch toestandsbeeld. Dit om vertekening door een ernstig psychiatrisch toestandsbeeld te voorkomen.

N.B. Bij de subschaal Habitueel gedrag (HAB) is het duurzame patroon van denken, voelen en handelen van belang

Omcirkel de antwoorden op de vragen om vervolgens per schaal de totaalscore te berekenen.

\section{Normering ouderen in de huisartsenpraktijk}

Allereerst wordt gescoord per subschaal en vervolgens worden beide subschalen beoordeeld ten einde een vermoeden uit te spreken over de aanwezigheid van een persoonlijkheidsstoornis.

Totaalscore Habitueel gedrag (HAB-schaal)

Score $0-1$ negatieve score

\section{Score $\geq 2$ positieve score}

Totaalscore Biografische gegevens (BIO-schaal)

Score 0 negatieve score

Score $\geq 1$ positieve score

Totaalscore GPS

Score $0-2$ negatieve score

Score $\geq 3$ positieve score

Vermoeden van persoonlijkheidsstoornis indien:

Positieve score HAB-schaal óf positieve score BIO-schaal

\section{Interpretatie}

De GPS is een screeningsinstrument voor de diagnostiek van persoonlijkheidsstoornissen bij ouderen en is gebaseerd op de algemene diagnostische criteria van de DSM-5. Dit instrument kan dienen als indicatie voor voortgezet psychodiagnostisch onderzoek. Indien de GPS-score voldoet aan een vermoeden van een persoonlijkheidsstoornis is uitvoerig persoonlijkheidsonderzoek aangewezen. De DSM-5-classificatie persoonlijkheidsstoornis kan echter niet enke op basis van de GPS worden gesteld. 


\section{Dankwoord}

Met plezier kijk ik terug op de afgelopen jaren waarin ik aan mijn onderzoek heb gewerkt. Daarbij heb ik zowel het genoegen en geluk gehad te mogen samenwerken met mensen die mij ondersteund, gemotiveerd en geïnspireerd hebben in de uitvoering van dit onderzoek. Deze laatste woorden wijd ik dan ook graag aan iedereen, die op welke manier dan ook, een bijdrage heeft geleverd aan de totstandkoming van dit proefschrift. Ik ben jullie dankbaar daarvoor! Een aantal personen wil ik hieronder graag persoonlijk bedanken.

Ik wil beginnen met de huisartsen Paul van Aubel, Jan Pieter Boode, Frank Guldemond, Martijn van Nunen en René Tummers te bedanken zonder wie dit onderzoek niet van start had kunnen gaan. Ik ben jullie dankbaar voor het selecteren van potentiële deelnemers, maar ook dat jullie me een kijkje hebben willen geven in jullie gedachten rondom persoonlijkheidsproblematiek bij ouderen, de frustratie en machteloosheid die hier soms bij komt kijken en jullie ervaringen met de afname van de GPS. Het was zeer boeiend; ik had het niet willen missen.

In het verlengde hiervan wil ik ook de praktijkondersteuners Anneke Coenen, Diana Huijnen-Beckers, Veerle Krekels en Vivian Smink-Bemelmans bedanken voor hun medewerking. Jullie openhartigheid, evenals jullie enthousiasme voor het thema heb ik zeer gewaardeerd.

Ik wil stilstaan bij alle 'ouderen' en informanten die tijd hebben vrijgemaakt om dee te nemen aan dit onderzoek. De huisbezoeken hebben naast veel informatie ook een hoop ervaringen opgeleverd waar ik met plezier op terugkijk. Van prachtige, ongewone huizen, het verhaal van een gebroken pols door actief gebruik van de Nintendo Wii, tot het aanbod om 10.00 uur 's ochtends een pilsje met een scheut energy drink mee te drinken. Ik kwam het allemaal tegen. Dank jullie wel voor jullie openheid en gastvrijheid.

Ik wil Mondriaan Ouderen en in het bijzonder Noud Engelen bedanken dat, ondanks dat mijn dienstverband aldaar eindigde, ik het onderzoek mocht blijven voorzetten.

De leden van de beoordelingscommissie, Prof. dr. R.C. Oude Voshaar, Prof. dr. R. W.H.M. Ponds, Prof. dr. E. Rosowsky, Prof. dr. J.M.G.A. Schols, onder voorzitterschap van Prof. dr. J.W.M. Muris, dank ik hartelijk voor het lezen en (positief) beoordelen van mijn proefschrift. 
Een speciaal woord van dank wijd ik aan mijn promotieteam bestaande uit Job Metsemakers, Bas van Alphen en Inge Peeters. Bedankt voor de fijne samenwerking de afgelopen jaren waarin ik veel van jullie heb geleerd.

Job, ik had nooit kunnen voorzien dat jij op meerdere gebieden in mijn leven een cruciale rol zou spelen en dat onze paden zich meermaals zouden gaan kruisen. Net geboren en daar was jij... Hiermee was je eerste rol in mijn leven geboren; die van huisarts. Later kwam ik je in het Geulse verenigingsleven tegen en zag ik je menig zaterdag terwijl ik aan het werk was bij de $\mathrm{AH}$ in Beek. Een andere belangrijke ro kwam in 2010; die van promotor. Door al deze rollen heb ik je leren kennen als een kundige, professionele en scherpzinnige man. Je feedback zette me altijd aan het denken. Ook heb ik van je geleerd dat het goed is meer mijn eigen pad te kiezen en hierbij niet te veel waarde te hechten aan de mensen om me heen. Dank je wel!

Bas, niet lang na het afstuderen leerde ik je kennen en wat ben ik daar dankbaar voor. Als onderzoeksassistente van een oud-collega zag je mijn mogelijkheden en ambitie voor wetenschappelijk onderzoek. Je gaf me de gelegenheid om mijn eigen onderzoek te starten, hetgeen later mijn promotieonderzoek zou worden. Jaren hebben we samengewerkt bij Mondriaan, maar ook toen ik naar Vivre (nu Envida) ging, bleven de lijntjes kort. Vol verwondering heb ik me herhaaldelijk afgevraagd hoe jij, ondanks je drukke agenda's, altijd ruimte vond om snel en inhoudelijk te reageren op mijn stukken. Wanneer ik (te?) kritisch was, gaf jij een tegengeluid en leerde je me hier wat meer balans in te krijgen. Dit is zeer waardevol! Dank je wel!

Inge, ik ben je dankbaar dat je me alle ruimte gaf om zelfstandig te werken. Je oog voor detail was zeer waardevol, zeker in de afrondende fase. Je leerde me dat iedereen een andere rol en bijdrage heeft in onderzoek en dat dat tezamen tot een succesvolle afronding leidt. Dank je wel!

Ook ben ik bijzonder veel dank verschuldigd aan Gina Rossi. Beste Gina, woorden schieten te kort om mijn dank aan jou kenbaar te maken. Hoewel je officieel geen deel van mijn promotieteam uitmaakte, voelde het voor mij wel zo. Jij bleek altijd bereikbaar voor al mijn statistische vragen, groot en klein. De snelheid waarmee je mijn mailtjes beantwoordde en voorzag van interessante literatuur of tijd maakte voor een skype-meeting is ongekend. Je enthousiasme, liefde en passie voor je vak werken aanstekelijk. Gina, ik kan met recht zeggen dat je me inspireert en een voorbeeld voor me bent!

Mijn dank gaat ook uit naar co-auteurs Inge Debast, Daniel Segal en Ezra van Zadelhoff. Onze samenwerking en jullie inbreng heb ik als buitengewoon waardevol en leerzaam ervaren.
Ook Envida heeft een zeer belangrijke rol in mijn onderzoek gespeeld. En dan denk gelijk ik aan Roger Ruijters, Jos Schols, Gildy Hertogs en mijn collega-psychologen.

Roger, wat ben ik blij en trots om in een organisatie te mogen werken die ook academisering een warm hart toedraagt, ondersteunt en stimuleert. Uit ervaring weet ik dat dit niet vanzelfsprekend is. Dank je wel hiervoor.

Jos, ik ben jou heel veel dank verschuldigd. Van meet af aan heb jij het mogelijk gemaakt om mijn werk als psycholoog te combineren met mijn onderzoek. Jij gaf mij, naast alle goede adviezen en vertrouwen dat ik het tot een goed eind zou brengen, iets wat onontbeerlijk is. Jij gaf mij (onderzoeks-) tijd!

Gildy, dank je wel dat je al die tijd rekening hield met mijn onderzoek. Hoewe het zorgde voor het nodige puzzelwerk, met name in het begin van 2020 , gaf je me desondanks de gelegenheid om te blijven werken aan mijn onderzoek. Ik waardeer(de) het ontzettend!

De vakgroep psychologie, wat ben ik blij dat ik van deze geweldige club mensen deel mag uitmaken. Ik wil jullie allen bedanken voor jullie interesse en steun gedurende de afgelopen jaren, maar ook voor het begrip dat ik niet altijd even bereikbaar of inzetbaar was.

In het bijzonder wil ik Anne van der Vorst bedanken. Eigenwijs als ik ben, heb ik er de voorkeur aan gegeven om het onderzoek vanuit thuis te doen. Heerlijk vond ik dat. Echter, door met jou een kamer in La Valence te delen, heb ik ervaren hoe prettig het is om snel even iets te kunnen vragen. Van het uitlenen van een boek, samen zoeken naar de juiste term, tot het uitwisselen van ervaringen; je maakte er altijd tijd voor. En toen we geen kamer meer deelden, overlegden we telefonisch of even snel na het vakgroepoverleg. Dank je wel!

Mijn familie en vrienden ben ik zeer dankbaar bij hun hulp bij het verzetten van mijn gedachten. In jullie aanwezigheid was het nagenoeg altijd mogelijk om even niet met het onderzoek bezig te zijn.

Peter, ik wil jou bedanken voor je steun en vertrouwen in mij. Lieve Peter, geduldig hoorde je mijn onderzoeks-perikelen aan en deelde je mijn frustraties wanneer het onderzoek of afspraken anders liepen dan verwacht of gehoopt. Tevens hielp je me in het begin met het telefonisch benaderen van deelnemers en het inplannen van de huisbezoeken. Ik vond het erg fijn dat je altijd bereid was om mee te denken en dat ik mijn overpeinzingen aan je voor mocht leggen. Je bleef vertrouwen in een goed eind houden en wist me, wanneer nodig, ook extrinsiek te motiveren door mij de Raden Starlight in het vooruitzicht te stellen. Tijdens de, nog voortdurende, grootschalige 
verbouwing prioriteerde je mijn werkkamer, een plek waar ik met veel plezier vele uren in alle rust aan mijn onderzoek heb kunnen werken. Ook nam je, met name in de laatste periode, zonder klagen taken van mij over. Jij leerde me dat een stabiele en liefdevol thuisbasis een belangrijke voorwaarde, of inclusiecriterium is voor het doen van promotieonderzoek, iets wat ik vooraf me niet zo beseft had.

Ten slotte, lieve Storm, nog te jong om te beseffen hoe groot jouw impact is (geweest). Naast onvoorwaardelijke liefde leerde jij me om mijn tijd zo efficiënt mogelijk te gebruiken.

\section{About the author}

Krystle Penders was born on October 29th, 1983, in Geulle (Limburg, the Netherlands) She attended secondary school (atheneum) in Stein. After obtaining her bachelor's degree in Mental Health Science (2005, Maastricht University), she completed the 2-year Research master in Abnormal Psychology (now Psychopathology, Maastricht University) in 2007. During this master's program, she conducted a combined clinical and research internship at Pro Psy (Sittard), where she acquired her psychodiagnostics registration (BAPD). Meanwhile, she also worked at InterUM (Maastricht University), in which she assisted in various research projects.

From December 2007 to February 2010, she worked as a research assistant at Mondriaan mental hospital (Heerlen), at which she later (2008-2009) also worked as a psychologist. In 2009 , she became the principal investigator of a research project addressing the detection of personality disorders in late life in general practice, which in 2010 would become her PhD-project. Since 2009, Krystle is a member of the Expert panel Personality in Older Adults (EPO), a Dutch-Belgian research group into personality disorders in late life.

From 2010 onwards, she works as a psychologist at Envida (previously known as Vivre) while combining it with an external PhD-position at Maastricht University (department of Family Medicine). Furthermore, she is also member of Envida's research committee.

Krystle is happily married to Peter Bartholet. Together they have a son named Storm (2018) 


\section{Publications and conference contributions}

\section{Articles}

Arntz, A., Bernstein, D., Gielen, D., van Nieuwenhuyzen, M., Penders, K., Haslam, N., \& Ruscio, J., (2009). Taxometric evidence for the dimensional structure of cluster $\mathrm{C}$, paranoid, and borderling personality disorders. Journal of Personality Disorders, 23(6), 606-628.

van Alphen, S. P.J., Bolwerk, N., Videler, A.C., Tummers, J.H.A., van Royen, R.J.J., Barendse, H.P.J., Penders, K.A.P., Scheepers, C., \& Verheul, R., (2010) Persoonlijkheidsstoornissen bij ouderen: delphi-onderzoek onder Nederlandse en Vlaamse experts over specifieke diagnostische en therapeutische aspecten. Tijdschrift voor Psychiatrie, 52(6), 375-386.

Penders, K.A.P., (2010). Persoonlijkheidsstoornissen bij ouderen. Op Eén Lijn, 38(3), 14.

Tummers, J. H. A., Hoijtink, J. H. A., Penders, K. A. P., Derksen, J. L. L., \& van Alphen S. P. J., (2011) Screening Items for Personality Disorders in Older Adults: A MultiCenter Study of Psychiatric Inpatients and Outpatients in The Netherlands. Clinical Gerontologist, 34(1), 34-44.

Penders, K.A.P., Rossi, G., Metsemakers, J.F.M., Duimel-Peeters, I.G.P., \& van Alphen, S.P.J., (2016). Diagnostic accuracy of the Gerontological Personality disorders Scale (GPS) in Dutch general practice. Aging and Mental Health, 20(3), 318-328.

Penders, K.A.P., van Zadelhoff, E., Rossi, G., Duimel-Peeters, I.G.P., van Alphen S.P.J., \& Metsemakers, J.F.M., (2019). Feasibility and acceptability of the Gerontological Personality disorders Scale (GPS) in general practice: a mixed methods study. Journal of Personality Assessment, 101(5), 534-543.

Penders, K.A.P., Peeters, I.G.P, Metsemakers, J. F. M., \& van Alphen, S.P.J., (2020) Personality disorders in older adults: a review of epidemiology, assessment and treatment. Current Psychiatry Reports, 22(3), 1-14.

Penders, K.A.P., Dierickx, S, Steenhaut., P., Dierckx., E., \& Rossi, G., (2020) Persoonlijkheidsstoornissen bij ouderen: Epidemiologische aspecten. Tijdschrift voor Geriatrie \& Gerontologie, 51(2), 1-26 


\section{Chapters}

Barendse, H.P.J., Penders, K.A.P., Metsemakers, J.F.M., van Alphen, S.P.J., (2018) Huisartsenpraktijk en generalistische basis-ggz. In: S. van Alphen, R. Oude Voshaar, F. Bouckaert, \& A. Videler (Red.). Handboek persoonlijkheidsstoornissen bij ouderen. Amsterdam, Nederland: de Tijdstroom.

\section{Oral presentations}

Penders, K.A.P., (2010). Persoonlijkheidsstoornissen bij ouderen. Regiobijeenkomst Psychologen, Horn.

Penders, K.A.P., (2011). Detectie van persoonlijkheidsstoornissen bij ouderen in de huisartspraktijk: Een psychometrische studie. Expertpanel Persoonlijkheid \& Ouderen, Eindhoven, Nederland

Penders, K.A.P., (2014). Persoonlijkheidsstoornissen bij ouderen. Broodje Wetenschap HAG, Maastricht, Nederland

Penders, K.A.P., van Alphen, S.P.J., Duimel-Peeters, I.G.P., \& Metsemakers, J.F.M (2014). Detection of personality disorders in the elderly in general practice: The psychometric properties of the Gerontological Personality disorder Scale (GPS) in general practice. WONCA, Lissabon, Portugal

Penders, K.A.P., (2016). “..Nieuwe glazen om in te kijken..”: een convergente parallelle mixed methods studie naar de bruikbaarheid en acceptatie van de GPS in de huisartspraktijk. Refereerbijeenkomst Envida, Maastricht, Nederland

Penders, K.A.P., Duimel-Peeters, I.G.P., Metsemakers, J.F.M., \& van Alphen, S.P.J (2019). De Gerontologische Persoonlijkheidsstoornissen Schaal (GPS): Een bruikbaar hulpmiddel in de huisartsenpraktijk. Voorjaarscongres Psychiatrie, Maastricht, Nederland

Penders, K.A.P., Debast., I., Rossi, G., Duimel-Peeters, I.G.P., Metsemakers, J.F.M., \& van Alphen, S.P.J., (2020; postponed because of COVID-19). Exploring Self-Informant Agreement using the GPS. The 12th Conference of the International Test Commission, Luxemburg.

\section{Poster presentations}

Penders, K.A.P., van Alphen, S.P.J., Duimel-Peters, I.G.P., \& Metsemakers, J.F.M., (2012). De signalering van persoonlijkheidsstoornissen bij ouderen in de huisartspraktijk. Een studie naar de diagnostische accuraatheid van de Gerontologische Persoonlijkheidsstoornissen Schaal (GPS). Voorjaarscongres Psychiatrie, Maastricht, Nederland

Penders, K.A.P., Duimel-Peeters, I.G.P., Metsemakers, J.F.M., \& van Alphen, S.P.J., (2019). Screening of Personality Disorders in Older Adults in General Practice. The $16^{\text {th }}$ Congress of the International Society for Study of Personality Disorders, Vancouver, Canada 